\title{
Adequate antimicrobial treatment in elderly patients
}

Citation for published version (APA):

Haeseker, M. B. (2015). Adequate antimicrobial treatment in elderly patients. [Doctoral Thesis, Maastricht University]. Maastricht University. https://doi.org/10.26481/dis.20150910mh

Document status and date:

Published: 01/01/2015

DOI:

10.26481/dis.20150910mh

Document Version:

Publisher's PDF, also known as Version of record

\section{Please check the document version of this publication:}

- A submitted manuscript is the version of the article upon submission and before peer-review. There can be important differences between the submitted version and the official published version of record.

People interested in the research are advised to contact the author for the final version of the publication, or visit the DOI to the publisher's website.

- The final author version and the galley proof are versions of the publication after peer review.

- The final published version features the final layout of the paper including the volume, issue and page numbers.

Link to publication

\footnotetext{
General rights rights.

- You may freely distribute the URL identifying the publication in the public portal. please follow below link for the End User Agreement:

www.umlib.nl/taverne-license

Take down policy

If you believe that this document breaches copyright please contact us at:

repository@maastrichtuniversity.nl

providing details and we will investigate your claim.
}

Copyright and moral rights for the publications made accessible in the public portal are retained by the authors and/or other copyright owners and it is a condition of accessing publications that users recognise and abide by the legal requirements associated with these

- Users may download and print one copy of any publication from the public portal for the purpose of private study or research.

- You may not further distribute the material or use it for any profit-making activity or commercial gain

If the publication is distributed under the terms of Article $25 \mathrm{fa}$ of the Dutch Copyright Act, indicated by the "Taverne" license above, 
Adequate antimicrobial treatment in elderly patients

Michiel Barend Haeseker 


\section{Colofon}

The research presented in this thesis was conducted at the School for Public Health and Primary Care (CAPHRI), Department of Medical Microbiology, of Maastricht University Medical Centre. CAPHRI participates in the Netherlands School of Primary Care Research (CaRe). CAPHRI was classified as 'excellent' by the external evaluation committee of leading international experts that reviewed CAPHRI in December 2010.

Printing of this thesis was financially supported by: Maastricht University Medical Centre+ and De Resolutie.

Cover design: Michiel Haeseker

Printed by: De Resolutie

CMichiel Haeseker, Maastricht 2015

All rights reserved. No part of this thesis may be reproduced, stored in a retrieval system of transmitted in any form or by any means, electronic or mechanical, including photocopy, without prior written permission of the publisher and copyright owner, or where appropriate, the publisher of the articles. 


\section{Adequate antimicrobial treatment in elderly patients}

\section{PROEFSCHRIFT}

ter verkrijging van de graad van doctor

aan de Universiteit Maastricht

op gezag van de Rector Magnificus,

Prof. Dr. L.L.G. Stoete

volgens het besluit van het College van Decanen,

in het openbaar te verdedigen

op donderdag 10 september 2015 om 14.00 uur

door

Michiel Barend Haeseker

Geboren op 27 mei 1974 te Dedza, Malawi 


\section{Promotores}

Prof. dr. A. Verbon (Erasmus MC Rotterdam)

Em. Prof. dr. C.A. Bruggeman

Prof. dr. C.J.P.A. Hoebe

\section{Copromotor}

dr. L.M.L. Stolk

\section{Beoordelingscommissie}

Prof. dr. C.P. van Schayck (voorzitter)

Prof. dr. J.W. Mouton (Erasmus MC Rotterdam en Radboud UMC Nijmegen)

Prof. dr. A.J.A.M. van der Ven (Radboud UMC Nijmegen)

Prof. dr. P.H.M. Savelkoul

Prof. dr. R.P. Koopmans 
“Optimisme is opium voor het volk! 'n Gezonde geest riekt naar domheid.

Leve Trotski!"

De Grap, Milan Kundera, Praag 1967. 



\section{Contents}

Chapter 1 General introduction \& outline of the thesis

Chapter 2 Trends in antibiotic prescribing in adults in Dutch general practice

Chapter 3 A simple and rapid RP-HPLC method to determine ciprofloxacin levels in human serum

Chapter 4 The ciprofloxacin target $\mathrm{AUC}_{24} / \mathrm{MIC}$ ratio is not reached in hospitalised patients with the recommended dosing regimens

Chapter 5 Is the standard dose of amoxicillin-clavulanic acid sufficient?

Chapter $6 \quad$ Vancomycin dosing in neutropenic patients

Chapter $7 \quad$ Evaluation of vancomycin prediction methods based on estimated creatinine clearance and trough levels

Chapter $8 \quad$ Summarising discussion $\&$ future perspectives

Nederlandse samenvatting

Valorisation of this manuscript

Epiloog

Curriculum vitae auctoris

List of publications 



\section{Chapter 1}

General introduction \& outline of the thesis 


\section{Short history of antimicrobial therapy}

The first antibacterial chemotherapy that revolutionised the treatment of bacterial infections was the sulphonamide Prontosil, discovered in 1932 and introduced in approximately 1935 [1-3]. The sulfonamides are synthetic antimicrobial agents developed in the German dye industry by Gerhard Domagk. He continued the work of Paul Ehrlich, who discovered arsphenamine (Salvarsan) in 1910, the "magic bullet" or "magische Kugel" for the treatment of syphilis [4]. Salvarsan is a chemical derivative of the toxic drug Atoxyl, which was used for the treatment of trypanosomiasis [5]. Much earlier than Salvarsan and Atoxyl, quinine was isolated from the cinchona bark in 1820 in Paris by Caventou and Pelletier [6, 7]. This bark was also known as pulvus indicus or Jezuits bark as a remedy for malaria, published by Herman van der Heyden in 1643 [8]. The first antibiotic was penicillin, discovered by Alexander Fleming in 1928, purified by Chain and Florey and introduced in approximately 1941 [2, 9]. Streptomycin was the first aminoglycoside discovered by Waksman and Schatz in 1943 and introduced in 1946 $[10,11]$. Waksman suggested to use the term antibiotic for a chemical substance produced by a micro-organism which has the capacity to inhibit the growth of and even to destroy bacteria and other micro-organisms [12]. Since then many antibiotics followed during the golden age of antibiotic discoveries. The approximate time line of the discoveries (and introductions) of the major antimicrobial classes, after sulphonamides and $\beta$-lactam antibiotics, is as follows: chloramphenicol discovery in 1946 (introduction in 1948), macrolide in 1948 (1951), tetracycline in 1944 (1952), glycopeptide in 1953 (1958), rifamycin in 1957 (1958), and quinolone (synthetic) in 1961 (1968) [2]. After this golden age, only few new antibiotics have been added: oxazolidinone (synthetic) in 1955 (2000) and lipopeptides in 1986 (2003) [2]. Resistance against antimicrobials was observed shortly after each antimicrobial discovery [2]. The antimicrobial use steadily increased with the discovery of all these antimicrobial drugs, and is still increasing [13]. A clear relationship has been found between the percentage of resistant strains and antimicrobial use. The selection of resistance was strongly associated with prior antimicrobial treatment and importantly suboptimal antimicrobial exposure. On the other hand, dosing regimens that result in high antimicrobial concentrations may lead to adverse events. Increasing antimicrobial resistance is a worldwide problem and antimicrobial stewardship programs are being developed to ensure that antimicrobial therapy is used correctly in all groups of patients. Elderly patients should be a specific target group for more in depth studies to improve the antimicrobial therapy, since the therapeutic width may be narrow due to pharmacokinetic changes associated with ageing.

\section{The elderly patient}

\section{Classification}

Ageing is a gradual process with interindividual variance. Any cut off for elderly patients can be criticised. A cut-off $>65-70$ years for elderly patients and a cut-off >80-85 years for the very elderly patients are generally used. A cut off 
depends on many factors, such as time and geography. E.g. in 1900 only $6 \%$ of the population in the Netherlands was older than 65 years [14]. The number of elderly people is rapidly growing in the Western world. Eurostat predicts that the percentage of elderly people ( $>65$ years) in the 27 countries of the European Union will rise from $17 \%$ in 2011 to $30 \%$ in 2060 and the very elderly people (>80 years) from 5\% to $12 \%$ [15]. In other parts of the world, such as Africa, the life expectancy is much lower. The World Health Organisation suggest a cut-off of 60 years for elderly patients in Africa, while others think a cut-off of 50 or 55 years would be more reasonable in Africa [16]. In parts of Sardinia and Sicily a strikingly high number of centenarians live, which lead to several research questions and could lead to a higher cut-off for elderly people in Sardinia and Sicily $[17,18]$.

\section{Infections and antimicrobial use in elderly patients}

Elderly patients have more co-morbidities, especially cardiovascular disease, neurological disease and diabetes, which influences host defence mechanisms [19]. Physiologic functions, such as cough reflex and wound healing are diminished in elderly patients [20, 21]. The innate, cellular and humeral immunity is decreasing in elderly patients without compelling evidence that this has direct clinical relevance [22]. Elderly people experience more infections with longer length of hospital stay and higher mortality rates [23]. For example, 50\% of the patients with a pneumonia are older than 65 years and $90 \%$ of the mortality due to pneumonia are in patients older than 65 years [24]. Other common infections in elderly patients are, urinary tract infections and skin infections [23, 24]. Only a few studies have shown higher antimicrobial consumption in elderly patients [25-27]. Taken together, the elderly people are a large and growing population with a high number of infections and a high use of antimicrobial therapy.

\section{Overview of pharmacokinetic changes with ageing}

Higher age is characterised by a decrease in functional capacity of most organs, leading to changes in absorption, distribution and protein binding [28]. Several reviews on antimicrobial therapy in elderly patients discuss the knowledge of pharmacokinetic changes that influence antimicrobial blood concentrations [29-36]. In Table 1 the different antimicrobial classes are shown with regard to the most important antimicrobial pharmacokinetic characteristics that influence antimicrobial blood concentrations in elderly patients, i.e. clearance and hydrophilic or lipophilic nature of the antimicrobial drugs.

\section{Absorption}

Although, elderly people have decreased acid production and delayed gastric emptying the total drug absorption seems similar to that of younger patients $[28,33$, $35,55,56]$. 
Table 1. Important pharmacokinetic characteristics of antimicrobial drug classes important in elderly patients.

\begin{tabular}{|c|c|c|}
\hline Clearance (CL) & Hydrophilic & Lipophilic \\
\hline Renal CL (\%) & $\begin{array}{l}\text { Aminoglycosides (90-95\%) [37] } \\
\text { Penicillines }(60-80 \%)[39-41] \\
\text { Cefalosporins } \\
\text { Carbapenems }(70-80 \%)[43-45] \\
\text { Glycopeptides }(80-90 \%)[46] \\
\text { Lipopeptides }(50 \%)[47]\end{array}$ & $\begin{array}{l}\text { Quinolones (40-93\%) [38] } \\
\text { Sulphonamides } \\
\text { Trimethoprim }(60-80 \%)[42]\end{array}$ \\
\hline Metabolic CL (\%) & & $\begin{array}{l}\text { Macrolides }(90 \%)[48] \\
\text { Rifamycins }(60-95 \%)[49-51] \\
\text { Clindamycin }(80-90 \%)[52] \\
\text { Tetracyclines }(60 \%)[53] \\
\text { Oxazolidinones }(60-70 \%) \\
\text { Sulphonamides }\end{array}$ \\
\hline
\end{tabular}

\section{Distribution}

The volume of distribution (Vd) of antimicrobial drugs is altered in elderly patients. With ageing the total body water from intra- and extracellular spaces decreases with 10-15\% [28]. This leads to a decrease of Vd hydrophilic drugs, which will increase the blood concentrations of hydrophilic drugs [57]. In men body fat increases from $18 \%$ to $36 \%$ and in women body fat increases from $33 \%$ to $45 \%$ with ageing $[28,58]$. This leads to an increase in $\mathrm{Vd}$ of lipophilic drugs, which will decrease the blood concentrations of lipid soluble drugs in elderly patients [59]. The decrease of blood concentrations of lipophilic drugs could be less pronounced, because of the already large Vd of most lipophilic drugs. Furthermore, frail elderly patients have lost their fat tissue again and consequently have lost their increase in Vd of lipid soluble drugs [60].

In conclusion, the $\mathrm{Vd}$ of hydrophilic drugs will decrease resulting in increased concentrations of hydrophilic antimicrobial drugs and the Vd of lipophilic drugs will increase, which will lead to lower concentrations of lipophilic antimicrobial drugs in elderly patients.

\section{Renal elimination}

Renal function is steadily decreasing with ageing. Reduced renal function leads to a longer half-life ( $\mathrm{T}^{1 / 2}$ ), higher antimicrobial blood concentrations and area under the curve (AUC). However, serum creatinine remains stable in elderly patients, because lean muscle mass also decreases [28]. Malmrose et al. showed the predictive accuracy of different estimated creatinine clearance (CLcr) ranges from $18-38 \mathrm{~mL} / \mathrm{min}$ in 762 high functioning community-dwelling elderly patients. Malmrose et al. advises to estimate CLcr only when urine specimens are impractical or when serum drug concentrations are not available [61]. Lindeman et al. showed a high interindividual decline in glomular filtration rate with ageing [62]. This variability of interindividual decline in glomular filtration rate and in the range of muscularity in elderly patients, make estimations of CLcr inaccurate in elderly patients [61]. For an elderly person, the only way to be certain about his or her renal function is to measure it with a 24-hour measurement of creatinine in urine [22]. However, this is often impractical. 
In conclusion, blood concentrations of renally cleared antimicrobial drugs are increased in elderly patients, due to a decreased kidney function. However, careful interpretation of estimated CLcr in elderly patients remains necessary.

\section{Metabolism}

The effect of age on liver function is less clear. Although, the volume of the liver and portal flow decreases with age, the liver function and cytochrome P450 (CYP) seem to remain fairly stable with ageing [28, 63]. On the other hand, the chance of drug-drug interaction increases with high rates of polypharmacy in elderly patients [29, 30, 32].

\section{Protein binding}

The free antimicrobial drug is active, antimicrobial drugs bound to proteins cannot act against microorganisms and are inactive. A decrease in serum albumin will decrease the protein bound drug fraction (inactive) and increase the free drug (active) in plasma. This may influence the distribution and clearance of highly protein bound antimicrobial drugs, but may not be clinically relevant [32].

\section{Conclusions}

The decrease in renal function and Vd of hydrophilic drugs seem to be the most important antimicrobial pharmacokinetic characteristics that influence antimicrobial blood concentrations in elderly patients. Therefore, the highest blood concentrations in elderly patients are expected with hydrophilic antimicrobial drugs that are renally cleared. The change in blood concentrations of lipophilic antimicrobial drugs that are renally cleared are likely to increase, but could decrease in individual elderly patients and the blood concentrations of lipophilic antimicrobial drugs that are metabolically cleared are expected to decrease. The pharmacokinetic studies in elderly patients are not conclusive and reviews on pharmacokinetic antimicrobial studies in elderly patients are scarce. With increasing numbers of elderly patients, accurate dosing advices for this age group is necessary. More pharmacokinetic studies in elderly patients and a new review on pharmacokinetic studies seems warranted.

\section{Antimicrobial pharmacokinetic studies in elderly patients}

Antimicrobial drugs in elderly patients are often dosed in the same manner as in young adult patients. On the other side of the age spectrum, neonates and young children also have more infections, and it has been shown that different antimicrobial dosing schedules are necessary in neonates and young children [64]. It is not clear why such adjustments in antimicrobial regimens have not been made for elderly patients in which risks for underdosing and overdosing of medication are readily available. To prevent overdosing, the aphorism "Start low, go slow" should be used for dosing medication in elderly patients, but this aphorism seems to be harmful for antimicrobial treatment. For antimicrobial therapy, Paul Ehrlich already advised in 1913 "Frapper fort et frapper vite", hit them hard and hit them fast [65]. This adagium is based on the thought that suboptimal antimicrobial blood 
concentrations will induce antimicrobial resistance and treatment failure. However, by avoiding underdosing of antimicrobial therapy in elderly patients, the risk of too high blood concentrations resulting in adverse drug events (ADE) and higher morbidity and mortality increases. The advice of Paul Ehrlich still is applied in antimicrobial therapy, but in elderly patients altered pharmacokinetics as a result of physiologic changes of ageing need to be taken into account. Antimicrobial regimens for adults in general may not be directly extrapolated to the elderly.

Only a limited number of pharmacokinetic studies in elderly patients have been reported. Ljungberg et al. and Meyers et al. have reviewed pharmacokinetic studies in elderly volunteers and elderly patients, in 1987 and in 1989, respectively [56, 66]. The first review of Ljungberg et al. included the first studies in elderly patients, from 1950s to 1987. The second review of Meyers et al. covered a short period of antibiotic pharmacokinetic studies from 1987-1989 [66]. Since 1989, several new antibiotics have been developed and new studies in elderly patients have been described. Furthermore, the methods for measuring blood concentrations of antibiotics have improved. For instance, agar disk diffusion bioassays are not used anymore, as this method is time consuming and the zone of inhibition is influenced by several variables [31]. High performance liquid chromatography (HPLC) is now most often used to determine concentrations of antimicrobial therapy, such as $\beta$ lactam antibiotics, quinolones and macrolides. For aminoglycosides and glycopeptides, fluorescence polarization immunoassays (FPIA) are used nowadays.

To determine the optimal dosing regimens for elderly patients, pharmacokinetic studies of antimicrobial drugs were reviewed.

\section{Selection of pharmacokinetic studies of antimicrobial therapy in elderly people}

English written studies were included that used comparable analytical methods, i.e. immunoassays for aminoglycosides and glycopeptides studies and HPLC for the other antimicrobial drugs. The bioassay studies were excluded. The US Food and Drug Administration (FDA) describes requirements for accuracy, precision, selectivity, sensitivity, reproducibility and stability in the Guidance for Industry Bioanalytical Method Validation [67]. At least an acceptable intra- and interbatch precision coefficient of variation (CV) must be within $15 \%$. Information on pharmacokinetic parameter calculations and pharmacokinetic program must be included. The study population should be well defined and elderly subjects (>65 years) should be compared with younger subjects, see Table 2.

Table 2. Selection criteria.

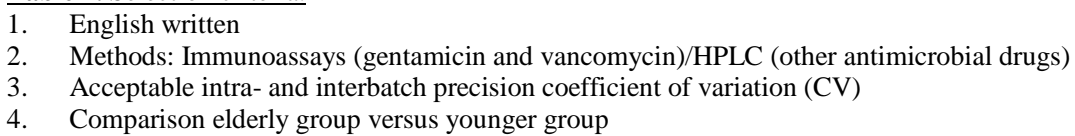

Publications were retrieved by a computerised search of MEDLINE (19662014). In the first stage of the search strategy Medical Subject Headings (MeSH) were used; aged (elderly) and pharmacokinetics. This strategy was combined with antibacterial therapy as a whole $\mathrm{MeSH}$ term: Anti-Bacterial agents and most commonly used single antibacterial therapy, i.e. MeSH terms: penicillin, 
flucloxacillin, amoxicillin, amoxicillin-potassium clavulanate combination, piperacillin, piperacillin tazobactam combination product, cefazolin, cefuroxime, ceftriaxone, ceftazidime, cefotaxime, cefepime, meropenem, doripenem, ertapenem, imipenem, aztreonam, gentamicin, tobramycin, amikacin, vancomycin, teicoplanin, daptomycin, erythromycin, clarithromycin, azithromycin, tetracycline, doxycycline, linezolid, clindamycin, trimethoprim, metronidazole, ciprofloxacin, levofloxacin, moxifloxacin and rifampin. Only English studies were selected by activating language filter in MEDLINE: English.

\section{Results of pharmacokinetic studies of antimicrobial therapy in elderly people}

The search strategy resulted in 1353 publications, 1306 were excluded, because they were not pharmacokinetic studies in elderly patients. Twenty three studies did not meet the selection criteria. In total 24 studies were included, Figure 1. These 24 pharmacokinetic studies in elderly volunteers $(n=15)$ and elderly patients $(n=9)$ are summarised in Table 3.

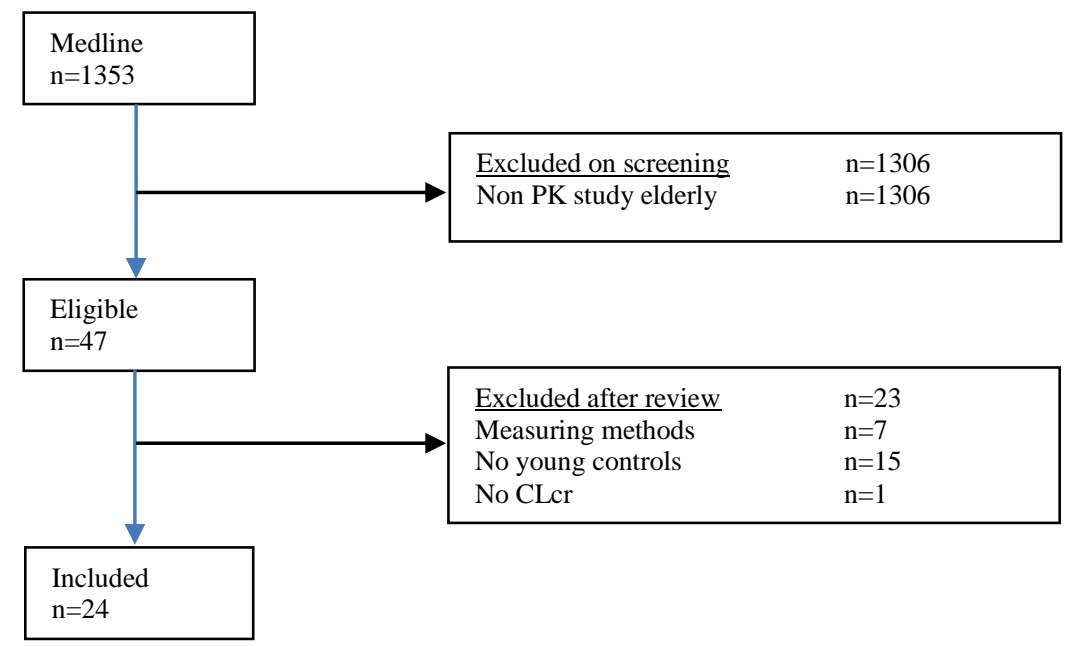

Figure 1. Search strategy and article selection.

\section{Aminoglycosides}

Aminoglycosides are the most hydrophilic of all antibiotics. Aminoglycosides distribute in the vascular space and the interstitial space of most tissues [68]. Aminoglycosides do not penetrate human biological membranes and are lipid insoluble. The extracellular water is decreased in elderly patients, which should lead to lower $\mathrm{Vd}$ and higher serum or plasma concentrations of aminoglycosides. However, Bauer et al. found lower Vd of gentamicin, but higher Vd of amikacin in younger patients compared to elderly patients $[69,70]$. The $\mathrm{Vd}$ of tobramycin was equal in younger and elderly patients. The $\mathrm{Vd}$ of aminoglycosides is not consistently 


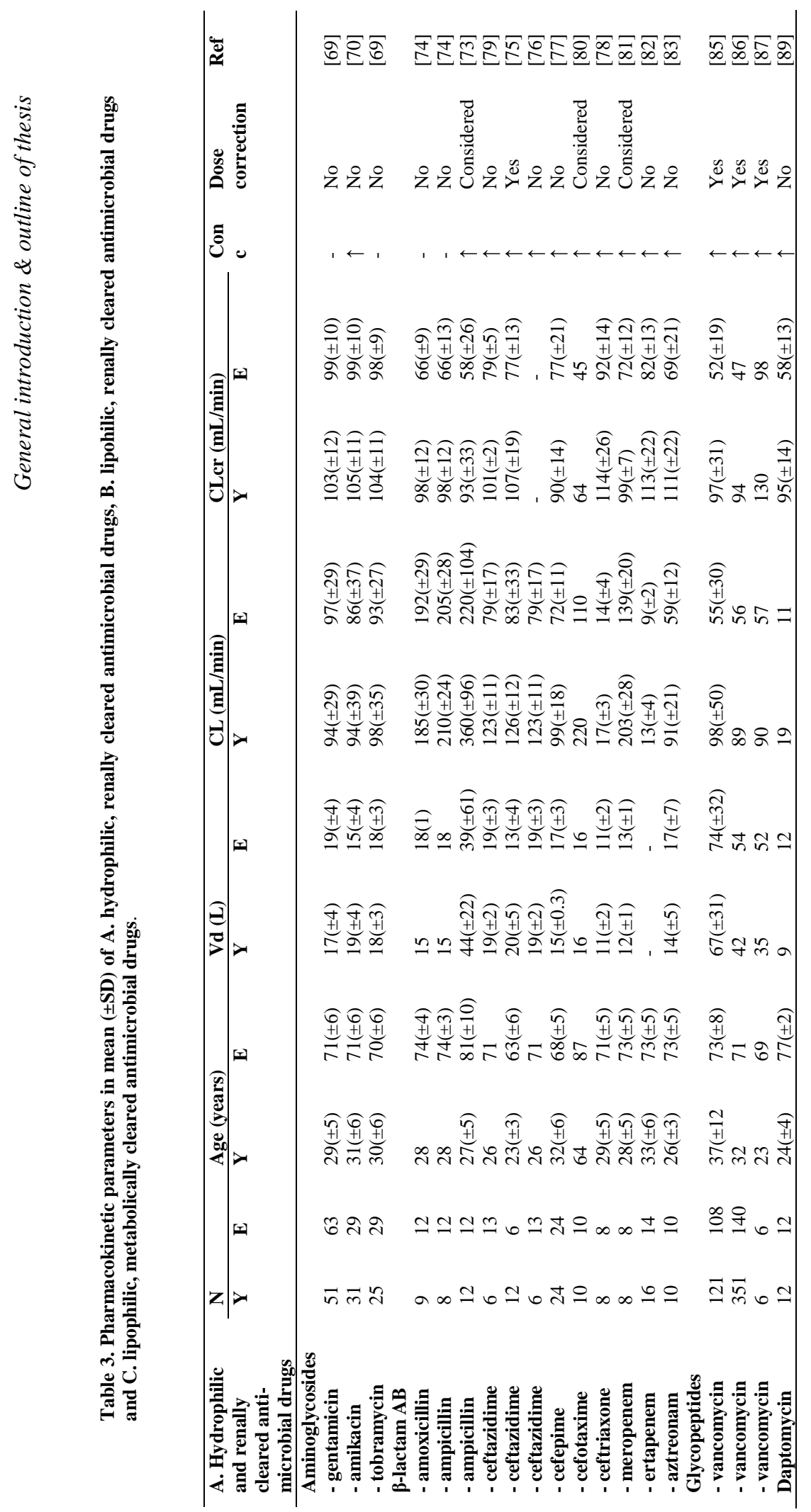




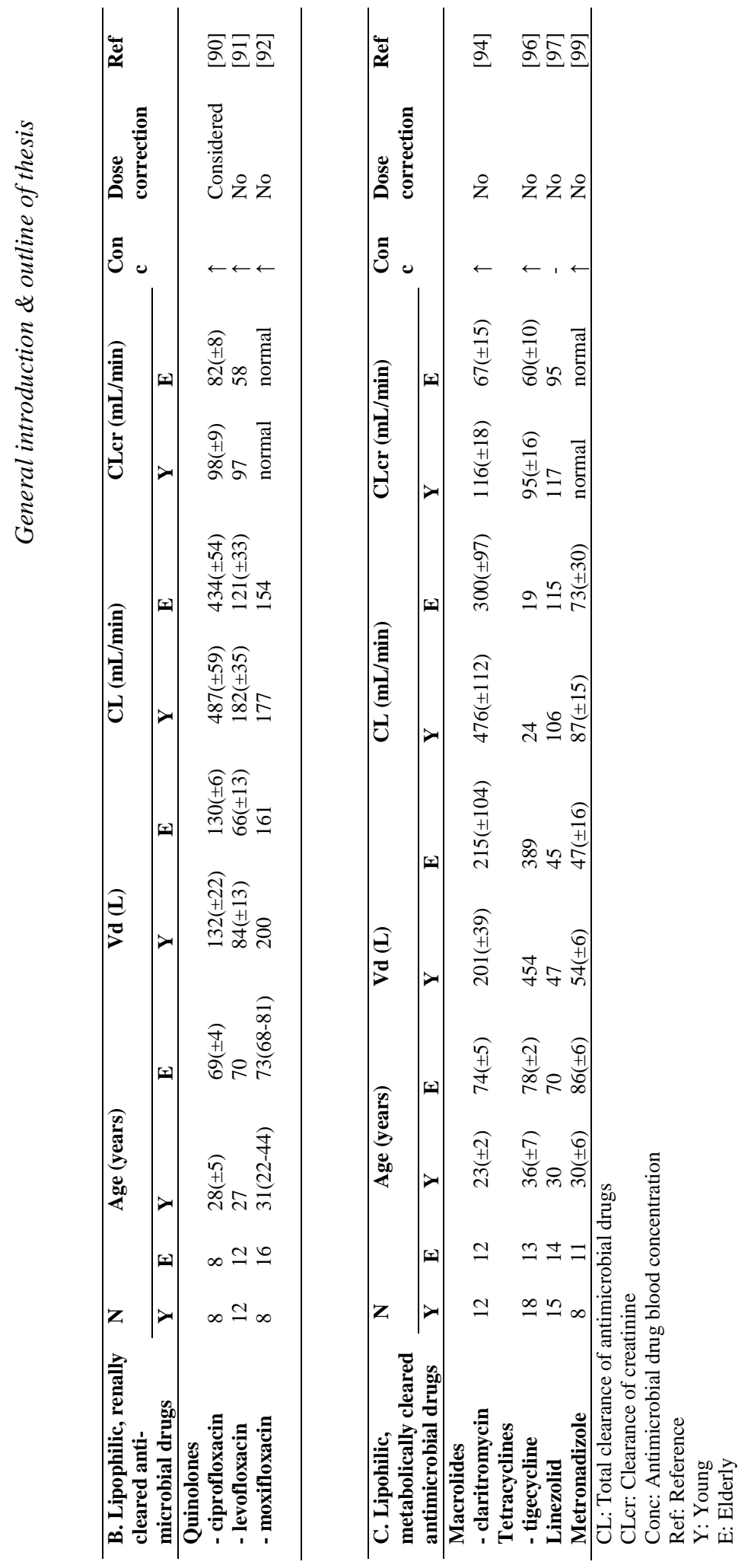


changed in these studies. Therefore, it is not possible to adjust aminoglycosides dosing according to changes in $\mathrm{Vd}$ with ageing.

Aminoglycosides are almost completely renally cleared. Only slightly decreased aminoglycoside clearance was found in the age group of 60-79 years compared to the age group of 20-39 years [69, 70]. However, with renal function steadily decreasing with ageing and small therapeutic range of the aminoglycosides, caution with aminoglycoside dosing in elderly patients seems warranted. In elderly patients monitoring of CLcr, therapeutic drug monitoring (TDM) and short courses ( $<3$ days) of aminoglycosides are to be advised to prevent high blood concentrations and prevent ADEs, such as nephrotoxicity [71, 72].

\section{$\beta$-lactam antibiotics}

$\beta$-lactam antibiotics are hydrophilic and are well distributed in most tissues. $\beta$-lactam antibiotics are relatively insoluble in lipid and penetrate cells poorly. Most $\beta$-lactam antibiotics are rapidly excreted into the urine and have short $\mathrm{T}^{1 / 2}(30-70$ $\mathrm{min}$ ). Exceptions are ceftriaxone and cefoperazone which are excreted both renally and by biliary route.

Penicillins. Sjoval et al. found higher $\mathrm{Vd}$ of amoxicillin and ampicillin in elderly volunteers, while Rho et al. found lower $\mathrm{Vd}$ in elderly volunteers, Table 3. Sjoval et al. did not find a difference in total amoxicillin clearance, while Rho et al. did find a decreased total amoxicillin clearance in elderly volunteers. A decreased renal clearance in elderly patients leads to higher blood concentrations in elderly patients $[73,74]$. However, the broad therapeutic window of amoxicillin makes dose adjustments usually not necessary in elderly patients.

Cephalosporins. Studies of ceftazidime in elderly patients are conflicting. Some studies showed decreased Vd and decreased clearance of ceftazidime in elderly patients, although dosage adjustments in healthy elderly adults were not deemed necessary [75, 76]. No difference in $\mathrm{Vd}$ and a slightly decreased clearance was found for ceftriaxone and cefepime in elderly compared to younger subjects without the need for dose adjustments $[77,78]$. In other studies higher Vd in elderly patients, reduced clearance of ceftazidime and increased AUC were reported and it was advised to lower the ceftazidime dose in elderly patients [79]. For cefotaxime, a decreased clearance in patients $>80$ years compared to 60-80 years was found, leading to the advice to decrease the dose in $>80$ years [80].

Carbapenems. Ljungberg et al. suggest to consider dose adjustments for meropenem, due to a reduced renal clearance of meropenem and its metabolite (ICI 213,689 ) and a possible decreased capacity to metabolize meropenem [81]. Vd of meropenem was not different between younger and elderly patients. The clearance of ertapenem was slightly decreased in elderly patients, but did not accumulate in elderly volunteers. Dose adjustments were not necessary for elderly patients [82].

Monobactams. Meyers et al. found higher aztreonam blood concentrations in elderly patients, due to decreased renal clearance [83]. The $\mathrm{Vd}$ of aztreonam was increased in elderly patients. Meyers et al. suggested altered dosages for elderly patients should be considered, because of an increased AUC.

Conclusion of $\beta$-lactam antibiotic studies in elderly patients. Only few $\beta$-lactam antibiotics have been studied in elderly subjects in comparison with younger subjects. Advices on dosing $\beta$-lactam antibiotics are inconsistent, due to inconsistent changes in $\mathrm{Vd}$ and renal clearance. Studies with FDA approved requirements for 
bioanalytical method validation and investigating elderly (>70 years) and very elderly patients ( $>80$ years) might show pharmacokinetic age associated differences.

\section{Glycopeptides}

Vancomycin is hydrophilic and diffuses well into epithelial lining fluid and reached good concentrations in kidney, liver, heart, lung and abscesses in a post mortem study [84]. Elderly patients had reduced clearance of vancomycin and an increased Vd. Age was an independent predictor of $\mathrm{T}^{1 / 2}, \mathrm{Vd}$ and clearance in the multivariable analysis [85-87]. Elderly patients required smaller daily dose than younger patients, $18( \pm 6)$ vs $25( \pm 8) \mathrm{mg} / \mathrm{kg}$ [85]. A population pharmacokinetic study of adult and elderly patients with normal serum creatinine showed lower vancomycin clearance and lower $\mathrm{Vd}$ in elderly patients [88]. Inconsistent changes of $\mathrm{Vd}$, decreased clearance of vancomycin and small therapeutic window make TDM and CLcr monitoring necessary in elderly patients. Studies with FPIA with selective monoclonal antibodies and FDA approved requirements for bioanalytical method validation and investigating elderly ( $>70$ years) and very elderly patients ( $>80$ years) might show pharmacokinetic age associated differences (i.e. $\mathrm{Vd}$ and vancomycin clearance).

\section{Lipopeptide (Daptomycin)}

Dvorchik et al. compared daptomycin pharmacokinetic in a group of young adult and elderly volunteers [89]. No significant differences in peak concentration (Cmax) and Vd were seen. Elderly volunteers had higher AUC (58\%), due to lower clearance of daptomycin. Therefore, lower dosage should be considered in elderly patients.

\section{Quinolones}

Ljungberg et al. found higher ciprofloxacin blood concentrations and AUC in elderly volunteers, due to a decreased ciprofloxacin clearance. Distribution was unaffected in elderly volunteers, but dose reductions should be considered [90]. The AUC of levofloxacin [91] and moxifloxacin [92] also increased in elderly patients, due to a reduced clearance of the quinolone. However, dose reductions were not advised by these authors. A fluoroquinolone Monte Carlo simulation based on 1000 simulated elderly patients with reduced CLcr of published pharmacokinetic and pharmacodynamic data showed that suggested dose reductions in elderly patients did not allow the same AUCs compared to normal dose in patients with normal CLcr. Reducing ciprofloxacin dose from $500 \mathrm{mg}$ to $250 \mathrm{mg}$ twice daily with CLcr 30-60 $\mathrm{mL} / \mathrm{min}$ and reducing levofloxacin from $500 \mathrm{mg}$ to $250 \mathrm{mg}$ once daily with CLcr 20$50 \mathrm{~mL} / \mathrm{min}$ levofloxacin lead to too low AUCs [93]. The estimated CLcr might not be accurate enough in elderly patients [61]. More in depth studies are necessary in elderly patients to improve dosing strategies of quinolones in elderly patients with CLcr reductions.

\section{Macrolides}

No difference in Vd of clarithromycin is seen in elderly volunteers, whereas the AUC is almost doubled, probably due to a decrease in renal clearance [94]. The differences in metabolite pharmacokinetic parameters were small [94]. Clarithromycin has a higher renal clearance (20-40\%), compared to azithromycin 
and erythromycin (5-12\%) [95]. Dose adjustments in elderly patients are usually not necessary. Closer clinical monitoring for ADE has been advised [45,46].

\section{Tetracyclines}

Tetracyclines are well distributed in most tissues. No significant differences were found in pharmacokinetic parameters of tigecycline in elderly volunteers, although elderly patients seemed to have lower clearance and lower Vd [96]. Blood concentrations were higher in elderly patients, but dose adjustments are not recommended as no ADEs were noticed.

\section{Oxazolidinones}

No differences were noted in AUC, Cmax, non-renal clearance and $\mathrm{T}^{1} 1 / 2$ between young and elderly volunteers [97]. In a Japanese population model, it was shown that bodyweight and age were influential covariates for linezolid clearance and elderly patients had lower linezolid clearance [98]. The difference might be explained by the difference in body weight. In the study of Sisson et al. the weight of the elderly patients was $10 \%$ higher than the younger patients. The effect of age might be blinded by the effect of higher bodyweight of the elderly patients.

\section{Nitro-imidazols}

No difference were found in elderly patients and young controls in blood concentrations, $\mathrm{Vd}$ en clearance of metronidazole [99].

\section{Conclusion}

This review shows the difficulty in interpretation of pharmacokinetic studies of antimicrobial therapy in elderly patients. Many pharmacokinetic studies have been done 20-40 years ago with different methods for determining drug concentrations. Since 1989, a few studies have been added, mainly on new antimicrobial agents. This gap in pharmacokinetic studies in elderly patients is striking. Pharmacokinetic studies in elderly patients are difficult to interpret, because the use of co-medication and co-morbidity. Ideally, methods used for measuring blood concentrations should be within FDA approved requirements and dosing studies should be done in well-defined age groups in both healthy elderly volunteers and in infected elderly patients. Young controls should be included in the studies. However, only limited pharmacokinetic studies are done in elderly patients and no antimicrobial drug is studied in an ideal setting. Furthermore, many old studies were not completely validated within FDA approved requirements for accuracy, precision, selectivity, sensitivity, reproducibility and stability [67]. The high interindividual variance of ageing further complicates exact dosing advices of antimicrobial drugs in elderly patients. Ageing is a gradual process where differences in pharmacokinetic changes with younger population become gradually visible. Most likely the largest differences can be found in the very elderly patients at the end of the age spectrum. Little advice about optimal dosing regimens is available for elderly patients.

The pharmacokinetic studies show that most antimicrobial blood concentrations are different in elderly patients. The decline in kidney function is the most important and consistent pharmacokinetic change in elderly patients $[73,75-$ 
87, 89]. However, a few studies did not find differences in antimicrobial clearance $[69,70,74]$. Despite changes in body composition in elderly patients [61], the $\mathrm{Vd}$ of hydrophilic and lipophilic antimicrobial drugs do no change consistently and do not seem to have a substantial impact on antimicrobial blood concentrations, Table 3 . However, the Vd is also affected by other factors, such as, obesity, sepsis, fever, fluid infusions, hypalbuminemia and protein binding. Furthermore, this age associated changes might be more clearly visible at the end of the age spectrum. Dose adjustments are usually not necessary in metabolic cleared antimicrobial drugs [94, 95, 97, 98].

Elderly patients need more accurate dosing strategies. Therefore, pharmacokinetic studies should not only be done in healthy volunteers, but also in real life hospitalised elderly patients. FDA approved requirements for bioanalytical methods should be used to determine the influences of pharmacokinetic parameters (i.e. renal clearance and $\mathrm{Vd}$ ) on antimicrobial blood levels when ageing. Elderly patients should be investigated at the end of the age spectrum and/or in specific elderly patient groups, such as frail elderly patients. Additionally, more accurate measurement of kidney function should be studied in pharmacokinetic studies.

\section{Aim of this thesis}

The aim of this thesis is to optimise dosing strategies in elderly people. Therefore, antimicrobial use and pharmacokinetic parameters of renally cleared hydrophilic (amoxicillin and vancomycin) and renally cleared lipophilic antimicrobial drugs (ciprofloxacin) were evaluated in hospitalised adult patients. Elderly (>70 years) and very elderly (>80 years) patients are compared to younger patients 


\section{Outline of thesis}

As discussed in the previous section, elderly patients consume more antimicrobial drugs and are more at risk for ADE and underdosing. Antimicrobial pharmacokinetics in elderly patients is different compared to younger patients due to physiologic changes of ageing. For safe and effective antimicrobial therapy in elderly patients, both knowledge of infections, antimicrobial consumption and pharmacokinetics are necessary. The backbone of this thesis is antimicrobial therapy in elderly patients. However, other research questions were investigated as well.

Elderly patients will use more antimicrobial therapy compared to younger patients. The majority of antimicrobial therapy $(>80 \%)$ is prescribed in Primary Care. In chapter 2 the antimicrobial prescriptions of elderly patients in general practice is investigated over a 10-year period. Additionally, adverse drug events of antimicrobials were investigated in relation to age. Elderly patients have changed pharmacokinetics due to ageing. The dosing of antimicrobial drugs in elderly patients should not be extrapolated from younger patients. In chapter 3 a high performance liquid chromatography method to measure ciprofloxacin blood levels is developed and validated by FDA required standards for accuracy, precision, selectivity, sensitivity, reproducibility and stability [67]. This method is used in chapter 4 to investigate the pharmacokinetics of ciprofloxacin intravenously in hospitalised patients. Elderly patients ( $>70$ years and $>80$ years) are compared to younger patients. In chapter $\mathbf{5}$ amoxicillin-clavulanic acid intravenously is investigated in hospitalised patients. In chapter $\mathbf{6}$ and $\mathbf{7}$ vancomycin intravenously is investigated with FPIA with monoclonal antibodies in hospitalised patients. FPIA with monoclonal antibodies are considered as the method of choice in renal failure, and consequently in elderly patients. Immunoassays with polyclonal antibodies can overestimate the active vancomycin concentration, by detection of accumulating vancomycin degradation products $[100,101]$. Again elderly patients are compared to younger patients. Chapter 6 focuses more on the vancomycin dosing of neutropenic patients. In chapter 7 different methods to estimate the creatinine clearance and different methods to estimate the vancomycin clearance are investigated. Chapter 8 compromises the general discussion and future perspectives. 


\section{References}

1. Lerner BH: Scientific evidence versus therapeutic demand: the introduction of the sulfonamides revisited. Annals of internal medicine 1991, 115(4):315-320.

2. Lewis K: Platforms for antibiotic discovery. Nature reviews Drug discovery 2013, 12(5):371-387.

3. Raju TN: The Nobel chronicles. 1939: Gerhard Domagk (1895-1964). Lancet 1999, 353(9153):681.

4. Morris M: A Case of Late Syphilitic Glossitis Treated by Salvarsan (Ehrlich-Hata). British medical journal 1912, 1(2674):712-712 711.

5. Breinl A, Todd JL: Atoxyl in the Treatment of Trypanosomiasis. British medical journal 1907, 1(2403):132-134.

6. Haas LF: Pierre Joseph Pelletier (1788-1842) and Jean Bienaime Caventou (1795-1887). Journal of neurology, neurosurgery, and psychiatry 1994, 57(11):1333.

7. Kyle RA, Shampe MA: Discoverers of quinine. JAMA : the journal of the American Medical Association 1974, 229(4):462.

8. Lindeboom GA: Dutch Medical Biography. A biographical Dictionary of Dutch Physicians and Surgeons 1475-1975. Pages: 860-861; 1984.

9. Abraham EP: Fleming's discovery. Reviews of infectious diseases 1980, 2(1):140.

10. Kingston W: Streptomycin, Schatz v. Waksman, and the balance of credit for discovery. Journal of the history of medicine and allied sciences 2004, 59(3):441-462.

11. Wainwright M: Streptomycin: discovery and resultant controversy. History and philosophy of the life sciences 1991, 13(1):97-124.

12. Waksman SA: What is an antibiotic or an antibiotic substance? Mycologia 1947, 39(5):565-569.

13. Adriaenssens N, Coenen S, Versporten A, Muller A, Minalu G, Faes C, Vankerckhoven V, Aerts M, Hens N, Molenberghs G et al: European Surveillance of Antimicrobial Consumption (ESAC): outpatient antibiotic use in Europe (1997-2009). The Journal of antimicrobial chemotherapy 2011, 66 Suppl 6:vi3-12.

14. CBS: http://statline.cbs.nl/StatWeb/publication/?DM=SLEN\&PA=37556ENG\&D1=044,53-60\&D2=1,11,21,31,41,51,61,71,81,91,101\&LA=EN\&VW=T.

15. Eurostat: http://epp.eurostat.ec.europa.eu/statistics_explained/index.php/Population structure an d_ageing. 2012.

16. WHO: http://www.who.int/healthinfo/survey/ageingdefnolder/en/.

17. Burkle A, Caselli G, Franceschi C, Mariani E, Sansoni P, Santoni A, Vecchio G, Witkowski $\mathrm{JM}$, Caruso C: Pathophysiology of ageing, longevity and age related diseases. Immunity \& ageing : I \& A 2007, 4:4.

18. Vasto S, Rizzo C, Caruso C: Centenarians and diet: what they eat in the Western part of Sicily. Immunity \& ageing : I \& A 2012, 9(1):10.

19. Engelhart ST, Hanses-Derendorf L, Exner M, Kramer MH: Prospective surveillance for healthcare-associated infections in German nursing home residents. The Journal of hospital infection 2005, 60(1):46-50.

20. Hogarth MB, Gallimore R, Savage P, Palmer AJ, Starr JM, Bulpitt CJ, Pepys MB: Acute phase proteins, $\mathrm{C}$-reactive protein and serum amyloid $\mathrm{A}$ protein, as prognostic markers in the elderly inpatient. Age and ageing 1997, 26(2):153-158.

21. Ross RD, Frengley JD, Mion LC, Kushner I: Elevated C-reactive protein in older people. Journal of the American Geriatrics Society 1992, 40(1):104-105.

22. Castle SC: Clinical relevance of age-related immune dysfunction. Clinical infectious diseases : an official publication of the Infectious Diseases Society of America 2000, 31(2):578-585.

23. Curns AT, Holman RC, Sejvar JJ, Owings MF, Schonberger LB: Infectious disease hospitalizations among older adults in the United States from 1990 through 2002. Archives of internal medicine 2005, 165(21):2514-2520.

24. Fry AM, Shay DK, Holman RC, Curns AT, Anderson LJ: Trends in hospitalizations for pneumonia among persons aged 65 years or older in the United States, 1988-2002. JAMA : the journal of the American Medical Association 2005, 294(21):2712-2719. 
25. Majeed A, Moser K: Age- and sex-specific antibiotic prescribing patterns in general practice in England and Wales in 1996. The British journal of general practice : the journal of the Royal College of General Practitioners 1999, 49(446):735-736.

26. Norris P, Horsburgh S, Keown S, Arroll B, Lovelock K, Cumming J, Herbison P, Crampton P, Becket G: Too much and too little? Prevalence and extent of antibiotic use in a New Zealand region. The Journal of antimicrobial chemotherapy 2011, 66(8):1921-1926.

27. Pan A, Buttazzi R, Marchi M, Gagliotti C, Resi D, Moro ML, Antibiotic U, Resistance Surveillance Study Group of Regione E-R: Secular trends in antibiotic consumption in the adult population in Emilia-Romagna, Italy, 2003-2009. Clinical microbiology and infection : the official publication of the European Society of Clinical Microbiology and Infectious Diseases 2011, 17(11):1698-1703.

28. Turnheim K: Drug dosage in the elderly. Is it rational? Drugs \& aging 1998, 13(5):357379.

29. Borrego F, Gleckman R: Principles of antibiotic prescribing in the elderly. Drugs \& aging 1997, 11(1):7-18.

30. Faulkner CM, Cox HL, Williamson JC: Unique aspects of antimicrobial use in older adults. Clinical infectious diseases : an official publication of the Infectious Diseases Society of America 2005, 40(7):997-1004.

31. Grieco MH: Use of antibiotics in the elderly. Bulletin of the New York Academy of Medicine 1980, 56(2):197-208.

32. Herring AR, Williamson JC: Principles of antimicrobial use in older adults. Clinics in geriatric medicine 2007, 23(3):481-497, v.

33. McCue JD: Antibiotic use in the elderly: issues and nonissues. Clinical infectious diseases : an official publication of the Infectious Diseases Society of America 1999, 28(4):750-752.

34. Noreddin AM, El-Khatib W, Haynes V: Optimal dosing design for antibiotic therapy in the elderly: a pharmacokinetic and pharmacodynamic perspective. Recent patents on antiinfective drug discovery 2008, 3(1):45-52.

35. Stalam M, Kaye D: Antibiotic agents in the elderly. Infectious disease clinics of North America 2004, 18(3):533-549, viii.

36. Gavazzi G, Krause KH: Ageing and infection. The Lancet infectious diseases 2002, 2(11):659-666.

37. Wilson TW, Mahon WA, Inaba T, Johnson GE, Kadar D: Elimination of tritiated gentamicin in normal human subjects and in patients with severely impaired renal function. Clinical pharmacology and therapeutics 1973, 14(5):815-822.

38. Sorgel F, Kinzig M: Pharmacokinetics of gyrase inhibitors, Part 2: Renal and hepatic elimination pathways and drug interactions. The American journal of medicine 1993, 94(3A):56S-69S.

39. McCracken GH, Jr.: Group B streptococci: the new challenge in neonatal infections. The Journal of pediatrics 1973, 82(4):703-706.

40. Meyers BR, Hirschman SZ, Strougo L, Srulevitch E: Comparative study of piperacillin, ticarcillin, and carbenicillin pharmacokinetics. Antimicrobial agents and chemotherapy 1980, 17(4):608-611.

41. Sutherland R, Croydon EA, Rolinson GN: Amoxycillin: a new semi-synthetic penicillin. British medical journal 1972, 3(5817):13-16.

42. Grose WE, Bodey GP, Loo TL: Clinical pharmacology of intravenously administered trimethoprim-sulfamethoxazole. Antimicrobial agents and chemotherapy 1979, 15(3):447451.

43. Majumdar AK, Musson DG, Birk KL, Kitchen CJ, Holland S, McCrea J, Mistry G, Hesney M, $\mathrm{Xi}$ L, Li SX et al: Pharmacokinetics of ertapenem in healthy young volunteers. Antimicrobial agents and chemotherapy 2002, 46(11):3506-3511.

44. Mouton JW, van den Anker JN: Meropenem clinical pharmacokinetics. Clinical pharmacokinetics 1995, 28(4):275-286.

45. Norrby SR, Alestig K, Bjornegard B, Burman LA, Ferber F, Huber JL, Jones KH, Kahan FM, Kahan JS, Kropp $\mathrm{H}$ et al: Urinary recovery of $\mathbf{N}$-formimidoyl thienamycin (MK0787) as affected by coadministration of $\mathbf{N}$-formimidoyl thienamycin dehydropeptidase inhibitors. Antimicrobial agents and chemotherapy 1983, 23(2):300-307.

46. Moellering RC, Jr.: Pharmacokinetics of vancomycin. The Journal of antimicrobial chemotherapy 1984, 14 Suppl D:43-52. 
Dvorchik BH, Brazier D, DeBruin MF, Arbeit RD: Daptomycin pharmacokinetics and safety following administration of escalating doses once daily to healthy subjects. Antimicrobial agents and chemotherapy 2003, 47(4):1318-1323.

Kirst HA, Sides GD: New directions for macrolide antibiotics: pharmacokinetics and clinical efficacy. Antimicrobial agents and chemotherapy 1989, 33(9):1419-1422.

Girling DJ: Adverse reactions to rifampicin in antituberculosis regimens. The Journal of antimicrobial chemotherapy 1977, 3(2):115-132.

Kunin CM, Brandt D, Wood H: Bacteriologic studies of rifampin, a new semisynthetic antibiotic. The Journal of infectious diseases 1969, 119(2):132-137.

Murdoch JM, Speirs CF, Wright N, Wallace ET: Rifampicin. Lancet 1969, 1(7605):1094.

Fass RJ, Saslaw S: Clindamycin: clinical and laboratory evaluation of parenteral therapy. The American journal of the medical sciences 1972, 263(5):368-382.

Klein NC, Cunha BA: Tetracyclines. The Medical clinics of North America 1995, 79(4):789801.

Stalker DJ, Jungbluth GL: Clinical pharmacokinetics of linezolid, a novel oxazolidinone antibacterial. Clinical pharmacokinetics 2003, 42(13):1129-1140.

Yoshikawa TT, Norman DC: Treatment of infections in elderly patients. The Medical clinics of North America 1995, 79(3):651-661.

Ljungberg B, Nilsson-Ehle I: Pharmacokinetics of antimicrobial agents in the elderly. Reviews of infectious diseases 1987, 9(2):250-264.

Vestal RE, McGuire EA, Tobin JD, Andres R, Norris AH, Mezey E: Aging and ethanol metabolism. Clinical pharmacology and therapeutics 1977, 21(3):343-354.

Vestal RE: Aging and pharmacology. Cancer 1997, 80(7):1302-1310.

Greenblatt DJ, Harmatz JS, Shader RI: Clinical pharmacokinetics of anxiolytics and hypnotics in the elderly. Therapeutic considerations (Part II). Clinical pharmacokinetics 1991, 21(4):262-273.

. Pijpers E, Ferreira I, van de Laar RJ, Stehouwer CD, Nieuwenhuijzen Kruseman AC: Predicting mortality of psychogeriatric patients: a simple prognostic frailty risk score. Postgraduate medical journal 2009, 85(1007):464-469.

1. Malmrose LC, Gray SL, Pieper CF, Blazer DG, Rowe JW, Seeman TE, Albert MS: Measured versus estimated creatinine clearance in a high-functioning elderly sample: MacArthur Foundation Study of Successful Aging. Journal of the American Geriatrics Society 1993, 41(7):715-721.

Lindeman RD, Tobin J, Shock NW: Longitudinal studies on the rate of decline in renal function with age. Journal of the American Geriatrics Society 1985, 33(4):278-285.

Schmucker DL: Liver function and phase I drug metabolism in the elderly: a paradox. Drugs \& aging 2001, 18(11):837-851.

Lewis DA, Reeves DS: Antibiotics at the extremes of age: choices and constraints. The Journal of antimicrobial chemotherapy 1994, 34 Suppl A:11-18.

P. E: Address in pathology in chemotherapeutic: scientific principles, methods and results. Lancet 1913: 445-51. Lancet 1913.

Meyers BR, Wilkinson P: Clinical pharmacokinetics of antibacterial drugs in the elderly. Implications for selection and dosage. Clinical pharmacokinetics 1989, 17(6):385-395.

$\begin{array}{ll}\text { validation } & \text { FGfi-Bm: }\end{array}$ http://www.fda.gov/downloads/drugs/guidancecomplianceregulatoryinformation/guidanc es/ucm368107.pdf. 2013.

Chadwick EG, Shulman ST, Yogev R: Correlation of antibiotic synergy in vitro and in vivo: use of an animal model of neutropenic gram-negative sepsis. The Journal of infectious diseases 1986, 154(4):670-675.

Bauer LA, Blouin RA: Influence of age on amikacin pharmacokinetics in patients without renal disease. Comparison with gentamicin and tobramycin. European journal of clinical pharmacology 1983, 24(5):639-642.

Bauer LA, Blouin RA: Influence of age on tobramycin pharmacokinetics in patients with normal renal function. Antimicrobial agents and chemotherapy 1981, 20(5):587-589.

1. Fraisse T, Gras Aygon C, Paccalin M, Vitrat V, De Wazieres B, Baudoux V, Lechiche C, Vicens A, Sotto A, Pagani L et al: Aminoglycosides use in patients over 75 years old. Age and ageing 2014, 43(5):676-681.

Triggs E, Charles B: Pharmacokinetics and therapeutic drug monitoring of gentamicin in the elderly. Clinical pharmacokinetics 1999, 37(4):331-341. 
73. Rho JP, Jones A, Woo M, Castle S, Smith K, Bawdon RE, Norman DC: Single-dose pharmacokinetics of intravenous ampicillin plus sulbactam in healthy elderly and young adult subjects. The Journal of antimicrobial chemotherapy 1989, 24(4):573-580.

74. Sjovall J, Alvan G, Huitfeldt B: Intra- and inter-individual variation in pharmacokinetics of intravenously infused amoxycillin and ampicillin to elderly volunteers. British journal of clinical pharmacology 1986, 21(2):171-181.

75. LeBel M, Barbeau G, Vallee F, Bergeron MG: Pharmacokinetics of ceftazidime in elderly volunteers. Antimicrobial agents and chemotherapy 1985, 28(5):713-715.

76. Naber KG, Kees F, Grobecker H: Ceftazidime: pharmacokinetics in young volunteers versus elderly patients and therapeutic efficacy with complicated urinary tract infections. The Journal of antimicrobial chemotherapy 1983, 12 Suppl A:41-45.

77. Barbhaiya RH, Knupp CA, Pittman KA: Effects of age and gender on pharmacokinetics of cefepime. Antimicrobial agents and chemotherapy 1992, 36(6):1181-1185.

78. Luderer JR, Patel IH, Durkin J, Schneck DW: Age and ceftriaxone kinetics. Clinical pharmacology and therapeutics 1984, 35(1):19-25.

79. Ljungberg B, Nilsson-Ehle I: Pharmacokinetics of ceftazidime in elderly patients and young volunteers. Scandinavian journal of infectious diseases 1984, 16(3):325-326.

80. Ludwig E, Szekely E, Csiba A, Graber H: Pharmacokinetics of cefotaxime and desacetylcefotaxime in elderly patients. Drugs 1988, 35 Suppl 2:51-56.

81. Ljungberg B, Nilsson-Ehle I: Pharmacokinetics of meropenem and its metabolite in young and elderly healthy men. Antimicrobial agents and chemotherapy 1992, 36(7):1437-1440.

82. Musson DG, Majumdar A, Holland S, Birk K, Xi L, Mistry G, Sciberras D, Muckow J, Deutsch P, Rogers JD: Pharmacokinetics of total and unbound ertapenem in healthy elderly subjects. Antimicrobial agents and chemotherapy 2004, 48(2):521-524.

83. Meyers BR, Wilkinson P, Mendelson MH, Bournazos C, Tejero C, Hirschman SZ: Pharmacokinetics of aztreonam in healthy elderly and young adult volunteers. Journal of clinical pharmacology 1993, 33(5):470-474.

84. Torres JR, Sanders CV, Lewis AC: Vancomycin concentration in human tissues-preliminary report. The Journal of antimicrobial chemotherapy 1979, 5(4):475-477.

85. Guay DR, Vance-Bryan K, Gilliland S, Rodvold K, Rotschafer J: Comparison of vancomycin pharmacokinetics in hospitalized elderly and young patients using a Bayesian forecaster. Journal of clinical pharmacology 1993, 33(10):918-922.

86. Ducharme MP, Slaughter RL, Edwards DJ: Vancomycin pharmacokinetics in a patient population: effect of age, gender, and body weight. Therapeutic drug monitoring 1994, 16(5):513-518.

87. Cutler NR, Narang PK, Lesko LJ, Ninos M, Power M: Vancomycin disposition: the importance of age. Clinical pharmacology and therapeutics 1984, 36(6):803-810.

88. Sanchez JL, Dominguez AR, Lane JR, Anderson PO, Capparelli EV, Cornejo-Bravo JM: Population pharmacokinetics of vancomycin in adult and geriatric patients: comparison of eleven approaches. International journal of clinical pharmacology and therapeutics 2010 , 48(8):525-533.

89. Dvorchik B, Damphousse D: Single-dose pharmacokinetics of daptomycin in young and geriatric volunteers. Journal of clinical pharmacology 2004, 44(6):612-620.

90. Ljungberg B, Nilsson-Ehle I: Pharmacokinetics of ciprofloxacin in the elderly: increased oral bioavailability and reduced renal clearance. European journal of clinical microbiology $\&$ infectious diseases : official publication of the European Society of Clinical Microbiology 1989, 8(6):515-520.

91. Chien SC, Chow AT, Natarajan J, Williams RR, Wong FA, Rogge MC, Nayak RK: Absence of age and gender effects on the pharmacokinetics of a single 500-milligram oral dose of levofloxacin in healthy subjects. Antimicrobial agents and chemotherapy 1997, 41(7):15621565.

92. Sullivan JT, Lettieri JT, Liu P, Heller AH: The influence of age and gender on the pharmacokinetics of moxifloxacin. Clinical pharmacokinetics 2001, 40 Suppl 1:11-18.

93. Leroy B, Uhart M, Maire P, Bourguignon L: Evaluation of fluoroquinolone reduced dosage regimens in elderly patients by using pharmacokinetic modelling and Monte Carlo simulations. The Journal of antimicrobial chemotherapy 2012, 67(9):2207-2212.

94. Chu SY, Wilson DS, Guay DR, Craft C: Clarithromycin pharmacokinetics in healthy young and elderly volunteers. Journal of clinical pharmacology 1992, 32(11):1045-1049. 
95. Periti P, Mazzei T, Mini E, Novelli A: Clinical pharmacokinetic properties of the macrolide antibiotics. Effects of age and various pathophysiological states (Part I). Clinical pharmacokinetics 1989, 16(4):193-214.

96. Muralidharan G, Fruncillo RJ, Micalizzi M, Raible DG, Troy SM: Effects of age and sex on single-dose pharmacokinetics of tigecycline in healthy subjects. Antimicrobial agents and chemotherapy 2005, 49(4):1656-1659.

97. Sisson TL, Jungbluth GL, Hopkins NK: Age and sex effects on the pharmacokinetics of linezolid. European journal of clinical pharmacology 2002, 57(11):793-797.

98. Abe S, Chiba K, Cirincione B, Grasela TH, Ito K, Suwa T: Population pharmacokinetic analysis of linezolid in patients with infectious disease: application to lower body weight and elderly patients. Journal of clinical pharmacology 2009, 49(9):1071-1078.

99. Loft S, Egsmose C, Sonne J, Poulsen HE, Dossing M, Andreasen PB: Metronidazole elimination is preserved in the elderly. Human \& experimental toxicology 1990, 9(3):155159.

100. Follin SL, Mueller BA, Scott MK, Carfagna MA, Kraus MA: Falsely elevated serum vancomycin concentrations in hemodialysis patients. American journal of kidney diseases : the official journal of the National Kidney Foundation 1996, 27(1):67-74.

101. Kingery JR, Sowinski KM, Kraus MA, Klaunig JE, Mueller BA: Vancomycin assay performance in patients with end-stage renal disease receiving hemodialysis. Pharmacotherapy 2000, 20(6):653-656. 


\section{Chapter 2}

Trends in antibiotic prescribing in adults in Dutch general practice

M.B. Haeseker, N.H.T.M. Dukers-Muijrers, C.J.P.A. Hoebe, C.A. Bruggeman, J.W.L. Cals, A.Verbon.

PLOSONE 2012;7(12):e51860 


\begin{abstract}
Introduction. Antibiotic consumption is associated with adverse drug events (ADE) and increasing antibiotic resistance. Detailed information of antibiotic prescribing in different age categories is scarce, but necessary to develop strategies for prudent antibiotic use. The aim of this study was to determine the antibiotic prescriptions of different antibiotic classes in general practice in relation to age.

Methods. Retrospective study of 22 rural and urban general practices from the Dutch Registration Network Family Practices (RNH). Antibiotic prescribing data were extracted from the RNH database from 2000-2009. Trends over time in antibiotic prescriptions were assessed with multivariate logistic regression including interaction terms with age. Registered ADEs as a result of antibiotic prescriptions were also analyzed.

Results. In total 658,940 patients years were analyzed. In $11.5 \%(n=75,796)$ of the patient years at least one antibiotic was prescribed. Antibiotic prescriptions increased for all age categories during 2000-2009, but the increase in elderly patients (>80 years) was most prominent. In $20009 \%$ of the patients $>80$ years was prescribed at least one antibiotic, which increased to $22 \%$ in $2009(P<0.001)$. Elderly patients had more ADEs with antibiotics and co-medication was identified as the only independent determinant for ADEs.

Conclusion/Discussion. The rate of antibiotic prescribing for patients who made a visit to the GP is increasing in the Netherlands with the most evident increase in the elderly patients. This may lead to more ADEs, which might lead to higher consumption of health care and more antibiotic resistance.
\end{abstract}




\section{Introduction}

The majority of antibiotics (80\%) in the Netherlands are prescribed in primary care [1]. Outpatient antibiotic consumption is higher in elderly patients than in the general population [2-4] and most antibiotics are prescribed in elderly patients for respiratory tract infections (RTI) [5], skin and soft tissue infections [6] and urinary tract infections (UTI) [7]. However, detailed information of antibiotic prescribing in elderly is scarce. The majority of studies have been done in children, who also have a high antibiotic consumption $[2,8,9]$. The paucity of data on antibiotic use in elderly is surprising since elderly patients are more susceptible to toxic effects of antibiotics. For instance, adverse drug events (ADEs) have been described more frequently in frail elderly with co-morbidity and co-medication [10]. Additionally, elderly patients have altered pharmacokinetics, such as decreased absorption and elimination, which alters antibiotic blood levels, thereby influencing the risk of ADEs [11].

Antibiotic use is slowly, but steadily increasing in the Netherlands since 2005 [12]. It is unknown whether the increase in antibiotic use is equal in all age categories. Trends over time in antibiotic use per age category have not been studied and more information on the highest age categories is crucial as a quarter of the Dutch population will be above 65 years in the near future, similar to other European countries [13].

To determine trends in antibiotic prescribing in elderly, we have assessed antibiotic prescription rates by age categories in general practices over a ten year period in a large general practice database. Additionally, we have analyzed the incidence of registered ADEs due to antibiotics. 


\section{Methods}

The data for this study are obtained retrospectively from the Dutch Registratie Netwerk Huisartsen (RNH, Registration Network Family Practices). The study group is described and regrouped into four different age categories: 18-44 years, 45-64 years, 65-79 years and $\geq 80$ years. In these age categories, we have compared rates and trends over time in antibiotic prescriptions. Individual prescriptions per patient in a year were used as measure of prescriptions. For each prescription (at the moment of the specific consultation) information on ADE (until 4 weeks after prescription) and co-medication (at and during the prescription) were used. Data were then aggregated over a specific patient and calendar year to obtain a meaningful measure (\% per patient-year).

\section{Data source}

The RNH is a continuous, computerized and anonymous database from 22 rural and urban general practices in the south of the Netherlands, Limburg, [14]. During the study period the average number of patients $>18$ years in the RNH was 65,894 patients. The population was stable with respect to general sociodemographic characteristics.

The GP is responsible for the inclusion of patients. When a patient is included a unique RNH number is attributed to the patient. The GP records patient characteristics, i.e. birthdates, sex, educational level, insurance, type of household, marital status, place of residence, date of entry, last update and end of registration. The GP records all relevant health problems, only permanent, chronic and recurrent (>3 recurrences within a period of 6 months) are recorded, or when they had lasting consequences for the functional status or prognosis of the patient. Medication prescriptions (coded according to the Anatomical Therapeutic Chemical Index 2012 by the WHO Collaborating Centre for Drug Statistics Methodology) are included in the RNH database Registration. This includes type of medication, start and end date, and dose. Diagnoses are coded in a standardized fashion, according to the International Classification of Primary Care, using the criteria of the International Classification of Health in Primary Care (ICPC) and the current guidelines of the Dutch College of GPs [15]. Monitoring by the RNH registry ends at migration or death. All practices use MicroHIS (Torex-Hiscom), a commercially developed general practice health information software program containing a basic module, a medical module and a pharmacy module, which enable the GP to keep up an automated registration of his patients. Quarterly the RNH data collection module enables the GP to exchange all registered data to the central database. The RNH assistant checks the data and the RNH test module provides the distribution of the practice population, e.g. tables with the age distribution and the twenty most registered ICPC codes. The RNH exports the database in an SPSS data format.

A number of instruments are available in order to improve the quality and to reduce the inter-doctor variation: all GPs participating in the RNH are instructed and trained, RNH help program exists with all guidelines and criteria described, regional consensus group meeting take place at least 4 times a year to discuss their registration difficulties, special software for data control in the health information system used by the GP and, special software for data control in the central database, 
several quality control experiments have been performed to gain insight into the quality of the database and several measures of agreement were done $[14,16]$.

\section{Data analysis}

Chronic diseases are selected from the classification from chronic diseases of Knottnerus [17]. We have included all chronic diseases, only congenital diseases have been excluded. Using ATC code J01 for all antibacterial medication for systemic use, further discrimination is made for antibiotic classes used in general practice, i.e. tetracycline (ATC J01A), penicillins (ATC J01C), sulphonamides and trimetroprim (ATC J01E), macrolides (ATC J01F), fluoroquinolones (ATC J01MA) and nitrofuran derivates (ATC J01XE). Antifungals (J02) and anti-tuberculosis drug (J03) excluded All other medication present at the moment when antibiotics have been prescribed are considered co-medication. Co-medication is registered in the following groups of medication: drugs for peptic ulcer and gastro-esophageal reflux (ATC A02B), antithrombotic agents (ATC B01A), cardiovascular medication (ATC C), corticosteroids for systemic use (ATC H02), anti-inflammatory and antirheumatic products, non-steroids anti-inflammatory drugs (ATC M01A), other analgesics and antipyretics (ATC N02B), anxiolytics (ATC N05B), hypnotics and sedatives (ATC N05C), antidepressants (ATC N06A), and antihistamines for systemic use (ATC R06). Since 1996 the RNH is recording all ADEs as ICPC code A85. All kinds of ADEs could be recorded at the discretion of the attending GP. ADEs are considered associated with antibiotic prescription if occurring within four weeks after start of antibiotics. The ADEs are self-reported by patients and were recorded as an $\mathrm{ADE}$ at the discretion of the attending GP.

\section{Statistical analysis and ethics}

Unit of analyses are patient years, where a patient contributed one patientyear when he or she had attended a GP in that calendar year. Outcome measures included in the analyses are: antibiotic prescriptions (yes/no in a year), the number of antibiotic prescriptions (cumulated within a patient over a year) and ADEs (yes/no in a year). For antibiotic prescriptions, a multivariate model was build including age, time, gender, education level and rural versus and urban general practice, and chronic disease. In analyses with ADE as outcome restricted the study population to patient-years with antibiotic prescription and the multivariate model included age, time, gender, education level and rural versus and urban general practice, chronic disease and co-medication. The variables on age and time were presented, as these were our main focus, while controlling for the other variables. Interaction terms between age and time were explored. Statistical analysis is done with SPSS 16.0. A p-value $<0.05$ is considered statistically significant.

All patients included in the RNH database have been informed about the potential anonymous use of their health information. If a patient does not agree, the inclusion of this patient in the RNH database is stopped. All data in this study were analyzed anonymously, only medications and clinical data were used. The Medical Ethics Committee of the Maastricht University Medical Center approved this study (METC 12-4-053). 


\section{Results}

A total of 658,940 patient years were analyzed from 2000-2009: $43 \%$ $(n=280,417)$ of the patients years were aged between $18-44$ years, 36\% $(n=237,524)$ between 45-64 years, 16\% $(n=108,131)$ between $65-79$ years and 5\% $(n=32,868)$ $\geq 80$ years. Forty eight percent $(n=318,621)$ of the patient years were comprised by male and $52 \%(n=340,319)$ were comprised by female, see Table 1 for population characteristics of the RNH. Sociodemographical characteristics of samples in other studies, which made use of the RNH database, have shown to be comparable to the Dutch population [16]. The elderly (>65 years) are slightly overrepresented in the $\mathrm{RNH}, 22 \%$ compared to $14 \%$ in the Dutch population in 2007 . Hence, we do consider our results to be accurate and representative for the Dutch population, with a high internal and external generalizability.

In total $11.5 \%(n=75,796)$ of the patient years at least one antibiotic per year was prescribed. Antibiotics were more often prescribed in elderly patients $(P<0.001)$, as shown in Figure 1. The association with higher age was present in all years studied. Prescription rates of all antibiotics increased in all age-categories over time (all $P<0.001$ ). Although an increase was observed in all age categories, the increase was strongest in patients $>80$ years (interaction between age and time: $P<0.001)$. This increase is seen for all antibiotic classes, with the exception of the macrolides (Figure 2). The number of antibiotic prescriptions per patient per year increased with age $(P<0.001)$ : two or more antibiotic courses were prescribed for $18 \%(n=1,571)$ of the patients years in $18-44$ years, $19 \%(n=5,042)$ in $45-64$ years, $23 \%(n=3,581)$ in $65-79$ years and $29 \%(n=1571)$ in $\geq 80$ years. The number of prescriptions independently increased with age and independently increased over time $(P<0.001)$.

Table 1. Population characteristics of the RNH in patient years.

\begin{tabular}{llll}
\hline & \multicolumn{2}{l}{ Antibiotic prescription } & Total \\
\cline { 2 - 3 } & No & Yes & \\
\cline { 1 - 3 } Age categories & & & \\
- $18-44$ yr & $252,120(43 \%)$ & $28,297(37 \%)$ & $280,417(43 \%)$ \\
- $45-64 \mathrm{yr}$ & $210,943(36 \%)$ & $26,581(35 \%)$ & $237,524(36 \%)$ \\
- $65-79 \mathrm{yr}$ & $92,691(16 \%)$ & $15,440(20 \%)$ & $108,131(16 \%)$ \\
- $>80 \mathrm{yr}$ & $27,390(5 \%)$ & $5,478(7 \%)$ & $32,868(5 \%)$ \\
\hline Gender & & & \\
- Male & $289,966(50 \%)$ & $28,655(38 \%)$ & $318,621(48 \%)$ \\
- Female & $293,178(50 \%)$ & $47,141(62 \%)$ & $340,319(52 \%)$ \\
\hline Education & & & \\
- Secondary school or lower secondary & $188,361(32 \%)$ & $30,161(40 \%)$ & $218,522(33 \%)$ \\
vocational education & & & \\
- Senior secondary vocational education & $81,523(14 \%)$ & $11,905(16 \%)$ & $93,428(14 \%)$ \\
- Higher education and University & $26,248(5 \%)$ & $3,352(4 \%)$ & $29,600(5 \%)$ \\
- Unknown & $287,012(49 \%)$ & $30,378(40 \%)$ & $317,390(48 \%)$ \\
\hline Chronic disease & & & \\
- No & $369,062(63 \%)$ & $39,161(52 \%)$ & $408,233(62 \%)$ \\
- Yes & $214,082(37 \%)$ & $36,635(48 \%)$ & $250,717(38 \%)$ \\
\hline General Practice & & & \\
- Rural & $386,365(66 \%)$ & $45,900(61 \%)$ & $432,265(66 \%)$ \\
- Urban & $196,779(34 \%)$ & $29,896(39 \%)$ & $226,675(34 \%)$ \\
\hline Total & $583,144(85 \%)$ & $75,796(15 \%)$ & $658,940(100 \%)$ \\
\hline
\end{tabular}




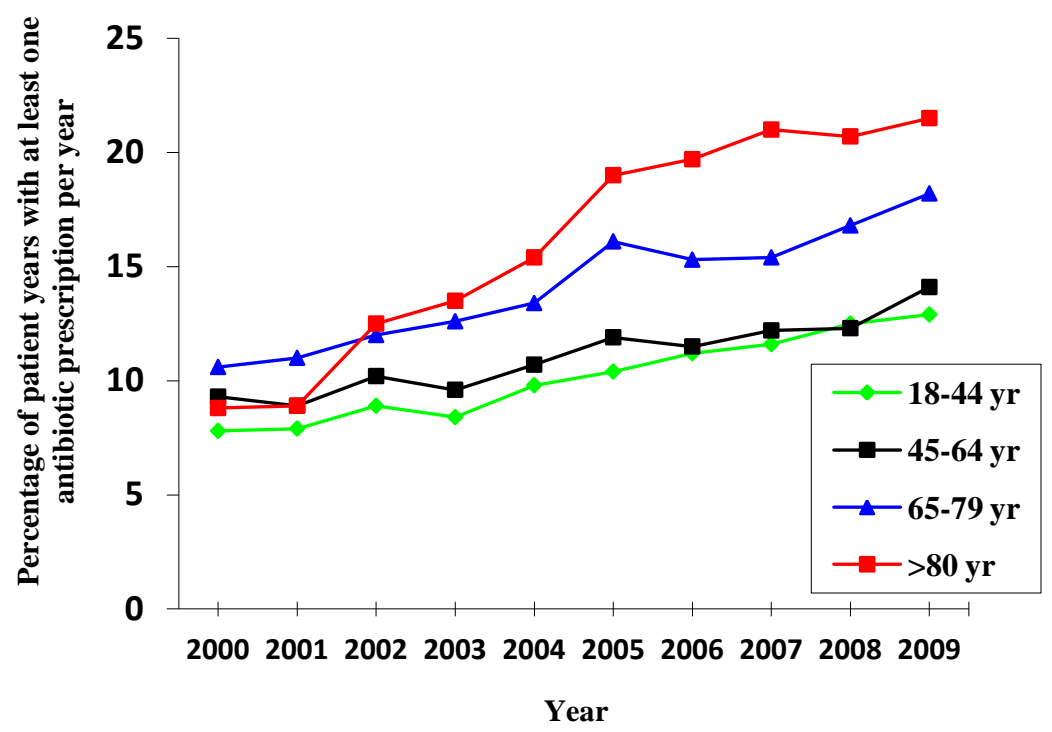

Figure 1. Percentage of patients years with at least one antibiotic prescription that year in different age categories during 2000-2009 $(P<0.001)$.

\section{ADEs, underlying diseases and co-medication}

Of all patients who received an antibiotic prescription, the minority (2\%; $\mathrm{n}=1,526 / 75,796)$ reported an $\mathrm{ADE}$ in the four weeks time window. In a random sample of 4 week periods from the same patients, compared to any 4 week period, excluding antibiotic prescriptions during this period, rates found were $0.06 \%$ $(\mathrm{n}=425 / 658,346)$ without antibiotics. No time trend in ADE reporting was observed. ADEs were not reported more frequently in the later years (2008/2009) compared to the earlier years (2000/2001). ADEs increased per age category per calendar year from $1.8 \%$ in $18-44$ years, $1.9 \%$ in $45-64$ years and $2.3 \%$ in $65-79$ years to $2.8 \%$ in $\geq 80$ years. However, co-medication also increased per age category from $23 \%$ $(\mathrm{n}=6,529)$ in $18-44$ years, $49 \%(\mathrm{n}=13,078)$ in $45-64$ years and $70 \%(\mathrm{n}=10,978)$ in $65-79$ years to $78 \%(\mathrm{n}=4,275)$ in $\geq 80$ years. As expected, underlying chronic diseases increased by age. Of all patient years analyzed $18 \%(n=50,924)$ were diagnosed with at least one chronic disease, $40 \%(n=94,376)$ in the $45-64,72 \%$ $(n=77,530)$ in $65-79$ and $85 \%(n=27,887)$ in $>80$ years age category. In the univariate analysis older age, having one or more chronic disease and co-medication were associated with occurrence of $\mathrm{ADE}$. In the multivariate analysis use of comedication remained associated with $\operatorname{ADE}(P<0.001)$ (Figure 3), while age and chronic disease were not. 

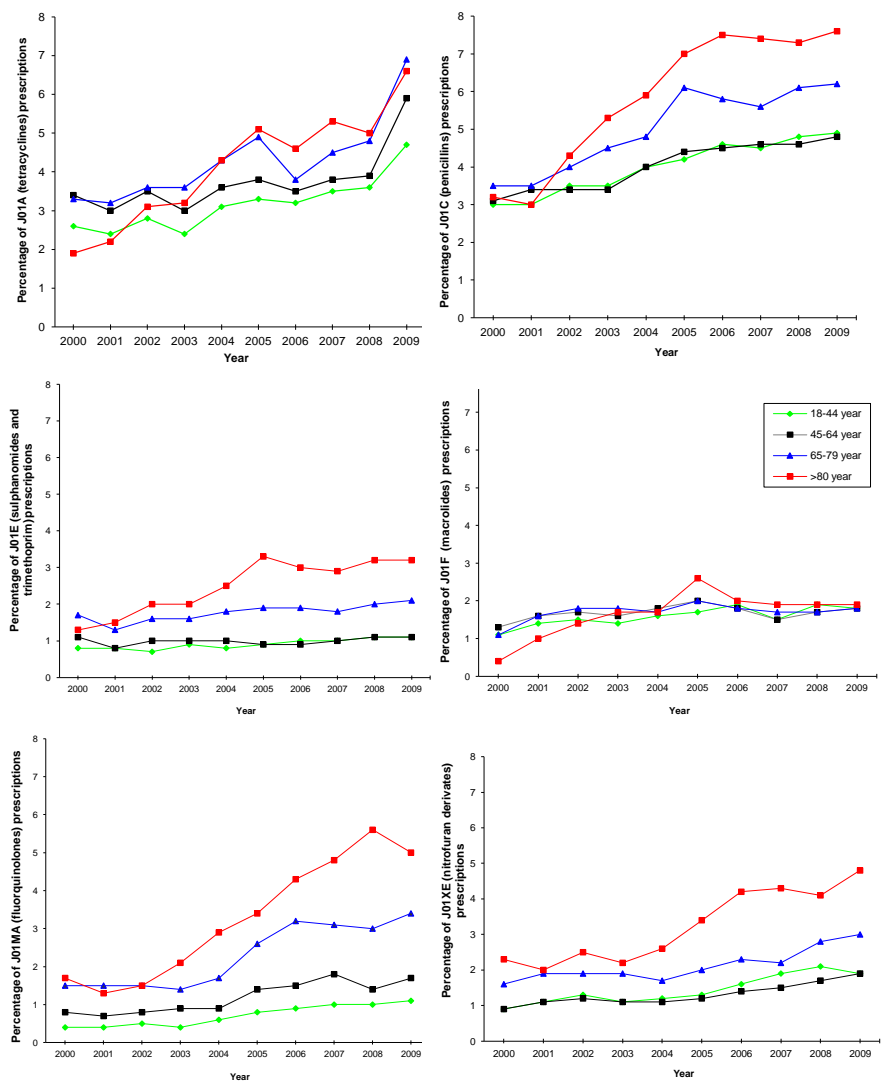

Figure 2. Percentage of patients with at least one antibiotic prescription that year for different classes of antibiotic prescriptions in different age categories during 2000-2009 $(P<0.001)$. 


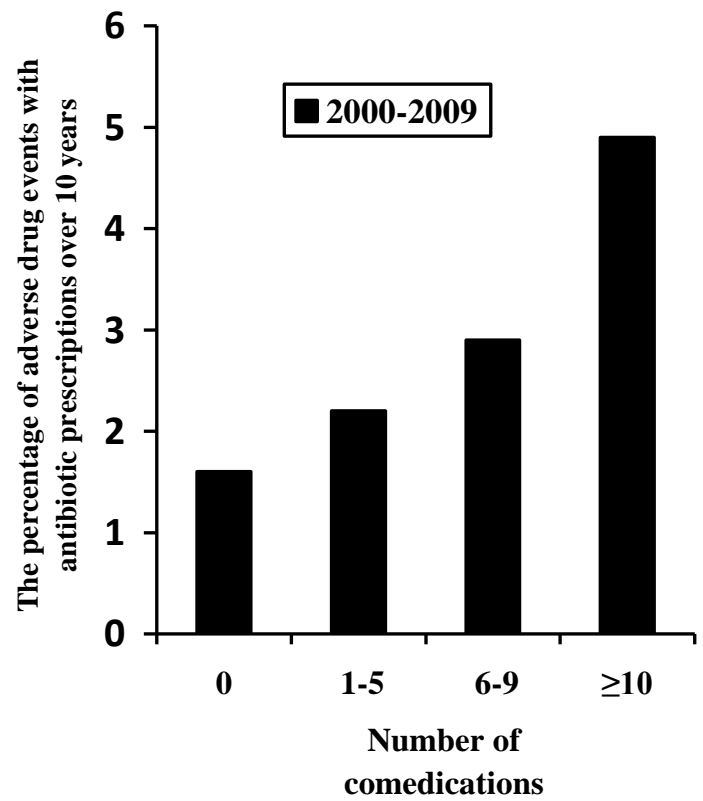

Figure 3. Percentage of adverse drug events with number of co-medication per age category during 20002009. 


\section{Discussion}

This large primary cohort shows that the rate of antibiotic prescribing for patients who made a visit to the GP has increased in Dutch general practice from 2000 to 2009 in all adult age categories. We have observed the highest increase in the rate of antibiotic prescriptions in elderly patients; from $9 \%$ of patients receiving at least one antibiotic in 2000 to $22 \%$ in 2009 . Additionally, elderly patients more often receive two or more antibiotic prescriptions per patient than younger patients. We have shown increasing trends for all antibiotic subgroups. This is particularly striking for the fluoroquinolones, as these are not indicated as first choice in any Dutch general practice guideline. In the United States nonapproved fluoroquinolone prescribing has already been described in 2005 [18]. Only the macrolides have shown a stable prescription pattern over time and across groups. Elderly patients have more ADEs associated with antibiotics. Co-medication has been identified as the only independent determinant for ADEs. Age was not an independent variable in the multivariate analysis.

Our finding that the antibiotic prescription is increasing since 2005 in the Netherlands is comparable with the increase in Europe as shown in the European Surveillance of Antimicrobial Consumption data [19]. Although, the prescription rate in the Netherlands is increasing, it is still low compared to other European countries [19]. The Dutch guidelines for GPs of common infections have not been changed significantly during these ten-years. However, the increase of the number of fluoroquinolone prescriptions suggests that guidelines are not always followed. The increase in antibiotic prescriptions might be explained by an increased consultation frequency for acute infections, such as RTIs and UTIs. Although, the consultation frequency historically has tended to decrease over the years [20], it was recently shown that consultation rates for lower RTIs are increasing in the Netherlands while RTI related consultations are stable in the UK [21]. In this study however, we did not have access to the ICPC coding for acute conditions such as acute respiratory tract infections.

To our knowledge only three previous studies, one in England/Wales, one in New Zealand and one in Italy, have shown higher antibiotic consumption in elderly patients (>75 years) $[2,3]$. We showed that elderly patients consistently have high antibiotic prescription rates compared to the younger patients and there is an increasing trend over time as well in these elderly patients.

The highest risk group to develop ADEs is aged over 80 years with multiple co-morbidity and co-medication $[22,23]$. Inappropriate prescriptions are a leading cause for the development of ADEs [24, 25]. Although, the observed rate of ADEs in our study is lower than the 5-35\% found in other studies [26-28]. Our study is in line with studies that show that co-medication and the number of co-medication is an independent association with ADEs due to antibiotic use [23, 29]. To prevent ADEs in elderly patients due to antibiotic use, the necessity of antibiotic treatment needs to be carefully determined, especially when co-medication is used. Minimizing unnecessary antibiotic treatment by even a small percentage could significantly reduce immediate and direct risks of $\mathrm{ADE}$ in individual patients [30].

The main strengths of this study are the long study period and the large representative study group. Since 1996 this RNH database is keeping records of all 
medications (including antibiotics) via a computerized medical registration program. Data accuracy can be guaranteed as data extraction takes place from electronic medical records of practices and regular training of the GPs and quality controls of the data take place $[14,16]$. All patients with multiple antibiotic prescriptions per year have been included only once per year. Therefore, this study group is not biased by a few fragile elderly patients with multiple antibiotic prescriptions.

However, this study has several limitations. Firstly, antibiotic prescriptions could not be given in daily defined dosages (DDDs) like some international data [31, 32], limiting comparability with other studies. Secondly, we have no diagnostic information on acute infections. Thirdly, ADEs were self-reported by the patients, most probably underestimating the incidence of $\mathrm{ADE}$ associated with antibiotics.

Based on our findings, future strategies to decrease the antibiotic consumption and antibiotic resistance in the Netherlands should be addressed to all adult age categories. The elderly could be a specific target group and more in-depth study into the reasons for increasing antibiotic prescribing is necessary.

\section{Acknowledgements}

The authors thank Alfons Schroten, Job Metsemakers and Marjan van den Akker for the database support. The authors are also grateful to the GPs of the RNH. 


\section{References}

1. Kuyvenhoven MM, van Balen FA, Verheij TJ: Outpatient antibiotic prescriptions from 1992 to 2001 in the Netherlands. J Antimicrob Chemother 2003, 52(4):675-678.

2. Majeed A, Moser K: Age- and sex-specific antibiotic prescribing patterns in general practice in England and Wales in 1996. Br J Gen Pract 1999, 49(446):735-736.

3. Norris P, Horsburgh S, Keown S, Arroll B, Lovelock K, Cumming J, Herbison P, Crampton P, Becket G: Too much and too little? Prevalence and extent of antibiotic use in a New Zealand region. J Antimicrob Chemother 2011, 66(8):1921-1926.

Pan A, Buttazzi R, Marchi M, Gagliotti C, Resi D, Moro ML: Secular trends in antibiotic consumption in the adult population in Emilia-Romagna, Italy, 2003-2009. Clin Microbiol Infect 2011, 17(11):1698-1703.

5. Feldman C: Pneumonia in the elderly. Med Clin North Am 2001, 85(6):1441-1459.

6. $\quad$ Laube S: Skin infections and ageing. Ageing Res Rev 2004, 3(1):69-89.

7. Richards CL: Urinary tract infections in the frail elderly: issues for diagnosis, treatment and prevention. Int Urol Nephrol 2004, 36(3):457-463.

8. Finkelstein JA, Metlay JP, Davis RL, Rifas-Shiman SL, Dowell SF, Platt R: Antimicrobial use in defined populations of infants and young children. Archives of pediatrics \& adolescent medicine 2000, 154(4):395-400.

9. Otters HB, van der Wouden JC, Schellevis FG, van Suijlekom-Smit LW, Koes BW: Trends in prescribing antibiotics for children in Dutch general practice. J Antimicrob Chemother 2004, 53(2):361-366.

10. Faulkner CM, Cox HL, Williamson JC: Unique aspects of antimicrobial use in older adults. Clin Infect Dis 2005, 40(7):997-1004.

11. Herring AR, Williamson JC: Principles of antimicrobial use in older adults. Clin Geriatr Med 2007, 23(3):481-497, v.

12. SFK: Antibioticagebruik groeit gestaag (Antibiotic use is growing). http://wwwsfknl/publicaties/farmacie in cijfers/2010/2010-07html 2010.

Eurostat yearbook 2010, page 167-168:

http://epp.eurostat.ec.europa.eu/portal/page/portal/eurostat/home/

14. Supplement. Akker van den M MJ, Limonard C and Knotnerus J: General Practice: a gold mine for research. Data and scientific use of the Registration Network Family Practices.; 2004.

15. Hofmans-Okkes IM, Lamberts H: The International Classification of Primary Care (ICPC): new applications in research and computer-based patient records in family practice. Fam Pract 1996, 13(3):294-302.

16. Metsemakers JF, Knottnerus JA, van Schendel GJ, Kocken RJ, Limonard CB: Unlocking patients' records in general practice for research, medical education and quality assurance: the Registration Network Family Practices. Int J Biomed Comput 1996, 42(12):43-50.

17. Knottnerus JA, Metsemakers J, Hoppener P, Limonard C: Chronic illness in the community and the concept of 'social prevalence'. Fam Pract 1992, 9(1):15-21.

18. Linder JA, Huang ES, Steinman MA, Gonzales R, Stafford RS: Fluoroquinolone prescribing in the United States: 1995 to 2002. The American journal of medicine 2005, 118(3):259-268.

19. Adriaenssens N, Coenen S, Versporten A, Muller A, Minalu G, Faes C, Vankerckhoven V, Aerts M, Hens N, Molenberghs G et al: European Surveillance of Antimicrobial Consumption (ESAC): outpatient antibiotic use in Europe (1997-2009). J Antimicrob Chemother 2011, 66 Suppl 6:vi3-12.

20. Cosby JL, Francis N, Butler CC: The role of evidence in the decline of antibiotic use for common respiratory infections in primary care. The Lancet infectious diseases 2007, 7(11):749-756.

21. Gulliford M, Latinovic R, Charlton J, Little P, van Staa T, Ashworth M: Selective decrease in consultations and antibiotic prescribing for acute respiratory tract infections in UK primary care up to 2006. J Public Health (Oxf) 2009, 31(4):512-520.

22. Beard K: Adverse reactions as a cause of hospital admission in the aged. Drugs \& aging 1992, 2(4):356-367.

23. Lazarou J, Pomeranz BH, Corey PN: Incidence of adverse drug reactions in hospitalized patients: a meta-analysis of prospective studies. JAMA 1998, 279(15):1200-1205. 
24. Beers MH: Explicit criteria for determining potentially inappropriate medication use by the elderly. An update. Archives of internal medicine 1997, 157(14):1531-1536.

25. O'Mahony D, Gallagher PF: Inappropriate prescribing in the older population: need for new criteria. Age Ageing 2008, 37(2):138-141.

26. Gandhi TK, Weingart SN, Borus J, Seger AC, Peterson J, Burdick E, Seger DL, Shu K, Federico F, Leape LL et al: Adverse drug events in ambulatory care. $N$ Engl J Med 2003, 348(16):1556-1564.

27. Hanlon JT, Schmader KE, Koronkowski MJ, Weinberger M, Landsman PB, Samsa GP, Lewis IK: Adverse drug events in high risk older outpatients. J Am Geriatr Soc 1997, 45(8):945948.

28. Hutchinson TA, Flegel KM, Kramer MS, Leduc DG, Kong HH: Frequency, severity and risk factors for adverse drug reactions in adult out-patients: a prospective study. $J$ Chronic Dis 1986, 39(7):533-542.

29. Laroche ML, Charmes JP, Nouaille Y, Picard N, Merle L: Is inappropriate medication use a major cause of adverse drug reactions in the elderly? British journal of clinical pharmacology 2007, 63(2):177-186.

30. Shehab N, Patel PR, Srinivasan A, Budnitz DS: Emergency department visits for antibioticassociated adverse events. Clin Infect Dis 2008, 47(6):735-743.

31. Ferech M, Coenen S, Malhotra-Kumar S, Dvorakova K, Hendrickx E, Suetens C, Goossens H: European Surveillance of Antimicrobial Consumption (ESAC): outpatient antibiotic use in Europe. J Antimicrob Chemother 2006, 58(2):401-407.

32. Goossens H, Ferech M, Coenen S, Stephens P: Comparison of outpatient systemic antibacterial use in 2004 in the United States and 27 European countries. Clin Infect Dis 2007, 44(8):1091-1095. 


\section{Chapter 3}

\section{A simple and rapid RP-HPLC method to determine ciprofloxacin levels in human serum}

M.B. Haeseker, A. Verbon, J. Welzen, C. Neef, C.A. Bruggeman, L.M.L. Stolk

Asian Journal of Pharmaceutical and Biomedical Research 2011 1(3):350-354 


\begin{abstract}
Introduction. Ciprofloxacin is a broad-spectrum antimicrobial drug for which therapeutic drug monitoring (TDM) has been suggested. A simple and rapid method to determine ciprofloxacin concentrations in serum is described.

Methods. The method has been validated for linearity, precision, accuracy and stability, following the guidelines for industry bioanalytical method validation recommended by the Food and Drug Administration (FDA). Serum samples were precipitated with acetonitril. An RP-HPLC method with fluorescence detection was used (excitation and emission wave lengths for ciprofloxacin were 278 and $440 \mathrm{~nm}$, respectively). The calibration range was 0.5 to $10.0 \mathrm{mg} / \mathrm{L}$. Three quality controls $(0.8,4$ and $8 \mathrm{mg} / \mathrm{L})$ were tested.

Results. The intra- and inter-assay variability was within $7.5 \%$. The lower limit of quantification (LLOQ) was determined at $0.2 \mathrm{mg} / \mathrm{L}$. The freeze-and-thaw, the shortterm, long-term, the stock solution and post-preparation stability were all determined and adequate. The extraction recovery was $82 \%, 87 \%$ and $88 \%$ at respectively $0.8,4$ and $8 \mathrm{mg} / \mathrm{L}$.

Conclusion. This simple and fast method is suitable for TDM and pharmacokinetic studies.
\end{abstract}




\section{Introduction}

The quinolone ciprofloxacin is a broad-spectrum antimicrobial drug, with bactericidal activity against both Gram-positive and Gram-negative bacteria. Individual therapeutic drug monitoring (TDM) is widely accepted for gentamicin and vancomycin. Although it has been suggested that TDM would also be useful for other antibiotics such as ciprofloxacin [1-5], this is not standard of care in the majority of hospitals.

A large number of high performance liquid chromatography (HPLC) methods have been described to determine ciprofloxacin concentrations in biological fluids, mainly in plasma and serum. The most commonly used technique is HPLC with ultra violet (UV) or fluorescence detection, extensively reviewed by Carlucci [6]. In this review [6] and in studies after 1998 [7, 8] complex methods for sample preparation with one or more than one extraction step have been used to determine ciprofloxacin blood levels. In general sample preparation methods based on extraction are slow and time consuming compared to protein precipitation. Moreover, an internal standard is not included in most of the studies in this review [6], although inclusion of an internal standard in samples extraction methods increases the quality of ciprofloxacin determination [7, 8]. On the other hand simple sample preparation methods have not always been validated as extensively as recommended by the Food and Drug Administration (FDA) of the USA [9]. The aim of this study is to develop and to validate a simple and reliable method for the quantification of ciprofloxacin levels in human serum. Such a method would be very valuable for studies evaluating TDM of ciprofloxacin in an era of increasing ciprofloxacin resistance. 


\section{Material and methods}

\section{Chemicals}

Ciprofloxacin hydrochloride (pure Ph Eur) was used as analytical standard (AppliChem, Darmstadt, Germany). Methanol (Lichrosolv ${ }^{\circledR}$ grade), acetonitrile (Lichrosolv $^{\circledR}$ grade), phosphoric acid (Pro-analysi grade) and ethanol (Emsure ${ }^{\mathrm{TM}}$ grade) were purchased from Merck (Darmstadt, Germany).

\section{Chromatography}

The RP-HPLC system consisted of an automatic sampler injector (model 717, Waters USA), a pump (model 1050, Hewlett Packard, New York), a Waters Atlantis T3 column $(4.6 \times 150 \mathrm{~mm} ; 5 \mu \mathrm{m})$ and an fluorescence detector (JASCO FP920). The mobile phase consisted of a phosphor buffer ( $\mathrm{pH} 3.0)$ and acetonitrile $(85: 15)$, degassed with helium. Ciprofloxacin levels were determined with a flow rate of $2.0 \mathrm{~mL} / \mathrm{min}$, at an excitation wavelength $278 \mathrm{~nm}$ and emission wavelength $440 \mathrm{~nm}$.

\section{Preparation of calibration standards and quality controls}

Two independent stock solutions of ciprofloxacin (400 mg/L) were prepared. Ciprofloxacin samples for calibration curves were made by dissolving $8.88 \mathrm{mg}$ of ciprofloxacin hydrochloride in $10 \mathrm{~mL}$ of ethanol and $10 \mathrm{~mL}$ in $\mathrm{H}_{2} \mathrm{O}$ (factor weight 387.84). For complete dissolution the mixture was placed for 5 minutes in an ultrasonic bath. This ciprofloxacin stock was used for the preparation of the calibration standards. Five calibration standards were prepared by adding the required amount of ciprofloxacin in blank human plasma to obtain concentrations of $0.5,1,2,5$ and $10 \mathrm{mg} / \mathrm{L}$ of ciprofloxacin. Another batch of ciprofloxacin stock solution was used to prepare 3 different concentrations of quality control samples $(0.8,4$ and $8 \mathrm{mg} / \mathrm{L})$. The required amount of ciprofloxacin was added to blank human plasma to obtain concentrations of $0.8,4$ and $8 \mathrm{mg} / \mathrm{L}$. The quality controls were stored in separate containers at $-20^{\circ} \mathrm{C}$.

\section{Sample preparation}

Plasma samples $(250 \mu \mathrm{L})$ for the calibration and the quality controls (QCs) were transferred into Eppendorf tubes and mixed with acetonitrile $(250 \mu \mathrm{L})$ for protein precipation. After 15 minutes centrifugation at $10.800 \mathrm{rpm}$ the clear supernatant was injected $(10 \mu \mathrm{L})$.

\section{Validation}

Validation followed the Guidance for industry bioanalytical method validation recommended by the Food and Drug Administration (FDA) of the USA [9]. The RP-HPLC method was validated for linearity, precision, accuracy and stability. Six calibration curves were constructed independently on six different days. The calibration curves $(1 / \mathrm{x})$ were considered linear when correlation coefficient $\left(\mathrm{r}^{2}\right)$ was higher than 0.99 . Three QCs $(0.8,4$ and $8 \mathrm{mg} / \mathrm{L})$ were prepared 
and analyzed on six times on one day and one time on six different days to determine intra- and interday precision and accuracy of the RP-HPLC assay. The precision coefficient of variation should not exceed $15 \%$ of the actual value except for the lower limit of quantification (LLOQ), where it should not exceed $20 \%$. Freeze and thaw stability was determined after 3 cycles. Short term temperature stability at room temperature was investigated by analyzing 3 QCs after 4-24 hours. Long-term stability of ciprofloxacin at $-20^{\circ} \mathrm{C}$ was determined by analyzing $3 \mathrm{QCs}$ after 1 month and 7 months. Stock solution stability was evaluated at room temperature for 6 hours. Post preparative stability was determined for 12 hours. 


\section{Results}

\section{Calibration curve and standard curve}

The preparation time was simple in a short time; one precipitation step with acetonitril and one 15 minutes centrifugation step. After the sample preparation the chromatographic analysis with 9 minutes run time was performed. The retention time of ciprofloxacin was 7.6 minutes (Figure 1). The calibration curves were linear, the correlation coefficients of the calibration curves were all higher than 0.99 $\left(r^{2}=0.9983, n=6\right)$. An example of a calibration curve is shown in Figure 1. The Lower Limit of Quantification (LLOQ) was $0.2 \mathrm{mg} / \mathrm{L}$ (precision 5.1\%; accuracy $11 \% ; n=5)$.

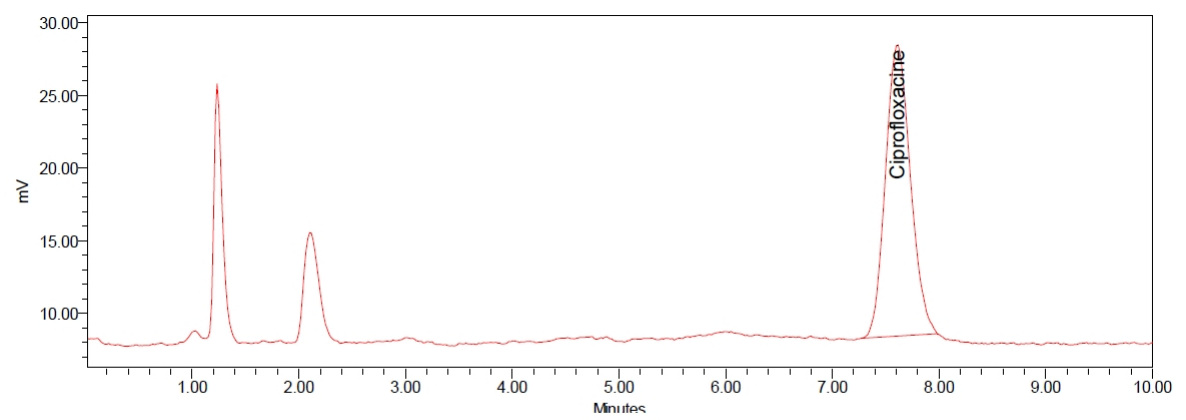

Figure 1. Chromatogram of ciprofloxacin $1 \mathrm{mg} / \mathrm{L}$ in blank human plasma.

\section{Accuracy, precision and recovery}

The intra-assay precision and accuracy were within $7.5 \%$ (Table 1). The inter-assay precision and accuracy were within 15\% (Table 1). The extraction recovery (in duplo) was $81.6 \%, 86.9 \%$ and $88.0 \%$ for respectively $0.8,4$ and 8 $\mathrm{mg} / \mathrm{L}$. The quadratic relationship between the measured serum concentration and the standard deviation (SD) is presented in Figure 2. The error pattern of the assay can be described by the following polynomial equation: $\mathrm{SD}=0.001+0.048 \mathrm{C}+0.002 \mathrm{C}^{2}$ $\left(r^{2}=1.000\right)$. This polynomial equation can be used to calculate the SD corresponding with each plasma concentration (C). 
Table 1. Intra- and interassay precision and accuracy of ciprofloxacin RP-HPLC assay

\begin{tabular}{lllllllll}
\hline & \multicolumn{7}{c}{ Intra-assay $(\mathbf{n}=6)$} & \multicolumn{3}{l}{ Inter-assay $(\mathbf{n}=6)$} \\
\hline $\begin{array}{l}\text { True } \\
\text { conc. } \\
(\mathbf{m g} / \mathbf{L})\end{array}$ & $\begin{array}{l}\text { Mean } \\
(\mathbf{m g} / \mathbf{L})\end{array}$ & $\begin{array}{l}\text { SD } \\
(\mathbf{m g} / \mathbf{L})\end{array}$ & $\begin{array}{l}\text { Precisi } \\
\text { on CV } \\
(\%)\end{array}$ & $\begin{array}{l}\text { Accu- } \\
\text { racy }(\%)\end{array}$ & $\begin{array}{l}\text { Mean } \\
(\mathbf{m g} / \mathbf{L})\end{array}$ & $\begin{array}{l}\text { SD } \\
(\mathbf{m g} / \mathbf{L})\end{array}$ & $\begin{array}{l}\text { Precisi } \\
\text { on CV } \\
(\%)\end{array}$ & $\begin{array}{l}\text { Accu- } \\
\text { racy } \\
(\%)\end{array}$ \\
\hline $0.8 \mathrm{mg} / \mathrm{L}$ & 0.71 & 0.050 & 7.09 & -11.25 & 0.78 & 0.04 & 5.20 & -2.13 \\
$4 \mathrm{mg} / \mathrm{L}$ & 3.96 & 0.164 & 4.15 & -1.08 & 4.04 & 0.22 & 5.50 & 0.95 \\
$8 \mathrm{mg} / \mathrm{L}$ & 7.71 & 0.305 & 3.90 & -3.96 & 7.92 & 0.42 & 5.33 & -1.01 \\
\hline
\end{tabular}

$\mathrm{CV}$ : coefficient of variation; SD: standard deviation

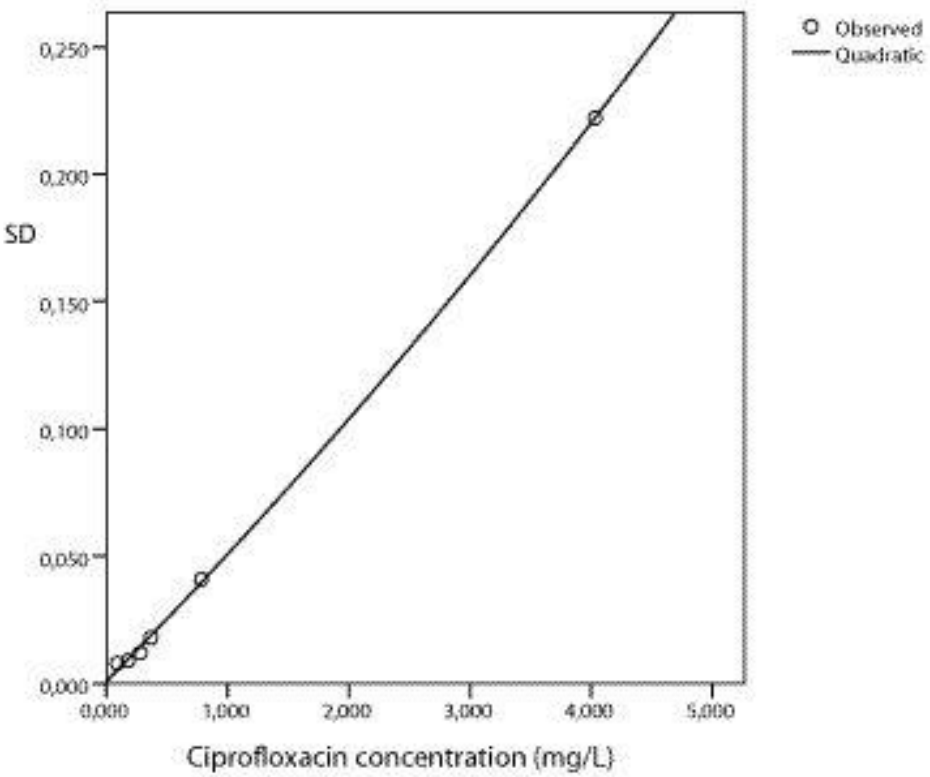

Figure 2. Error pattern of the ciprofloxacin RP-HPLC assay $(n=6)$.

\section{Stability}

Freeze and thaw stability of ciprofloxacin was better than $97 \%$ after 3 cycles for all three concentrations. The short term room temperature stability (in duplo) after 4 hours was $98 \%$ for $0.8 \mathrm{mg} / \mathrm{L}, 94 \%$ for $4 \mathrm{mg} / \mathrm{L}$ and $95 \%$ for $8 \mathrm{mg} / \mathrm{L}$. This was $91 \%$ for $0.8 \mathrm{mg} / \mathrm{L}, 92 \%$ for $4 \mathrm{mg} / \mathrm{L}$ and $90 \%$ for $8 \mathrm{mg} / \mathrm{L}$ after 24 hours. The long term stability (in duplo) at $-20^{\circ} \mathrm{C}$ of $0.8 \mathrm{mg}$ was $103 \%, 4 \mathrm{mg}$ was $97 \%$ and $8 \mathrm{mg}$ was $100 \%$ after 7 months. Stock solution stability at room temperature after 6 hours was $100 \%$. Stock solution stability at refrigeration $\left(6-8{ }^{\circ} \mathrm{C}\right)$ was $103 \%$ after 3 weeks. The post-preparative stability (in duplo) in the auto sampler after 12 hours was $96 \%$ for $0.8 \mathrm{mg} / \mathrm{L}, 96 \%$ for $4 \mathrm{mg} / \mathrm{L}$ and $97 \% \mathrm{mg} / \mathrm{L}$ for $8 \mathrm{mg} / \mathrm{L}$. 


\section{Discussion}

A simple RP-HPLC method with fluorescence detection for the measurement of ciprofloxacin has been developed and validated in our laboratory. Our RP-HPLC method is acute and precise with only one protein precipitation step and without an internal standard. An internal standard is very important in extraction methods. In extraction methods the internal standard has to be very similar to the material that has to be extracted. In protein precipitation this is not necessary; an in internal standard is mainly useful for injection fluctuations. Nowadays the injection fluctuations are very low in automatic injection sampler machines. Our method is simpler and faster compared to similar methods [10-12]. All these studies are more time consuming; Imre et al. [10] has a complicated mobile phase with a gradient profile, Wu et al. and Maya et al. $[11,12]$ have used an UV detector with an internal standard. Furthermore in all these studies [10-12] the chromatographic analysis time is longer, respectively 12 minutes, 12 minutes and 14 minutes. Our chromatographic analysis time is 9 minutes per sample.

Our method has been extensively validated, as recommended by the FDA [9]. All aspects of accuracy, precision, recovery, calibration curves and stability are satisfactory; therefore this simple and fast method is reliable. Serum samples can be stored without loss of ciprofloxacin concentration for at least 7 months in $-20^{\circ} \mathrm{C}$. Also the post-preparative stability was satisfactory during at least 12 hours. Therefore 80 samples can be measured within each run ( 9 minutes per sample). This fast method is suitable in TDM and/or for other studies requiring ciprofloxacin concentrations.

\section{Acknowledgements}

We thank all analysts of the laboratory of Department of Clinical Pharmacy and Toxicology for their excellent technical support.

This work was supported by Care and Public Health Research Institute (CAPHRI), Maastricht, the Netherlands and the Medical University Center Maastricht, the Netherlands. All authors have no conflicts of interest to declare. 


\section{References}

1. Conil JM, Georges B, de Lussy A, Khachman D, Seguin T, Ruiz S, Cougot P, Fourcade O, Houin G, Saivin S: Ciprofloxacin use in critically ill patients: pharmacokinetic and pharmacodynamic approaches. Int J Antimicrob Agents 2008, 32(6):505-510.

2. Forrest A, Nix DE, Ballow CH, Goss TF, Birmingham MC, Schentag JJ: Pharmacodynamics of intravenous ciprofloxacin in seriously ill patients. Antimicrob Agents Chemother 1993, 37(5):1073-1081.

3. Matsuo K: Investigation of the Clinical Efficacy and Dosage of Intravenous Ciprofloxacin in Patients with Respiratory Infection. Journal of pharmacy \& pharmaceutical sciences 2008, 11(4):111s-117s.

4. Scaglione F, Esposito S, Leone S, Lucini V, Pannacci M, Ma L, Drusano GL: Feedback dose alteration significantly affects probability of pathogen eradication in nosocomial pneumonia. Eur Respir J 2009, 34(2):394-400.

5. van Zanten AR, Polderman KH, van Geijlswijk IM, van der Meer GY, Schouten MA, Girbes AR: Ciprofloxacin pharmacokinetics in critically ill patients: a prospective cohort study . Journal of Critical Care 2008, 23(3):422-430.

6. Carlucci G: Analysis of fluoroquinolones in biological fluids by high-performance liquid chromatography. Journal of Chromatography A 1998, 812(1-2):343-367.

7. van Geijlswijk IM, van Zanten AR, van der Meer YG: Reliable new high-performance liquid chromatographic method for the determination of ciprofloxacin in human serum. Ther Drug Monit 2006, 28(2):278-281.

8. Zotou A, Miltiadou N: Sensitive LC determination of ciprofloxacin in pharmaceutical preparations and biological fluids with fluorescence detection. J Pharm Biomed Anal 2002, 28(3-4):559-568.

9. $\quad$ FDA: Guidance for Industry Bioanalytical Method Validation. 2001.

10. Imre S, Dogaru MT, Vari CE, Muntean T, Kelemen L: Validation of an HPLC method for the determination of ciprofloxacin in human plasma. Journal of Pharmaceutical and Biomedical Analysis 2003, 33(1):125-130.

11. Maya MT, Goncalves NJ, Silva NB, Morais JA: Simple high-performance liquid chromatographic assay for the determination of ciprofloxacin in human plasma with ultraviolet detection. J Chromatogr B Biomed Sci Appl 2001, 755(1-2):305-309.

12. Wu SS, Chein CY, Wen YH: Analysis of ciprofloxacin by a simple high-performance liquid chromatography method. J Chromatogr Sci 2008, 46(6):490-495. 


\title{
Chapter 4
}

The ciprofloxacin target $\mathrm{AUC}_{24} / \mathrm{MIC}$ ratio is not reached in hospitalised patients with the recommended dosing regimens

\author{
M.B. Haeseker, L.M.L. Stolk, F. Nieman, C.J.P.A. Hoebe, C. Neef, \\ C.A. Bruggeman and A. Verbon
}

British Journal of Clinical Pharmacology 2012;75(1):180-185 


\begin{abstract}
Introduction. The aim of this study was to determine the ciprofloxacin serum concentrations in hospitalised patients and to determine which percentage reached the efficacy target of $\mathrm{AUC}_{24} / \mathrm{MIC}>125$. Additionally, the influence of demographic anthropomorphic and clinical parameters on the pharmacokinetics and pharmacodynamics of ciprofloxacin were investigated.

Methods. In serum of 80 hospitalised patients ciprofloxacin concentrations were measured with reverse phase high performance liquid chromatography with fluorescence detection. The ciprofloxacin dose was 400-1200 mg/day iv in two or three doses depending on renal function and causative bacteria. Pharmacokinetic parameters were calculated with maximum a posteriori Bayesian estimation (MWIPHARM 3.60). A two-compartment open model was used.

Results. Mean $( \pm \mathrm{sd})$ age was $66( \pm 17)$ years, the mean clearance corrected for bodyweight was $0.24 \mathrm{~L} / \mathrm{h} / \mathrm{kg}$ and the mean $\mathrm{AUC}_{24}$ was $49 \mathrm{mg} \times \mathrm{h} / \mathrm{L}$. Ciprofloxacin clearance and thus $\mathrm{AUC}_{24}$ were associated with both age and serum creatinine. Of all patients, $21 \%$ and $75 \%$ of the patients, did not reach the proposed ciprofloxacin $\mathrm{AUC}_{24} / \mathrm{MIC}>125$ target with MICs of 0.25 and $0.5 \mathrm{mg} / \mathrm{L}$, respectively. A computer simulated increase in the daily dose from $800 \mathrm{mg}$ to $1200 \mathrm{mg}$, decreased these percentages to $1 \%$ and $37 \%$, respectively.

Conclusion. A substantial proportion of the hospitalised patients did not reach the target ciprofloxacin $\mathrm{AUC}_{24} / \mathrm{MIC}$ and are suboptimal dosed with recommended doses. Taken into account the increasing resistance for ciprofloxacin worldwide, a ciprofloxacin dose of $1200 \mathrm{mg}$ iv daily in patients with a normal renal function is necessary to reach the targeted $\mathrm{AUC}_{24} / \mathrm{MIC}>125$.
\end{abstract}




\section{Introduction}

Ciprofloxacin, a broad-spectrum antimicrobial drug, has been extensively used in inpatient and outpatient settings. The probability of cure of an infection has been shown to be dependent on the 24 hours area under the curve $\left(\mathrm{AUC}_{24}\right)$ of ciprofloxacin and the minimal inhibitory concentration (MIC) for specific bacteria [1-5]. The quotient $\mathrm{AUC}_{24} / \mathrm{MIC}$ needed for a high probability of cure varies in different studies. $\mathrm{AUC}_{24} / \mathrm{MIC}>125$ was found to be predictive of microbiological and clinical cure in patients with serious Gram-negative infections and in Intensive Care Unit (ICU) patients [3, 5]; microbiological cure was reached in $86 \%$ above and in $26 \%$ below this breakpoint and clinical cure in $82 \%$ above and in $42 \%$ below this breakpoint [5]. Using a clinical outcome-based Monte Carlo simulation, it was shown that in patients with Enterobacteriaceae bacteraemia an $\mathrm{AUC}_{24} / \mathrm{MIC}>250$ was associated with cure rates of $91 \%$ in patients with values above and of $29 \%$ below this breakpoint [4]. Moreover in nosocomial pneumonia dose alterations based on plasma drug concentration and bacterial MIC value improved the probability of good clinical outcome and pathogen eradication [6].

In the nineties, it was shown that $80 \%$ of treatment failures during ciprofloxacin treatment were due to drug resistance [7]. The MIC predicted clinical response, especially in patients with infections caused by organisms for which the MICs were at the marginal points of susceptibility. Development of resistance to ciprofloxacin was largely confined to marginally susceptible organisms such as Staphylococcus aureus, Streptococcus pneumoniae and Pseudomonas aeruginosa. Recently Enterobacteriaceae were added to this marginally susceptible group based on a Monte Carlo simulation [4]. Both MIC and resistance for ciprofloxacin are steadily increasing. In the Netherlands ciprofloxacin resistance increased from 1 to $15 \%$ in Escherichia coli and from 1 to $13 \%$ in Klebsiella pneumoniae from 2001 untill 2009, and in susceptible bacteria MICs increased [8, 9]. In Greece ciprofloxacin resistance for $E$. coli increased from $9 \%$ in 2001 to $23 \%$ in 2009 and ciprofloxacin resistance for K. pneumoniae increased from 54\% to $66 \%$ from 2005 to $2009 \%$ [10].

With increasing $\mathrm{MICs}$, the targeted $\mathrm{AUC}_{24} / \mathrm{MIC}>125$ may be less often reached, resulting in increasing ciprofloxacin resistance and higher clinical failure rates. Indeed, Perreiter et al. calculated with a population model from the literature that $66 \%$ reached the minimum $\mathrm{AUC}_{24} / \mathrm{MIC}$ target of $>100$ [11], Neef et al. found in 2002 from an in vitro model that $1200 \mathrm{mg}$ was the optimal dose to be given if the MIC was $0.25 \mathrm{mg} / \mathrm{L}$ [12] and recent studies on critically ill patients on ICUs have shown that the $\mathrm{AUC}_{24} / \mathrm{MIC}$ target of $>125$ is reached in only $31-84 \%$ of the patients $[1,3]$. In these studies $\mathrm{AUC}_{24}$ of ciprofloxacin was usually low, respectively $42 \pm 36$ [1] and $57 \pm 33.5 \mathrm{mg} \times \mathrm{h} / \mathrm{L}$ [3]. In a recent study in 25 critically ill patients with chronic obstructive pulmonary disease low $\mathrm{AUC}_{24}$ values and high variability of kinetic parameters were found with ciprofloxacin $1200 \mathrm{mg}$ [13]. However, ciprofloxacin is also widely used in patients admitted to the general hospital wards and only sparse data regarding ciprofloxacin $\mathrm{AUC}_{24} / \mathrm{MIC}$ are available in this particular population. Therefore, we have measured ciprofloxacin blood levels in patients admitted to such wards that were given ciprofloxacin intravenously (iv) and 
evaluated the $\mathrm{AUC}_{24} / \mathrm{MIC}$ ratio. Additionally, the influence of demographic anthropomorphic and clinical parameters on the pharmacokinetics and pharmacodynamics of ciprofloxacin were investigated. 


\section{Methods}

\section{Study design}

Patients above 18 years of age with iv ciprofloxacin treatment hospitalised at the Maastricht University Medical Centre (MUMC), a 715 bed university hospital, admitted to general wards were included from April 2009 until April 2010. Ciprofloxacin blood levels were measured in samples drawn for routine assays. Patients with minimal two blood levels available were included. Ciprofloxacin Kabi (Fresenius Kabi, Bad Homburg, Germany) was started at the discretion of the attending physician, usually when an infection was suspected or cultured pathogens proved susceptible to ciprofloxacin. Ciprofloxacin was dosed from 400 to 1200 $\mathrm{mg} /$ day in two or three doses; the standard dose was $800 \mathrm{mg} / \mathrm{day}, 400 \mathrm{mg} /$ day was prescribed when the creatinine clearance was less than $30 \mathrm{ml} / \mathrm{min}$ and $1200 \mathrm{mg} / \mathrm{day}$ was prescribed for patients with a $P$. aeruginosa infection and normal renal function. A solution for infusion of $2 \mathrm{mg} / \mathrm{ml}(400 \mathrm{mg} / 200 \mathrm{ml}$ and $200 \mathrm{mg} / 100 \mathrm{ml})$ was used. The $400 \mathrm{mg} / 200 \mathrm{ml}$ infusion was run in 60 minutes and the $200 \mathrm{mg} / 100 \mathrm{ml}$ was run in 30 minutes. Demographic and clinical data, i.e. age, gender, weight, co-medication, ciprofloxacin dose, times of ciprofloxacin doses and blood collections, serum creatinine, admission days, C-reactive protein (CRP) and culture results were retrieved from the electronic patient file (iSoft, the Netherlands). Creatinine clearance was calculated with the Modification of Diet in Renal Disease formula (MDRD). Cultures were performed and ciprofloxacin MICs were determined as standard clinical care with the Becton Dickinson Phoenix ${ }^{\mathrm{TM}}$ Automated Microbiology System (Franklin Lakes, New Jersey, USA) using the ID/AST Combo panels UNMIC/ID53 and NMIC/ID75 for Gram negative bacteria and the AST panel PMIC-58 for Gram positive bacteria. Clinical outcome was defined by CRP decrease, number of admission days and clinical cure (defeveresence, microbiological cure and discharge from the hospital).

This study was registered at the Dutch Trial Register (NTR 1725) and was approved by the Medical Ethical Committee of the MUMC (MEC 08-4-063).

\section{HPLC analysis}

A simple, fast and specific method for measuring ciprofloxacin serum levels has been validated for linearity, precision, accuracy and stability, following the guidelines for industry bioanalytical method validation recommended by the Food and Drug Administration (FDA) [14]. In short, serum samples were precipitated with acetonitrile. A reverse phase high pressure liquid chromatography method with fluorescence detection was used (excitation and emission wave lengths for ciprofloxacin were 278 and $440 \mathrm{~nm}$, respectively). The calibration range was 0.5 to $10.0 \mathrm{mg} / \mathrm{L}$. Three quality controls $(0.8,4$ and $8 \mathrm{mg} / \mathrm{L})$ were tested. The intra- and inter-assay variability was within $7.5 \%$. The lower limit of quantification was 0.2 $\mathrm{mg} / \mathrm{L}$. The freeze-and-thaw, the short-term, long-term, the stock solution and postpreparation stability were all determined and adequate. The extraction recovery was $82 \%, 87 \%$ and $88 \%$ at respectively $0.8,4$ and $8 \mathrm{mg} / \mathrm{L} \mathrm{[15].}$ 


\section{Pharmacokinetic analysis}

Pharmacokinetic parameters of ciprofloxacin in individual patients were calculated with maximum a posteriori Bayesian estimation program (MW/PHARM 3.60, Mediware, the Netherlands). We used a two-compartment open pharmacokinetic model based on a previous clinical study [5]. The $\mathrm{AUC}_{24}$ was calculated from 48 to 72 hours after start of therapy, assuming a steady state is reached.

\section{Statistical analysis}

Metric variables are tested for normality of distribution by the ShapiroWilk test. If normally distributed, means and standard deviations are used to characterize the univariate distributions, if not; score ranges are also given. Categorical variables are presented as frequencies and percentages. Scores for main outcome parameter (CL/W of ciprofloxacin) turned out to be non-normally distributed and had to be ${ }^{10} \log$-transformed to validly perform parametric tests. Univariate analysis on ${ }^{10} \mathrm{log}-\mathrm{CL} / \mathrm{W}$ with categorical variables is either done by Student t-test or by one-way ANOVA (using the Bonferroni correction for polychotomous categories). Pearson correlation coefficients (r) for this outcome with the dichotomous predictor (gender) and metric variables are also presented. All data analysis is done with SPSS-pc version 16.0. A $P$-value of $<0.05$ is considered to be statistically significant. 


\section{Results}

\section{Study group}

A total of 80 patients with a median of 4 (range: 2 to 7) blood samples were included. The average age was 66 years and $60 \%$ were male (Table 1). One third was diagnosed as having pneumonia and $10 \%$ had sepsis (Table 1). Patients were admitted throughout all wards of the hospital. Co-medication did not interfere with pharmacokinetic parameters of ciprofloxacin (data not shown).

At least one culture was taken from all patients; 21 urine cultures, 20 blood cultures, 15 sputum cultures, 15 wound cultures and 9 cultures of drains and/or abdominal fluid. Forty five of the 80 patients (58\%) had a positive culture. Of the positive cultures $35(78 \%)$ were Gram-negative bacteria; E. coli $(\mathrm{n}=12)$, Klebsiella spp. $(\mathrm{n}=10)$, Enterobacteriaceae $(\mathrm{n}=6)$, Proteus spp. $(\mathrm{n}=4)$ and P. aeruginosa $(\mathrm{n}=3)$. In urine cultures MICs were not determined lower than $0.5 \mathrm{mg} / \mathrm{L}$ by the UNMIC/ID53 panel (standard clinical care). Therefore MIC values were available in $27 / 35(77 \%)$ in patients with a Gram negative bacterium cultured. Gram positive bacterium were cultured in 10/80 patients (12\%); S. aureus 4/80 (5\%), Enterococcus spp. 4/80 (5\%), CNS 1/80 (1\%) and S. pneumoniae 1/80 (1\%).

Table 1. Patient characteristics of 80 hospitalised patients.

\begin{tabular}{|c|c|}
\hline & Median (Range) \\
\hline Age (years) & $68(19-101)$ \\
\hline Weight $(\mathrm{kg})$ & $70(32-110)$ \\
\hline Ciprofloxacin iv (days) & $8(2-45)$ \\
\hline Admission (days) & $20(5-122)$ \\
\hline CRP before therapy $(\mathrm{mg} / \mathrm{L})$ & $203(1-469)$ \\
\hline CRP after therapy $(\mathrm{mg} / \mathrm{L})$ & $67(3-405)$ \\
\hline Gender & Frequency (Percentage) \\
\hline - $\quad$ Male & $48(60 \%)$ \\
\hline - $\quad$ Female & $32(40 \%)$ \\
\hline Infection & Frequency (Percentage) \\
\hline - $\quad$ Pneumonia & $26(33 \%)$ \\
\hline - Wound infection & $18(23 \%)$ \\
\hline - UTI & $18(23 \%)$ \\
\hline - $\quad$ Sepsis & $8(10 \%)$ \\
\hline - Abdominal infection & $6(6 \%)$ \\
\hline - $\quad$ Other & $4(5 \%)$ \\
\hline Ciprofloxacin combination with & Frequency (Percentage) \\
\hline - $\quad$ Monotherapy & $18(23 \%)$ \\
\hline - $\quad$-lactam antibiotics & $45(56 \%)$ \\
\hline - Clindamycin & $9(11 \%)$ \\
\hline - $\quad$ Other & $8(10 \%)$ \\
\hline Comedication & Frequency (Percentage) \\
\hline - $\quad$ None & $13(16 \%)$ \\
\hline - Cardiovascular & $35(43 \%)$ \\
\hline - Immunosupressive medication & $20(25 \%)$ \\
\hline - Diabetes mellitus & $10(13 \%)$ \\
\hline - $\quad$ Other & $15(19 \%)$ \\
\hline
\end{tabular}

UTI, urinary tract infection. 


\section{Pharmacokinetic and pharmacodynamic analysis}

The average CL/W was $0.24 \mathrm{~L} / \mathrm{h} / \mathrm{kg}$, SD: $0.13 \mathrm{~L} / \mathrm{h} / \mathrm{kg}$ (median: 0.23 , range: 0.04-0.57 L/h/ $/ \mathrm{kg}$ ), the average volume of distribution corrected for weight (V/W) was $2.5 \mathrm{~L} / \mathrm{kg} \mathrm{SD}: 0.9 \mathrm{~L} / \mathrm{kg}$ (median: 2.5 , range: 0.9-5.9), average $\mathrm{AUC}_{24}$ was 49 $\mathrm{mg} \times \mathrm{h} / \mathrm{L}$, SD: $23 \mathrm{mg} \times \mathrm{h} / \mathrm{L}$ (median: 43, range:15-128), the average creatinine was $148 \mu \mathrm{mol} / \mathrm{L}$ SD: $125 \mu \mathrm{mol} / \mathrm{L}$, median: 91, range: 40-625) and 23 (29\%) of the patients had a $400 \mathrm{mg}$ dose, $1(1 \%)$ a dose of $600 \mathrm{mg}, 51(64 \%)$ a $800 \mathrm{mg}$ dose and 5 (6\%) $11200 \mathrm{mg}$ dose. The interindividual variability of pharmacokinetic parameters is large (Table 2). Patients above 80 years had lower CL/W $(P=0.001)$ and higher $\mathrm{AUC}_{24}$ compared to younger patients $(P=0.04)$, Table 2 . The ciprofloxacin efficacy target $\left(\mathrm{AUC}_{24} / \mathrm{MIC}>125\right)$ was reached in $100 \%$ of the patients with the current dosing regimens when Gram-negative bacteria have a MIC $\leq 0.125 \mu \mathrm{g} / \mathrm{ml}, 79 \%$ of the patients reached this target with an $\mathrm{MIC} \leq 0.25 \mathrm{mg} / \mathrm{L}, 25 \%$ with an $\mathrm{MIC} \leq 0.5 \mathrm{mg} / \mathrm{L}$ and only $1 \%$ of the patients reached this target when the MIC $\geq 1 \mathrm{mg} / \mathrm{L}$ (Fig. 1). In our study, 16/27 (59\%) of all Gram-negative bacteria had a $\mathrm{MIC} \leq 0.125 \mathrm{mg} / \mathrm{L}, 3 / 27$ (11\%) had a MIC of $0.5 \mathrm{mg} / \mathrm{L}$ and $8 / 27(30 \%)$ had a MIC of $2 \mathrm{mg} / \mathrm{L}$.

Table 2. $\mathrm{CL}_{\mathrm{cr}}, \mathrm{CL} / \mathrm{W}, \mathrm{V} / \mathrm{W}$ and $\mathrm{AUC}_{24}$ broken down for ciprofloxacin 24-hour dose categories and age group.

\begin{tabular}{|c|c|c|c|c|c|}
\hline $\begin{array}{l}\text { 24h dose } \\
{[\mathrm{mg}]}\end{array}$ & $\mathbf{N}$ & $\begin{array}{l}\mathrm{CL}_{\mathrm{cr}}[\mathrm{mL} / \mathrm{min}] \\
\text { median (range) } \\
\text { mean (SD) }\end{array}$ & $\begin{array}{l}\mathrm{CL} / \mathrm{W}[\mathrm{L} / \mathrm{h} / \mathrm{kg}] \\
\text { median (range) } \\
\text { mean }(\mathrm{SD})\end{array}$ & $\begin{array}{l}\mathrm{V} / \mathrm{W}[\mathrm{L} / \mathrm{kg}] \\
\text { median (range) } \\
\text { mean (SD) }\end{array}$ & $\begin{array}{l}\mathrm{AUC}_{24}[\mathrm{mg} \times \mathrm{h} / \mathrm{L}] \\
\text { median (range) } \\
\text { mean }(\mathrm{SD})\end{array}$ \\
\hline \multirow[t]{2}{*}{$400-600$} & 24 & $24(8-184)$ & $0.15(0.06-0.45)$ & $2.4(0.9-4.4)$ & $39(15-78)$ \\
\hline & & $39(43)$ & $0.17(0.09)$ & $2.3(0.8)$ & 41 (16) \\
\hline \multirow[t]{2}{*}{800} & 51 & $81(12-162)$ & $0.25(0.04-0.51)$ & $2.5(1.2-5.9)$ & $45(23-128)$ \\
\hline & & $81(39)$ & $0.26(0.11)$ & $2.6(1.0)$ & $52(25)$ \\
\hline \multirow[t]{2}{*}{1200} & 5 & $131(37-173)$ & $0.52(0.12-0.57)$ & $2.7(1.3-4.4)$ & $44(29-89)$ \\
\hline & & $113(52)$ & $0.39(0.21)$ & $2.9(1.2)$ & $53(27)$ \\
\hline $\begin{array}{l}\text { Age } \\
\text { group } \\
\text { [years] }\end{array}$ & $\mathbf{N}$ & $\begin{array}{l}\mathrm{CL}_{\mathrm{cr}}[\mathrm{mL} / \mathrm{min}] \\
\text { median (range) } \\
\text { mean }(\mathrm{SD})\end{array}$ & $\begin{array}{l}\mathrm{CL} / \mathrm{W}[\mathrm{L} / \mathrm{h} / \mathrm{kg}] \\
\text { median (range) } \\
\text { mean }(\mathrm{SD})\end{array}$ & $\begin{array}{l}\mathrm{V} / \mathrm{W}[\mathrm{L} / \mathrm{kg}] \\
\text { median (range) } \\
\text { mean }(\mathrm{SD})\end{array}$ & $\begin{array}{l}\mathrm{AUC} 24[\mathrm{mg} \times \mathrm{h} / \mathrm{L}] \\
\text { median (range) } \\
\text { mean }(\mathrm{SD})\end{array}$ \\
\hline \multirow[t]{2}{*}{$<70$} & 41 & $79(12-184)$ & $0.27(0.07-0.57)$ & $2.1(1.3-4.4)$ & $38(15-125)$ \\
\hline & & 85 (49) & $0.29(0.13)$ & $2.6(0.7)$ & $43(20)$ \\
\hline \multirow[t]{2}{*}{$70-80$} & 24 & $55(8-131)$ & $0.20(0.04-0.45)$ & $2.4(1.0-6.0)$ & $47(23-96)$ \\
\hline & & $58(40)$ & $0.21(0.11)$ & $2.4(1.2)$ & $52(22)$ \\
\hline \multirow[t]{2}{*}{$>80$} & 15 & $37(12-119)$ & $0.13(0.06-0.37)$ & $2.4(0.9-5.7)$ & $63(24-128)$ \\
\hline & & $51(33)$ & $0.16(0.09)$ & $2.3(1.1)$ & $59(27)$ \\
\hline
\end{tabular}

$\mathrm{CL}_{\mathrm{cr}}$, creatinine clearance.

$\mathrm{CL} / \mathrm{W}$, ciprofloxacin clearance corrected for bodyweight.

$\mathrm{V} / \mathrm{W}$, volume of distribution corrected for bodyweight.

$\mathrm{AUC}_{24}$, area under the curve in 24-hours.

\section{Analysis of influence of co-variates on pharmacokinetic and pharmacodynamic parameters}

To determine which covariates have an effect on pharmacokinetic and pharmacodynamic parameters of ciprofloxacin, a univariate analysis was done using a predetermined set of predictors (Table 3). In the univariate analysis CL/W was related to age, gender, V/W and creatinine (Table 3). No significant associations were found between $\mathrm{AUC}_{24} / \mathrm{MIC}$ (and $\mathrm{AUC}_{24}$ ) and CRP decrease or increase, admission days and clinical outcome (data not shown). 
Table 3. Univariate Pearson correlation coefficients between ciprofloxacin, ${ }^{10} \log \mathrm{CL} / \mathrm{W}$ and predictors used in this study.

\begin{tabular}{lll}
\hline & \multicolumn{2}{l}{ Univariate ${ }^{10} \log \mathrm{CL} / \mathrm{W}$} \\
\hline Creatinine & $\mathrm{R}$ & $P$-value \\
Age & -0.547 & $<0.001$ \\
Gender & -0.468 & $<0.001$ \\
V/W & -0.165 & 0.072 \\
24h dose/1000 & 0.416 & $<0.001$ \\
\hline
\end{tabular}

CL/W, ciprofloxacin clearance corrected for bodyweight.

$\mathrm{V} / \mathrm{W}$, volume of distribution corrected for bodyweight.

\section{Dosing simulations}

To determine whether increasing the dose of ciprofloxacin would lead to sufficiently high $\mathrm{AUC}_{24} / \mathrm{MIC}$ values the $\mathrm{AUC}_{24}$ was calculated with $\mathrm{MW} / \mathrm{PHARM}$ 3.60 for all patients. When increasing the daily dose of all patients by $400 \mathrm{mg}$ (i.e. $1200 \mathrm{mg} / 24 \mathrm{~h}$ in patients with normal renal function), 99\% reached the $\mathrm{AUC}_{24} / \mathrm{MIC}$ target with a $\mathrm{MIC} \leq 0.25 \mathrm{mg} / \mathrm{L}$ and $63 \%$ reached the $\mathrm{AUC}_{24} / \mathrm{MIC}$ target with a $\mathrm{MIC} \leq 0.5 \mathrm{mg} / \mathrm{L}$. When increasing the daily dose off all patients by $800 \mathrm{mg}$ (i.e. 1600 $\mathrm{mg} / 24 \mathrm{~h}$ in patients with normal renal function), $100 \%$ reached the $\mathrm{AUC}_{24} / \mathrm{MIC}$ target with a $\mathrm{MIC} \leq 0.25 \mathrm{mg} / \mathrm{L}$ and $91 \%$ reached the $\mathrm{AUC}_{24} / \mathrm{MIC}$ target with a $\mathrm{MIC} \leq 0.5$ $\mathrm{mg} / \mathrm{L}$ (Figure 1).

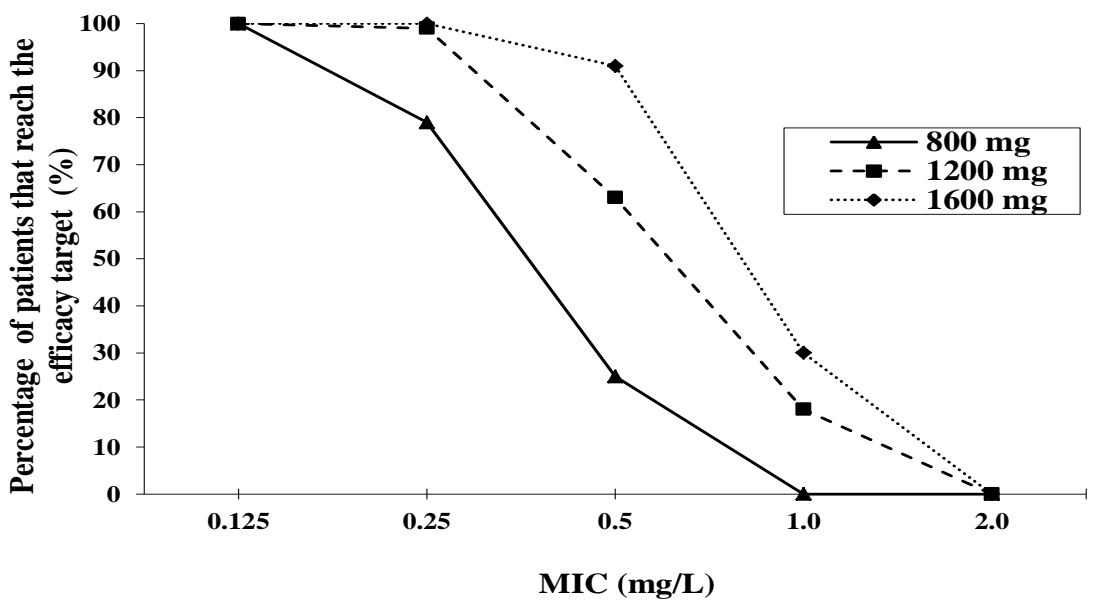

Figure 1. Calculated percentage of patients with an adequate $\mathrm{AUC}_{24} / \mathrm{MIC}$ ratio $>125$ at $\mathrm{MIC} 0.125,0.25$, $0.5,1.0$ and $2.0 \mathrm{mg} / \mathrm{L}$ for increasing ciprofloxacin dosages based on the pharmacokinetics obtained at current dosage regimens. 


\section{Discussion}

This study shows that the majority of hospitalised patients using ciprofloxacin have low $\mathrm{AUC}_{24}$ with current iv dose regimens. A substantial part (21$75 \%$ ) of hospitalised patients on general wards did not reach the target $\mathrm{AUC}_{24} / \mathrm{MIC}$ ratio when the MIC is between $0.25-0.5 \mathrm{mg} / \mathrm{L}$. A ciprofloxacin daily dose of 1200 mg may be more effective, but fear for adverse drug events (ADEs) might hamper the use of this dosage. In general ciprofloxacin is considered safe and is well tolerated [16-18], even in higher doses [5, 19]. Most common ADEs are mild; gastrointestinal reactions (nausea and diarrhoea), but CNS toxicity (anxiety, restlessness and seizures) occurs, as do skin reactions and hepatotoxicity [16-18, 20]. However, even at high dose seizures are rarely reported [18]. The pharmacodynamic better dose of $1600 \mathrm{mg} /$ day cannot yet be recommended, although to our knowledge no increase in frequency or severity of ADE has been described. The variability in pharmacokinetic parameters is high, therefore dosing should be optimised individually. The ciprofloxacin dose is adjusted to the individual renal clearance to prevent high ciprofloxacin levels. However, other covariates, such as age also influence the ciprofloxacin clearance independently. Adjusting for all co-variates might not be feasible and therapeutic drug monitoring (TDM) could further prevent high and low ciprofloxacin blood levels and could be useful in reaching the target $\mathrm{AUC}_{24} / \mathrm{MIC}$ ratio. Although TDM for ciprofloxacin has been advocated [1,3-6], it is not standard of care in most hospitals. Taken together, with increasing MICs of Gram-negative bacteria, higher daily doses of ciprofloxacin seem necessary and feasible with regard to ADEs and TDM may be the appropriate tool to decrease development of ciprofloxacin resistance.

A limitation of this study is that no effect of low $\mathrm{AUC}_{24} / \mathrm{MIC}$ ratio on clinical outcome could be demonstrated. Although cultures were taken in all patients, in only $44 \%$ Gram negative bacteria could be cultured. Furthermore, the group that used ciprofloxacin monotherapy was small. A different study and much larger numbers of patients are needed for this endpoint. On the other hand, low $\mathrm{AUC}_{24}$ were shown in our study and low $\mathrm{AUC}_{24} / \mathrm{MIC}$ ratio's and worse clinical outcome has been shown in several studies [4-6].

\section{Conclusion}

The majority of hospitalised patients did not reach the target $\mathrm{AUC}_{24} / \mathrm{MIC}$ ratio with the current iv doses. Taken into account the increasing resistance for ciprofloxacin worldwide, TDM and subsequent dose adjustment may decrease development of ciprofloxacin resistance. A large randomized clinical trial of ciprofloxacin treatment is needed to confirm the $\mathrm{AUC}_{24} / \mathrm{MIC}>125$ or higher $\mathrm{AUC}_{24} / \mathrm{MIC}$ ratios (>250) are needed for good clinical and microbiological outcome.

\section{Acknowledgements}

We acknowledge the support provided by department of Clinical Chemistry and the Pharmacy laboratory. We also acknowledge the assistance of Dr. Bekers and the excellent technical assistance of Jeroen Welzen, Inez Widow and Pauline Vinken. 
This work was supported by Care and Public Health Research Institute (CAPHRI), Maastricht, the Netherlands and the Medical University Centre Maastricht, the Netherlands. 


\section{References}

1. Conil JM, Georges B, de Lussy A, Khachman D, Seguin T, Ruiz S, Cougot P, Fourcade O, Houin G, Saivin S: Ciprofloxacin use in critically ill patients: pharmacokinetic and pharmacodynamic approaches. Int J Antimicrob Agents 2008, 32(6):505-510.

2. Schentag JJ, Nix DE, Adelman MH: Mathematical examination of dual individualization principles (I): Relationships between AUC above MIC and area under the inhibitory curve for cefmenoxime, ciprofloxacin, and tobramycin. DICP 1991, 25(10):1050-1057.

3. van Zanten AR, Polderman KH, van Geijlswijk IM, van der Meer GY, Schouten MA, Girbes AR: Ciprofloxacin pharmacokinetics in critically ill patients: a prospective cohort study. $J$ Crit Care 2008, 23(3):422-430.

4. Zelenitsky SA, Ariano RE: Support for higher ciprofloxacin AUC 24/MIC targets in treating Enterobacteriaceae bloodstream infection. J Antimicrob Chemother 2010, 65(8):1725-1732.

5. Forrest A, Nix DE, Ballow CH, Goss TF, Birmingham MC, Schentag JJ: Pharmacodynamics of intravenous ciprofloxacin in seriously ill patients. Antimicrob Agents Chemother 1993, 37(5):1073-1081.

6. Scaglione F, Esposito S, Leone S, Lucini V, Pannacci M, Ma L, Drusano GL: Feedback dose alteration significantly affects probability of pathogen eradication in nosocomial pneumonia. Eur Respir J 2009, 34(2):394-400.

7. Fish DN, Piscitelli SC, Danziger LH: Development of resistance during antimicrobial therapy: a review of antibiotic classes and patient characteristics in 173 studies. Pharmacotherapy 1995, 15(3):279-291.

8. Oudhuis GJ, Verbon A, Hoogkamp-Korstanje JA, Stobberingh EE: Antimicrobial resistance in Escherichia coli and Pseudomonas aeruginosa from Intensive Care Units in The Netherlands, 1998-2005. Int J Antimicrob Agents 2008, 31(1):58-63.

9. Nethmap.: Consumption of antimicrobial agents and antimicrobial resistance among medically important bacteria in the Netherlands. 2010.

10. ECDC.: European Centre for Disease Prevention and Control. Antimicrobial Resistance Surveillance in Europe in 2009. . 2009.

11. Perreiter AP, Nix, D.E., Matthias, K.R.: Appropriateness of ciprofloxacin dosing based on a population pharmacokinetic model. Hospital Pharmacy 2010, 45(3):237-243.

12. Neef C, van Gils SA, WL IJ: Analogy between temperature-dependent and concentrationdependent bacterial killing. Comput Biol Med 2002, 32(6):529-549.

13. Kontou P, Chatzika K, Pitsiou G, Stanopoulos I, Argyropoulou-Pataka P, Kioumis I: Pharmacokinetics of ciprofloxacin and its penetration into bronchial secretions of mechanically ventilated patients with chronic obstructive pulmonary disease. Antimicrob Agents Chemother 2011, 55(9):4149-4153.

14. FDA.: Guidance for Industry. Bioanalytical Method Validation, U.S. Department of Health and Food Science, Rockville, MD, USA, Food and Drug Administration (FDA). . 2001.

15. Haeseker MB, Verbon A, Welzen J, Neef C, Bruggeman CA, Stolk LML: A Simple and Rapid RP-HPLC Method to Determine Ciprofloxacin Level In Human Serum. Asian Journal of Pharmaceutical and Biological Research 2011:350-354.

16. Stahlmann R, Lode H: Safety considerations of fluoroquinolones in the elderly: an update. Drugs Aging 2010, 27(3):193-209.

17. Bertino J, Jr., Fish D: The safety profile of the fluoroquinolones. Clin Ther 2000, 22(7):798-817; discussion 797.

18. Stahlmann R: Safety profile of the quinolones. J Antimicrob Chemother 1990, 26 Suppl D:31-44.

19. Lipman J, Scribante J, Gous AG, Hon H, Tshukutsoane S: Pharmacokinetic profiles of highdose intravenous ciprofloxacin in severe sepsis. The Baragwanath Ciprofloxacin Study Group. Antimicrob Agents Chemother 1998, 42(9):2235-2239.

20. Alan C, Kocoglu H, Ersay AR, Ertung Y, Kurt HA: Unexpected severe hepatotoxicity of ciprofloxacine: two case reports. Drug Chem Toxicol 2011., 34(2):189-191. 


\title{
Chapter 5
}

\section{Is the standard dose of amoxicillin-clavulanic acid sufficient?}

\author{
M.B. Haeseker, T.R.A. Havenith, L.M.L Stolk, C. Neef, C.A. \\ Bruggeman and A. Verbon
}

BMC Pharmacology and Toxicology 2014;15:38 


\begin{abstract}
Introduction. The pharmacodynamic (PD) efficacy target of amoxicillin is $40 \%$ time above the minimal inhibition concentration (40\% $>\mathrm{MIC})$. Recent studies of other antibiotics have shown that PD-efficacy targets are not always reached. The aim of this study was to evaluate the percentage of hospitalised patients, using amoxicillin/clavulanic acid intravenously (iv), that reach the pharmacodynamic efficacy target $40 \% \mathrm{~T}>\mathrm{MIC}$. Additionally, the association of demographic anthropomorphic and clinical parameters with the pharmacokinetics and pharmacodynamics of amoxicillin were determined.
\end{abstract}

Methods. In serum of 57 hospitalised patients amoxicillin concentrations were measured using high performance liquid chromatography. Patients were older than 18 years and most patients had an abdominal infection. The standard amoxicillin/clavulanic acid dose was 4 times a day 1000/200 $\mathrm{mg}$ iv. Pharmacokinetic parameters were calculated with maximum a posteriori Bayesian estimation (MW\Pharm 3.60). A one-compartment open model was used. Individual dosing simulations were performed with MW\Pharm.

Results. In our study population, the mean $( \pm \mathrm{SD})$ age was $67( \pm 16)$ years and the mean clearance corrected for bodyweight was $0.17( \pm 0.07) \mathrm{L} / \mathrm{h} / \mathrm{kg}$. Only, $65 \%$ of the patients reached the proposed amoxicillin $40 \% \mathrm{~T}>\mathrm{MIC}$ with amoxicillin/clavulanic acid for bacterial MICs of $8 \mathrm{mg} / \mathrm{L}$. A computer simulated increase of the standard dose to 6 times daily, increased this percentage to $95 \%$. In this small study group $40 \% \mathrm{~T}>\mathrm{MIC}$ was not associated with clinical or microbiological cure.

Conclusion. A substantial proportion of the hospitalised patients did not reach the $40 \% \mathrm{~T}>\mathrm{MIC}$ with the standard dose amoxicillin/clavulanic acid for a bacterial MIC of $8 \mathrm{mg} / \mathrm{L}$. Therefore, we suggest increasing the standard dose of amoxicillin/clavulanic acid to 6 times a day in patients with severe Enterobacteriaceae infections. 


\section{Introduction}

In vitro and animal studies have shown that $\beta$-lactam antibiotics for Grampositive bacteria and Gram-negative bacteria are effective when the percentage time above the minimal inhibition concentration (\% $>\mathrm{MIC})$ of the unbound serum concentration is more than $35-40 \%$. Maximal effects are reached with $\% \mathrm{~T}>\mathrm{MIC}$ above $60-70 \%$ [1-3]. Only sparse pharmacokinetic/pharmacodynamic (PK/PD) data are estimated in human clinical studies. Pharmacokinetic analysis of amoxicillin/clavulanic acid has mostly been done in healthy individuals $[4,5]$. In human clinical studies amoxicillin/clavulanic acid has been found to cure Streptococcus pneumoniae and Haemophilus influenza infections clinically and microbiologically when $\% \mathrm{~T}>\mathrm{MIC}$ was $\geq 40 \%$ [1]. To our knowledge, there are no human pharmacodynamic efficacy studies for Enterobacteriaceae.

Amoxicillin/clavulanic acid is a commonly used broad spectrum antibiotic. Clavulanic acid extends the spectrum of amoxicillin to $\beta$-lactamase producing strains, such as E. coli, $K$. pneumoniae, $H$. influenzae and $S$. aureus. Clavulanic acid has very little intrinsic antibacterial effect. Clavulanic acid irreversibly inhibits $\beta$ lactamase, protecting amoxicillin [6]. Therefore, amoxicillin is measured for determining the PD-efficacy target. Susceptibility patterns of Enterobacteriaceae have changed over time, and recent studies have shown that efficacy targets of other antibiotics, such as ciprofloxacin [7, 8], ceftazidim [9] and gentamicin [10] are not reached in a significant percentage of patients. In the EUCAST rationale document the target attainment rates for different doses of amoxicillin for different MICs based on Monte Carlo simulations are reported [11]. Amoxicillin blood levels have not been measured in these simulations. The aim of this study was to measure the amoxicillin serum concentrations in hospitalised patients using amoxicillinclavulanic acid intravenously (iv) and to determine if the efficacy target of $40 \% \mathrm{~T}>\mathrm{MIC}$ was reached. Additionally, we have investigated the association of demographic anthropomorphic and clinical parameters with pharmacokinetics and pharmacodynamics of amoxicillin. 


\section{Methods}

\section{Study design}

Patients above 18 years of age treated with amoxicillin/clavulanic acid iv and hospitalised at the Maastricht University Medical Centre (MUMC), a 715 bed university hospital, were included from January 2010 until October 2010. Amoxicillin blood levels were measured in residual samples drawn for routine assays. Patients with at least two blood samples available were included and blood samples taken during or within 0.5 hours after infusion were excluded. Amoxicillin/clavulanic acid (Sandoz, Holzkirchen, Germany) was started at the discretion of the attending physician, either empirically or as therapy for bacteria susceptible to amoxicillin/clavulanic acid. The standard dose of amoxicillin/clavulanic acid was 1000/200 mg 4 times a day and 1000/200 mg 2 times a day was prescribed when the creatinine clearance (CLcr) was $10-50 \mathrm{~mL} / \mathrm{min}$. Amoxicillin/clavulanic acid 1000/200 mg/100 mL infusion was infused in 30 minutes. Demographic and clinical data, such as age, gender, weight, temperature, co-medication, length of hospital stay, time of administration of amoxicillin/clavulanic acid and laboratory parameters, such as, serum creatinine, Creactive protein (CRP) were retrieved from the electronic patient file (iSoft, the Netherlands). Clinical outcome was defined by CRP normalisation, number of admission days, and discharge from the hospital, time to defeveresence and microbiological cure. CLcr was calculated with the Cockroft-Gault formula using the lean body mass.

This study was registered at the Dutch Trial Register (NTR 1725) [12] and was approved by the Medical Ethical Committee of the Maastricht University Medical Centre (MEC 08-4-063). All data in this study were analysed anonymously and amoxicillin blood levels were measured in residual samples drawn for routine assays. Therefore, no consent was required from the patient. This is in agreement with the Medical Research Involving Human Subjects Act, the code for proper use of human tissue as formulated by the Dutch Federation of Medical Scientific Societies and the policy of the Medical Ethics Committee of the Maastricht University Medical Centre.

\section{HPLC analysis}

A simple, fast and specific method for measuring amoxicillin serum levels has been validated for linearity, precision, accuracy and stability, following the guidelines for industry bioanalytical method validation recommended by the Food and Drug Administration (FDA) [13]. In short, serum samples were precipitated with perchloric acid $3 \%$. A reverse phase high pressure liquid chromatography (RPHPLC) method was used. The calibration range was 10 to $200 \mathrm{mg} / \mathrm{L}$. Six quality controls $(8,20,40,60,80$ and $160 \mathrm{mg} / \mathrm{L})$ were tested. The intra- and inter-assay variability was within $7.5 \%$. The relationship between plasma concentration and sd was fitted with a polynomial of second order [14]. With this polynomial the lower limit of quantification with a precision of $20 \%$ has been calculated and was 0.8 $\mathrm{mg} / \mathrm{L}$ [15]. All our measured concentrations were above $0.8 \mathrm{mg} / \mathrm{L}$. 


\section{Pharmacokinetic analysis}

Pharmacokinetic parameters of amoxicillin in individual patients were calculated with maximum a posteriori (MAP) Bayesian estimation program (computer program MW/Pharm 3.60, Mediware, the Netherlands). A onecompartment open pharmacokinetic model was used. With MAP Bayesian estimation [16, 17] all patient characteristics and measured amoxicillin concentrations are fitted on an existing population model [4, 5]. With two concentrations per patient individual pharmacokinetic parameters can be adequately calculated with MAP Bayesian estimation [17]. With these individual fitted pharmacokinetic parameters, dosing simulations were made to adjust the dose individually; this MAP Bayesian estimation is standard procedure in laboratories which provide therapeutic drug monitoring service. A population kinetic model from our population was not made. The free fraction of amoxicillin was fixed at $80 \%$. The $\% \mathrm{~T}>\mathrm{MIC}$ was determined with the formula of Turnidge; \% $>\mathrm{MIC}=$ $\ln \left(\right.$ Dose/VdxMIC) $\times \mathrm{T}^{1} / 2 / \ln (2) \times 100 /$ dosing interval [18]. Individual dosing simulations were performed with MW-Pharm (3 times 1000-2000 mg, 4 times 2000 mg, 5 times 1000-2000 mg, 6 times 1000-2000 mg).

\section{Microbiological analysis}

Identification of the causative bacterium (ID) and antibiotic susceptibility testing (AST) were performed with the Becton Dickinson Phoenix ${ }^{\mathrm{TM}}$ Automated Microbiology System (Franklin Lakes, New Jersey, USA) using the ID/AST Combo panels UNMIC/ID53 and NMIC/ID75 for Gram negative bacteria and the AST panel PMIC-58 for Gram positive bacteria. In urine cultures the lowest MIC detectable was $0.5 \mathrm{mg} / \mathrm{L}$ by the UNMIC/ID53 panel (standard clinical care). MIC values were not determined by the Becton Dickinson Phoenix ${ }^{\mathrm{TM}}$ for Streptococcal spp. and Anaerobes. Susceptibility testing for Streptococcal spp. and Anaerobes was done with the disc diffusion method.

\section{Statistical analysis}

Metric variables were tested for normality of distribution by the ShapiroWilk test and presented as mean $( \pm \mathrm{SD})$. If not, median and ranges were also given. Categorical variables are presented as frequencies and percentages. Univariate analysis on the amoxicillin clearance corrected for bodyweight $(\mathrm{CLam} / \mathrm{W})$ with categorical variables was either done by Student t-test or by one-way ANOVA. Data analysis was done with SPSS-pc version 16.0. A $P$-value of $<0.05$ is considered to be statistically significant. 


\section{Results}

\section{Study group}

A total of 57 patients with a mean $( \pm$ SD) of $3( \pm 0.9)$ blood samples (median: 2, range 2-5 blood samples) were included. The mean age was $67( \pm 16)$ years (median: 69, range 23-93 years) and 70\% were male (Table 1). About half of the patients had an abdominal infection, $18 \%$ a wound infection and $10 \%$ a pneumonia (Table 1).

Table 1. Characteristics of 57 hospitalised patients.

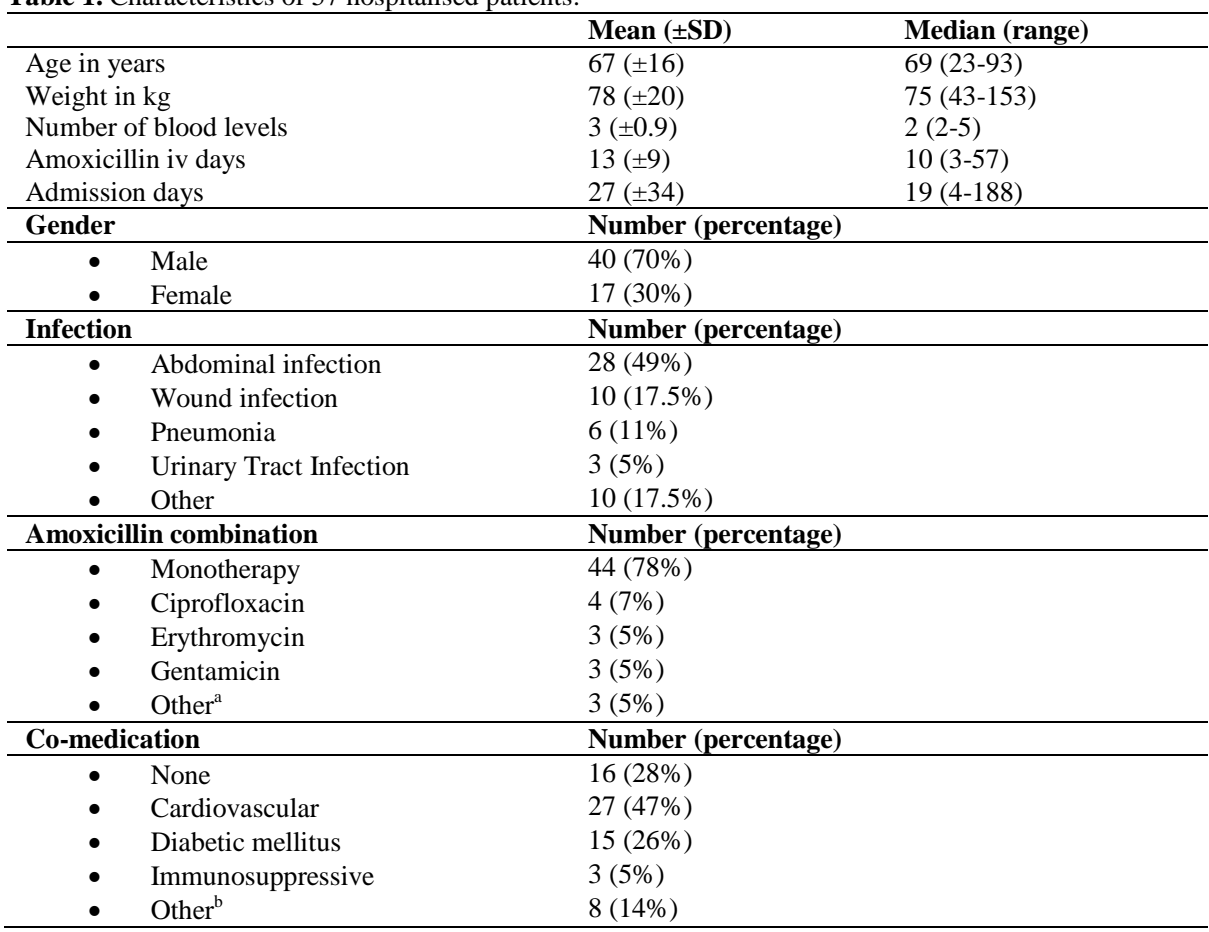

${ }^{a}$ Other: rifampicin, cefuroxim and metronidazol

bother: haloperidol, levothyroxine, painkillers, anticoagulant

\section{Pharmacokinetic and pharmacodynamic analysis}

The mean CLam/W was $0.17( \pm 0.07) \mathrm{L} / \mathrm{h} / \mathrm{kg}$ (median: 0.16 , range: 0.05 $0.37 \mathrm{~L} / \mathrm{h} / \mathrm{kg}$ ) and the mean volume of distribution corrected for bodyweight (V/W) was $0.31( \pm 0.07) \mathrm{L} / \mathrm{kg}$ (median: 0.30, range: $0.19-0.50 \mathrm{~L} / \mathrm{kg})$. The mean volume of distribution (V) was $24( \pm 5.6) \mathrm{L}$ (median: 24 , range: 14-36 L) and the mean elimination half-life $\left(\mathrm{t}^{\mathrm{t}} / 2\right)$ was $1.5( \pm 0.6) \mathrm{h}$ (median: 1.3 , range: $\left.0.6-3.29 \mathrm{~h}\right)$ which is in the same range as described in the EUCAST rationale document [11]. The mean serum creatinine was $90( \pm 36) \mu \mathrm{mol} / \mathrm{L}$ (median: 90 , range: $49-210 \mu \mathrm{mol} / \mathrm{L})$. Fiftyfive $(96 \%)$ patients received the standard dose of amoxicillin/clavulanic acid 4 times a day 1000/200 mg iv, 1 patient 3 times 1000/200 mg iv and 1 patient 2 times a day $1000 / 200 \mathrm{mg}$ iv, both because of renal insufficiency. Patients above 70 years had 
lower $\mathrm{CLam} / \mathrm{W}(P=0.02)$, Table 2. A significant correlation was found between $\mathrm{CLam} / \mathrm{W}$ and age $(P<0.001)$.

The measured concentrations of amoxicillin were plotted against the sampling times in Figure 1. There was a good linear correlation $\left(\mathrm{R}^{2}=0.96\right)$ between the amoxicillin actual measured concentration and estimated concentration with MAP Bayesian fitting (MW/Pharm 3.60, Mediware, the Netherlands), Figure 2. The amoxicillin efficacy target the $(40 \% \mathrm{~T}>\mathrm{MIC})$ was reached in $100 \%$ of patients with a bacterial $\mathrm{MIC} \leq 2 \mathrm{mg} / \mathrm{L}$ of Gram negative bacteria, in $93 \%$ of patients with a $\mathrm{MIC}=4$ $\mathrm{mg} / \mathrm{L}$ and in $65 \%$ of patients with a $\mathrm{MIC}=8 \mathrm{mg} / \mathrm{L}$ (Figure 3 ). When divided in age categories, arbitrarily set at 70 years; all patients older than 70 years reached the $40 \% \mathrm{~T}>\mathrm{MIC}$ with a MIC of $4 \mathrm{mg} / \mathrm{L}$ and $87 \%$ of the patients younger than 70 years. For a MIC of $8 \mathrm{mg} / \mathrm{L}$, the $40 \% \mathrm{~T}>\mathrm{MIC}$ was reached in $81 \%$ of the patients older than 70 years and in $52 \%$ of the patients younger than 70 years (Figure 3 ).

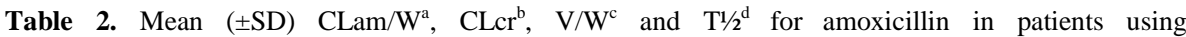
amoxicillin/clavulanic acid broken down per age group.

\begin{tabular}{llllll}
\hline $\begin{array}{l}\text { Age } \\
\text { group in } \\
\text { years }\end{array}$ & $\mathbf{N}$ & $\begin{array}{l}\mathbf{C L a m} / \mathbf{W} \text { in } \\
\mathbf{L} / \mathbf{h} / \mathbf{k g}\end{array}$ & $\begin{array}{l}\mathbf{C L c r i n} \\
\mathbf{m L} / \mathbf{m i n}\end{array}$ & $\begin{array}{l}\mathbf{V} / \mathbf{W} \text { in } \\
\mathbf{L} / \mathbf{k g}\end{array}$ & $\begin{array}{l}\mathbf{T} 1 / 2 \\
\text { in } \mathbf{h}\end{array}$ \\
\hline$<70$ & 31 & $0.19( \pm 0.08)$ & $82( \pm 25)$ & $0.30( \pm 0.06)$ & $1.26( \pm 0.44)$ \\
$>70$ & 26 & $0.14( \pm 0.06)$ & $55( \pm 19)$ & $0.32( \pm 0.08)$ & $1.83( \pm 0.71)$ \\
P-value & & 0.02 & $<0.01$ & 0.82 & $<0.01$ \\
\hline
\end{tabular}

${ }^{\mathrm{a}} \mathrm{CLam} / \mathrm{W}$ : amoxicillin clearance corrected for bodyweight

${ }^{\mathrm{b}} \mathrm{CLcr}$ : creatinine clearance

${ }^{\mathrm{c}} \mathrm{V} / \mathrm{W}$ : volume of distribution corrected for bodyweight

${ }^{\mathrm{d}} \mathrm{T} 1 / 2$ : amoxicillin half life

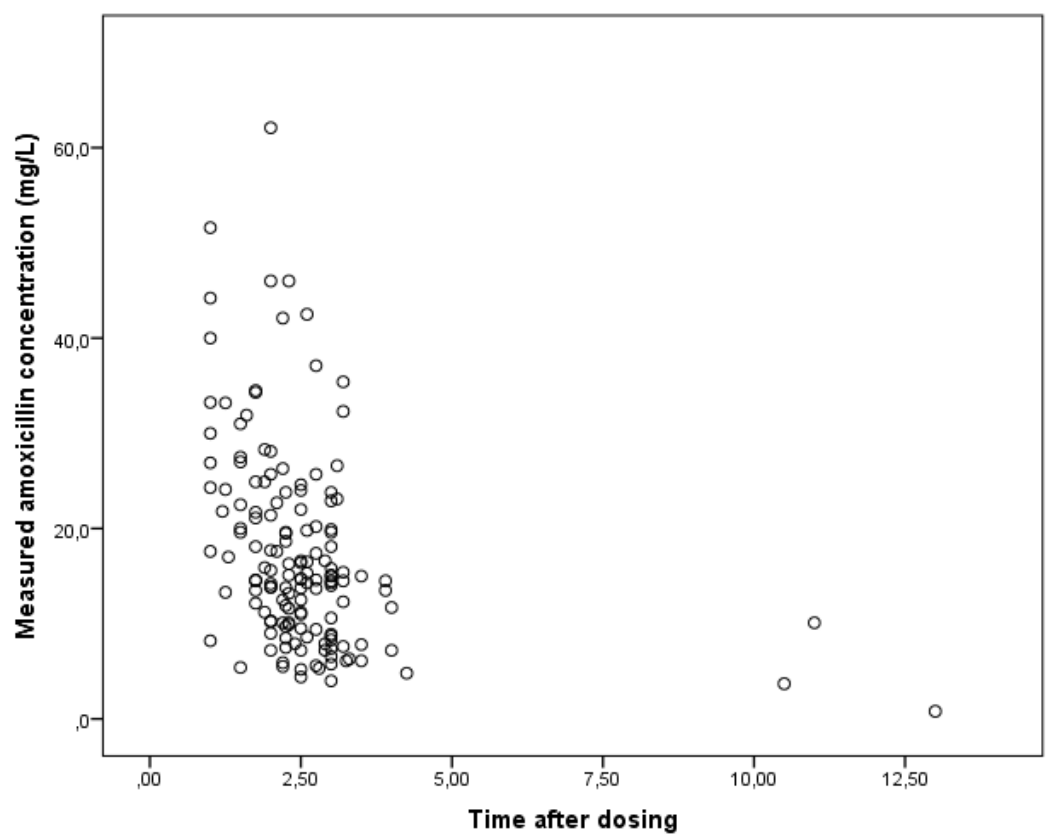

Figure 1. The measured concentrations of amoxicillin plotted against the time after amoxicillin administration. 


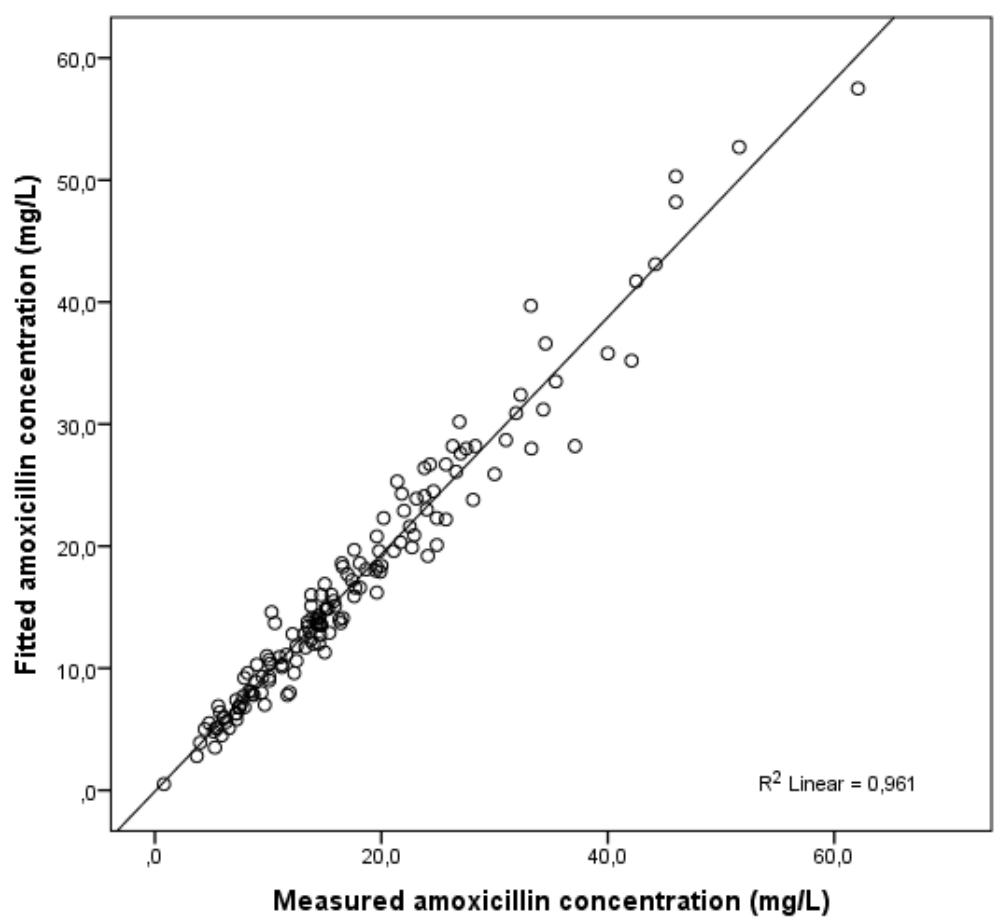

Figure 2. Correlation between amoxicillin actual measured concentration and estimated with maximum a posteriori Bayesian fitting (MW/Pharm 3.60, Mediware, the Netherlands).

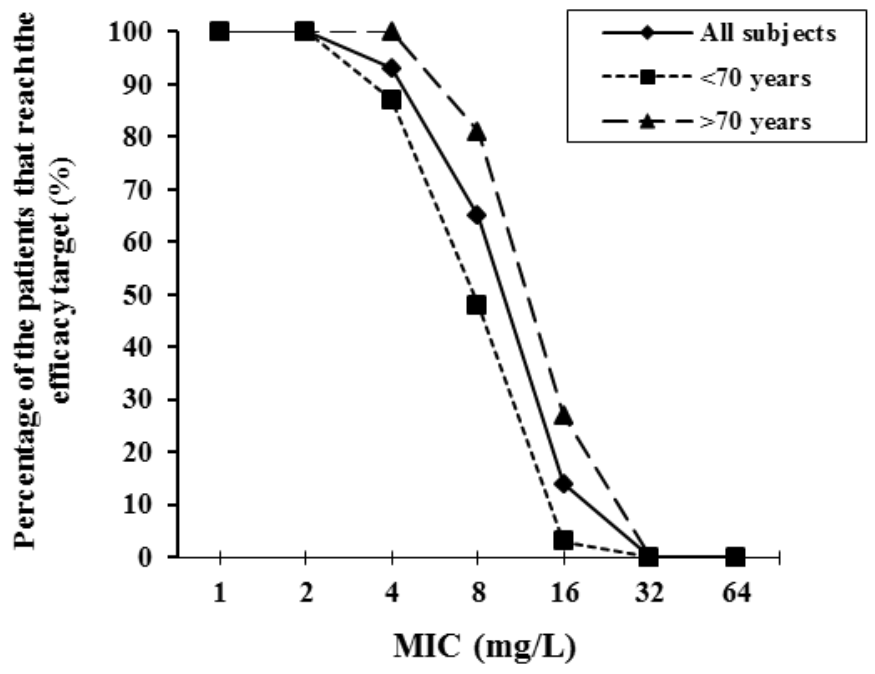

Figure 3. The percentage of patients that reach the $40 \% \mathrm{~T}>\mathrm{MIC}$ for different age categories at different MICs. 


\section{Analysis of influence of co-variates on pharmacokinetic and pharmacodynamic parameters}

To determine which co-variates have an effect on the pharmacokinetic parameters of amoxicillin, a univariate analysis was done using a predetermined set of predictors (Table 3). In the univariate analysis CLam/W was related to age, creatinine, CLcr, V/W and 40\% $>$ MIC. Linear correlations were found between CLam/W, creatinine and age $\left(\mathrm{R}^{2} 0.327\right), \mathrm{Vd}\left(\mathrm{R}^{2} 0.370\right)$ and age $\left(\mathrm{R}^{2} 0.227\right)$. In the univariate analysis age was not correlated to creatinine ( $\mathrm{R} 0.10, P=0.467)$ and no linear correlation $\left(\mathrm{R}^{2} 0.01\right)$ was found.

Table 3. Univariate Pearson correlation coefficients between amoxicillin/clavulanic acid, $\mathrm{CLam} / \mathrm{W}$ and predictors used in this study.

\begin{tabular}{lll}
\hline & \multicolumn{2}{l}{ Univariate CLam/W } \\
\hline Creatinine & $\mathrm{R}$ & $P$-value \\
Age & -0.584 & $<0.001$ \\
Gender & -0.476 & $<0.001$ \\
V/W & -0.034 & 0.812 \\
$40 \% \mathrm{~T}>$ MIC & -0.608 & $<0.001$ \\
\hline
\end{tabular}

CLam/W, amoxicillin/clavulanic acid clearance corrected for bodyweight

$\mathrm{V} / \mathrm{W}$, amoxicillin/clavulanic acid volume of distribution corrected for bodyweight

\section{Dosing simulations}

To determine whether increasing the dose of amoxicillin/clavulanic acid would lead to sufficiently high $\% \mathrm{~T}>\mathrm{MIC}$, the $\% \mathrm{~T}>\mathrm{MIC}$ was calculated for all patients with increasing doses with the Turnidge formula [18]. When increasing the dosage frequency from 4 times to 6 times a day all patients with bacterial MIC $\leq 4$ reach the efficacy target and $95 \%(54 / 57)$ of the patients with bacterial $\mathrm{MIC} \leq 8$ (Figure 4).

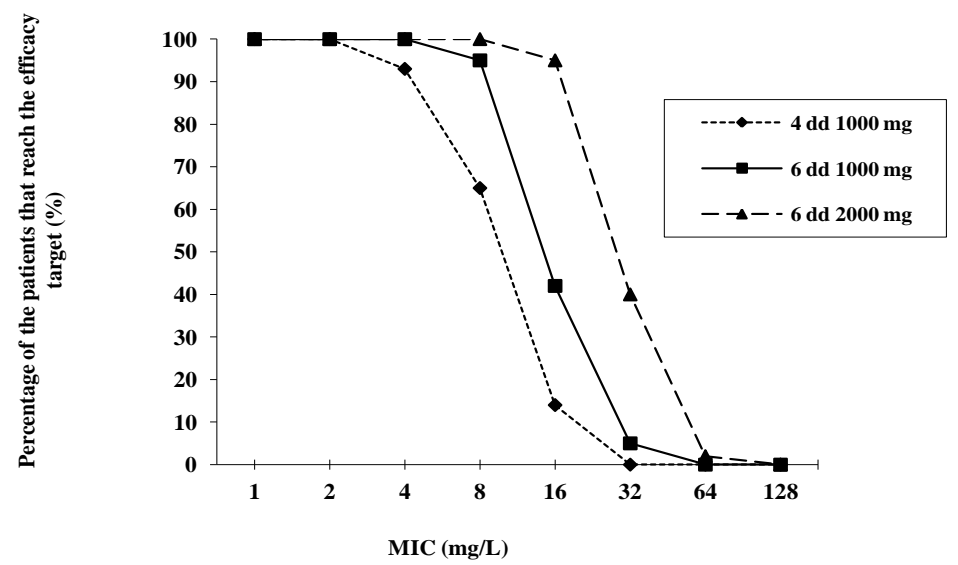

Figure 4. Calculated percentage of patients with $40 \% \mathrm{~T}>\mathrm{MIC}$ at different MICs for increasing amoxicillin dosages. 


\section{Microbiological analysis}

Sixteen out of twenty one abdominal fluid cultures became positive, 8/10 wound cultures, 7/16 blood cultures, 4/5 urine cultures and 1/2 sputum cultures became positive. Of three patients no cultures were taken. In total thirty-six of the 57 patients $(63 \%)$ had a positive culture. Of the positive cultures, 30 (83\%) were Enterobacteriaceae; E. coli $(\mathrm{n}=21)$, Klebsiella spp. $(\mathrm{n}=6)$, Enterobacter $\mathrm{spp} .(\mathrm{n}=2)$ and Proteus spp. $(\mathrm{n}=1)$. In three patients two bacteria were isolated. Of the Gram positive cultures, 6 were Enterococcus spp, 3 Staphylococcus aureus and 1 coagulase negative staphylococcus. Forty MIC values were available in 36 patients. Of the isolated Enterobactericeae $17 / 30$ (57\%) of had a $\mathrm{MIC} \leq 4 \mathrm{mg} / \mathrm{L}, 4 / 30(13 \%)$ had a $\mathrm{MIC}=8 \mathrm{mg} / \mathrm{L}$ and $9 / 30(30 \%)$ had a $\mathrm{MIC} \geq 16 \mathrm{mg} / \mathrm{L}$. Of the isolated Gram positive bacteria $8 / 10(80 \%)$ of had a MIC $\leq 1 \mathrm{mg} / \mathrm{L}$ and $2 / 10(20 \%)$ had a $\mathrm{MIC} \geq 4$ $\mathrm{mg} / \mathrm{L}$. Clinical cure was reached in 46 patients, 8 patients switched antibiotic therapy and in 3 patients cure was not reached (of which two died). No significant associations were found between $40 \% \mathrm{~T}>\mathrm{MIC}$ and defeverescence, CRP decrease or increase, admission days and clinical outcome (data not shown). 
Is the standard dose of amoxicillin-clavulanic acid sufficient?

\section{Discussion}

In this study, we demonstrate that the efficacy target of $40 \% \mathrm{~T}>\mathrm{MIC}$ for amoxicillin/clavulanic acid was reached in $93 \%$ of the patients tested when the MIC was $4 \mathrm{mg} / \mathrm{L}$ and only in $65 \%$ of the patients tested when the MIC was $8 \mathrm{mg} / \mathrm{L}$. In the EUCAST and CLSI criteria Enterobacteriaceae are considered to be susceptible for amoxicillin/clavulanic acid with bacterial MIC $\leq 8 \mathrm{mg} / \mathrm{L}$ [11]. High bacterial MICs for amoxicillin/clavulanic acid are an increasing problem in the Netherlands and in Europe $[19,20]$. To prevent treatment failure for individual patients and to prevent development of antibiotic resistance on population level, increasing the standard dose of amoxicillin/clavulanic acid seems warranted. Dosing simulation showed that increasing the standard dose of amoxicillin/clavulanic acid to 6 times a day $1000 / 200 \mathrm{mg}$ increased the number of patients reaching $40 \% \mathrm{~T}>\mathrm{MIC}$ to $100 \%$ for bacterial $\mathrm{MIC} \leq 4$ and to $95 \%$ with bacterial $\mathrm{MIC} \leq 8$. Continuous iv dosing is an alternative for frequent dosing of time dependent $\beta$-lactam antibiotics. Unfortunately, amoxicillin is not very suitable for continuous iv dosing, because of the instability of amoxicillin at room temperature. Therefore, we suggest increasing the dose of amoxicillin/clavulanic acid to 6 times a day in patients with severe Enterobacteriaceae sepsis or intra-abdominal infection.

In general amoxicillin/clavulanic acid is well tolerated. The most frequent adverse drug events are diarrhoea, nausea and vomiting. However, amoxicillin/clavulanic acid is also associated with liver injury, which is estimated to occur from 1 to 1.7 per 10.000 users [21, 22]. Clavulanic acid seems to be responsible for the adverse drug reaction, since amoxicillin alone is rarely associated with liver injury and causes less gastrointestinal problems than the combination preparation [23-25]. In vitro pharmacodynamic studies demonstrate that low dose of clavulanic acid suffice and the $\beta$-lactamase inhibition of clavulanic acid lasts for 812 hours [26, 27]. Therefore, increasing the standard dose of amoxicillin/clavulanic acid of 4 times a day 1000/200mg iv with amoxicillin twice daily $1000 \mathrm{mg}$ iv may be a safe and effective alternative.

$\mathrm{CLam} / \mathrm{W}$ is correlated with CLcr and the amoxicillin dose is adjusted with to the CLcr. However, other covariates also influence the CLam/W. CLam/W was significantly correlated with age. However, age and creatinine were not correlated to each other, meaning that elderly patients can have both a normal creatinine and a decreased CLam/W. Therefore, the correlation of age with CLam/W seems independent of the creatinine. Furthermore, the 4 patients that did not reach the efficacy target with bacterial $\mathrm{MIC}=4$ were all young patients with excellent clearance. Our measured attainment results are lower than those calculated attainment results in the EUCAST rationale document, in which Monte Carlo simulations were used to calculate the target attainment rates $(40 \% \mathrm{~T}>\mathrm{MIC})$ of different dosing regimens (from $500 \mathrm{mg} 3$ times a day to $2 \mathrm{~g} 4$ times a day) for different bacterial MICs $(0.5-32 \mathrm{mg} / \mathrm{L})$ [11]. The target attainment in the EUCAST rationale document for the standard dose $(1000 / 200 \mathrm{mg} 4$ times a day) is $100 \%$ at bacterial $\mathrm{MIC} \leq 4$ and $75 \%$ with bacterial $\mathrm{MIC} \leq 8 \mathrm{mg} / \mathrm{L}$ [11]. In our real life blood level determination study, these percentages were $93 \%$ and $65 \%$, respectively. This difference may be explained by the larger interindividual variability of our population and in particular by a group of younger patients with normal renal 
clearance (CLcr>60 mL/min). Remarkably, in the EUCAST rationale document, the interindividual variation is extremely small; $t \frac{1}{2}$ is $1.1( \pm 0.1) h$, versus $t^{1 / 2}$ is 1.5 $( \pm 0.6) \mathrm{h}$ in our study. The higher $\mathrm{t} 1 / 2$ in our study may be due to the high mean age of our population.

No significant associations have been found between the target $40 \% \mathrm{~T}>\mathrm{MIC}$ and clinical outcome. As expected, our study population was too small and too heterogeneous. A large number of patients are needed to draw conclusions for this endpoint. Moreover, in an in vitro study, ceftazidim has been shown to be maximally effective when $40 \% \mathrm{~T}>\mathrm{MIC}$ was reached for concentrations four times the MIC or higher [28]. In our study, the target of $40 \% \mathrm{~T}>4 \times \mathrm{MIC}$ was only reached in $100 \%$ for low MICs $(\leq 1 \mathrm{mg} / \mathrm{L})$, but never for bacterial MICs of 4 and $8 \mathrm{mg} / \mathrm{L}$. Our study was not designed to isolate a large number of bacterial MICs and therefore only a limited number of clinical bacterial MICs were available in our study. Taken together a large clinical PK/PD study of amoxicillin/clavulanic acid is needed with microbiological and clinical cure endpoints to establish the association between clinical endpoints and the efficacy target $40 \% \mathrm{~T}>\mathrm{MIC}$.

\section{Conclusions}

The current standard dose of amoxicillin/clavulanic acid 4 times a day $1000 / 200 \mathrm{mg}$ iv is too low to reach the $40 \% \mathrm{~T}>\mathrm{MIC}$ for bacterial MIC of $8 \mathrm{mg} / \mathrm{L}$ in a high percentage of patients. To prevent treatment failure for individual patients and to prevent development of antibiotic resistance on population level, we suggest increasing the standard dose of amoxicillin/clavulanic acid to 6 times a day in patients with an Enterobacteriaceae sepsis or intra-abdominal infection.

\section{Acknowledgements}

We acknowledge the support provided by department of Clinical Chemistry and the Pharmacy laboratory. We also acknowledge the assistance of Dr. Bekers and the excellent technical assistance of Jeroen Welzen and Pauline Vinken. This work was supported by Care and Public Health Research Institute (CAPHRI), Maastricht, the Netherlands and the Medical University Centre Maastricht, the Netherlands. 


\section{References}

1. Craig WA: Antimicrobial resistance issues of the future. Diagn Microbiol Infect Dis 1996, 25(4):213-217.

2. Vogelman B, Craig WA: Kinetics of antimicrobial activity. J Pediatr 1986, 108(5 Pt 2):835840 .

3. Craig WA: Interrelationship between pharmacokinetics and pharmacodynamics in determining dosage regimens for broad-spectrum cephalosporins. Diagn Microbiol Infect Dis 1995, 22(1-2):89-96.

4. Adam D, de Visser I, Koeppe P: Pharmacokinetics of amoxicillin and clavulanic acid administered alone and in combination. Antimicrob Agents Chemother 1982, 22(3):353357.

5. Sjovall J, Alvan G, Huitfeldt B: Intra- and inter-individual variation in pharmacokinetics of intravenously infused amoxycillin and ampicillin to elderly volunteers. British journal of clinical pharmacology 1986, 21(2):171-181.

6. Matsuura M, Nakazawa H, Hashimoto T, Mitsuhashi S: Combined antibacterial activity of amoxicillin with clavulanic acid against ampicillin-resistant strains. Antimicrob Agents Chemother 1980, 17(6):908-911.

7. van Zanten AR, Polderman KH, van Geijlswijk IM, van der Meer GY, Schouten MA, Girbes AR: Ciprofloxacin pharmacokinetics in critically ill patients: a prospective cohort study. $J$ Crit Care 2008, 23(3):422-430.

8. Haeseker M, Stolk L, Nieman F, Hoebe C, Neef C, Bruggeman C, Verbon A: The ciprofloxacin target AUC : MIC ratio is not reached in hospitalized patients with the recommended dosing regimens. British journal of clinical pharmacology 2013, 75(1):180185 .

9. Aubert G, Carricajo A, Coudrot M, Guyomarc'h S, Auboyer C, Zeni F: Prospective determination of serum ceftazidime concentrations in intensive care units. Ther Drug Monit 2010, 32(4):517-519.

10. Rea RS, Capitano B, Bies R, Bigos KL, Smith R, Lee H: Suboptimal aminoglycoside dosing in critically ill patients. Ther Drug Monit 2008, 30(6):674-681.

11. EUCAST: Amoxicillin Rationale for the EUCAST clinical breakpoints. http://www.eucast.org/documents/rd/ 2010.

12. http://www.trialregister.nl/trialreg/admin/rctview.asp?TC=1725.

13. FDA.: Guidance for Industry. Bioanalytical Method Validation, U.S. Department of Health and Food Science, Rockville, MD, USA, Food and Drug Administration (FDA). 2001.

14. Review of the $\mathbf{1 9 9 3}$ Veterinary Drug Bioequivalence Workshop, held on March 29-31, 1993, in Rockville, Maryland. Journal of veterinary pharmacology and therapeutics 1994, 17(2):85-119.

15. Pullen J, Stolk LM, Neef C, Zimmermann LJ: Microanalysis of amoxicillin, flucloxacillin, and rifampicin in neonatal plasma. Biomed Chromatogr 2007, 21(12):1259-1265.

16. Proost $\mathrm{JH}$, Meijer DK: MW/Pharm, an integrated software package for drug dosage regimen calculation and therapeutic drug monitoring. Computers in biology and medicine 1992, 22(3):155-163.

17. van der Meer AF, Marcus MA, Touw DJ, Proost JH, Neef C: Optimal sampling strategy development methodology using maximum a posteriori Bayesian estimation. Ther Drug Monit 2011, 33(2):133-146.

18. Turnidge JD: The pharmacodynamics of beta-lactams. Clin Infect Dis 1998, 27(1):10-22.

19. Blaettler L, Mertz D, Frei R, Elzi L, Widmer AF, Battegay M, Fluckiger U: Secular trend and risk factors for antimicrobial resistance in Escherichia coli isolates in Switzerland 1997-2007. Infection 2009, 37(6):534-539.

20. SWAB: Consumption of antimicrobial agents and antimicrobial resistance among medically important bacteria in the Netherlands. http://www.swab.nl/2011.

21. de Abajo FJ, Montero D, Madurga M, Garcia Rodriguez LA: Acute and clinically relevant drug-induced liver injury: a population based case-control study. British journal of clinical pharmacology 2004, 58(1):71-80.

22. Garcia Rodriguez LA, Stricker BH, Zimmerman HJ: Risk of acute liver injury associated with the combination of amoxicillin and clavulanic acid. Archives of internal medicine 1996, 156(12):1327-1332. 
23. Salvo F, Polimeni G, Moretti U, Conforti A, Leone R, Leoni O, Motola D, Dusi G, Caputi AP: Adverse drug reactions related to amoxicillin alone and in association with clavulanic acid: data from spontaneous reporting in Italy. J Antimicrob Chemother 2007, 60(1):121126.

24. Bolzan H, Spatola J, Castelletto R, Curciarello J: [Intrahepatic cholestasis induced by amoxicillin alone]. Gastroenterologia y hepatologia 2000, 23(5):237-239.

25. Schwarze C, Schmitz V, Fischer HP, Sauerbruch T, Spengler U: Vanishing bile duct syndrome associated with elevated pancreatic enzymes after short-term administration of amoxicillin. European journal of gastroenterology \& hepatology 2002, 14(11):1275-1277.

26. Aguilar L, Martin M, Balcabao IP, Gomez-Lus ML, Dal-Re R, Prieto J: In vitro assessment of the effect of clavulanic acid at concentrations achieved in human serum on the bactericidal activity of amoxicillin at physiological concentrations against Staphylococcus aureus: implications for dosage regimens. Antimicrob Agents Chemother 1997, 41(6): 1403-1405.

27. Cooper CE, Slocombe B, White AR: Effect of low concentrations of clavulanic acid on the in-vitro activity of amoxycillin against beta-lactamase-producing Branhamella catarrhalis and Haemophilus influenzae. J Antimicrob Chemother 1990, 26(3):371-380.

28. Mouton JW, Punt N, Vinks AA: Concentration-effect relationship of ceftazidime explains why the time above the MIC is $\mathbf{4 0}$ percent for a static effect in vivo. Antimicrob Agents Chemother 2007, 51(9):3449-3451. 


\section{Chapter 6}

\section{Vancomycin dosing in neutropenic patients}

M.B. Haeseker, S. Croes, C. Neef, C.A. Bruggeman, L.M.L. Stolk and A.Verbon

PLoS ONE 2014:9(11):e112008 


\begin{abstract}
Introduction. To compare vancomycin pharmacokinetic parameters in patients with and without neutropenia.

Methods. Patients $\geq 18$ years admitted on general wards were included. Routinely vancomycin trough and peak plasma concentrations were measured with a fluorescence polarization immunoassay. Pharmacokinetic parameters of individual patients were determined with maximum a posterior Bayesian estimation (MW Pharm 3.60). Neutropenia was defined as neutrophils $<0.5 \times 10^{9}$ cells $/ \mathrm{L}$.

Results. A total of 171 patients were included. Patients with neutropenia $(n=56)$ had higher clearance of vancomycin (CLva), $67( \pm 26) \mathrm{mL} / \mathrm{min}$, compared to patients without neutropenia $(\mathrm{n}=115)$, CLva $50( \pm 22) \mathrm{mL} / \mathrm{min}(P<0.001)$. No significant difference was found in serum creatinine and vancomycin volume of distribution. Neutropenia was positively associated with CLva, independently of relevant covariables (B: $12.122,95 \% \mathrm{CI}: 1.095$ to $23.149, P=0.031$ ). On average patients with neutropenia needed $33 \%$ higher doses of vancomycin to attain adequate exposure, i.e. $\mathrm{AUC}_{24} \geq 400 \mathrm{mg} \times \mathrm{h} / \mathrm{L}$. Furthermore, 15 initially neutropenic patients in our study group received vancomycin for a second administration period. Ten patients received the second administration period during another neutropenic period and 5 patients during a non-neutropenic phase. All 5 patients with vancomycin during both neutropenic and non-neutropenic phase had higher CLva $(91( \pm 26) \mathrm{mL} / \mathrm{min})$ during the neutropenic period and lower CLva $(45( \pm 10) \mathrm{mL} / \mathrm{min})$ during the nonneutropenic phase $(P=0.009)$.

Conclusion. This study shows that most patients with neutropenia have augmented CLva. In a small group of patients that received vancomycin during two episodes, the augmented CLva seems to be reversible in the non-neutropenic period. Our data indicate that it is important to increase the daily dose with one third in patients with neutropenia (from $15 \mathrm{mg} / \mathrm{kg}$ twice daily to $13 \mathrm{mg} / \mathrm{kg}$ three times daily). Frequent performance of therapeutic drug monitoring in patients with neutropenia may prevent both therapy failure due to low AUCs and overcomes toxicity due to high vancomycin trough concentrations during recovery from neutropenia.
\end{abstract}




\section{Introduction}

Mortality from infections after cytostatic conditioning regimens in hematologic neutropenic patients requiring hematopoietic cell transplantation is high [1]. Bacterial infections are common during neutropenic phases and antibiotics, such as vancomycin, are often required [2]. In a recent surveillance study, Gram positive organisms are the most common cause of bacteremia in hematology patients, i.e. coagulase negative staphylococci (36\%), followed by, Streptococci (11\%), S. aureus $(8 \%)$ and Enterococci (4\%) [3]. Antibiotics should be started within 1 hour in patients with severe sepsis. However, adequate dosing of vancomycin can be difficult. Augmented clearance has been increasingly described in critically ill patients at the Intensive Care Unit (ICU) [4-6]. Changes in volume of distribution $(\mathrm{Vd})$, changes in renal function and severe hypoalbuminemia are often present, influencing vancomycin plasma concentrations. Augmented clearance of vancomycin leads to lower vancomycin plasma concentrations, decreased 24-hour area under the curve $\left(\mathrm{AUC}_{24}\right)$ and leads to diminished clinical outcome [6]. Augmented clearance of vancomycin in patients with hematological malignancies has been reported, but the augmented clearance was not associated with population specific covariables [7]. In another study low teicoplanin trough concentrations in neutropenic patients were reported, suggesting augmented clearance of teicoplanin in neutropenic patients [8]. In addition, elevated clearance of piperacillin and ceftazidime has also been noticed in patients with febrile neutropenia $[9,10]$. The mechanism of augmented clearance of antibiotics is not completely understood and is poorly investigated in patients with hematologic malignancies or in patients with neutropenia. The aim of this study is to compare vancomycin pharmacokinetic parameters in patients with and without neutropenia at non-ICUs in a University Hospital. 


\section{Methods}

\section{Study group}

In this observational study patients were prospectively followed. Patients older than 18 years treated with vancomycin intravenously (iv) and hospitalized at the Maastricht University Medical Centre (MUMC), a 715 bed university hospital, were included from May 2011 until July 2013. Patients were excluded when admitted at the ICU or when insufficient data was collected. Vancomycin was started at the discretion of the attending physician, either empirically or as therapy for bacteria susceptible to vancomycin. Dose individualization was applied since an initial loading dose of $15 \mathrm{mg} / \mathrm{kg}$ was followed by dose adjustment based on therapeutic drug monitoring (TDM) and renal function. Demographic and clinical data, such as age, gender, weight, temperature, co-medication, length of hospital stay, time of administration of vancomycin and laboratory parameters, such as, serum creatinine (Jaffé method), and leucocytes were retrieved from the electronic patient file (SAP®, the Netherlands). Neutropenia was defined as $<0.5 \times 10^{9}$ cells $/ \mathrm{L}$. Creatinine clearance (CLcr) was calculated with the Cockcroft and Gault formula [(140 - age in years $) \times$ weight in $\mathrm{kg}] /$ [serum creatinine in $\mu \mathrm{mol} \times$ factor] using total bodyweight [11].

\section{Ethics statement}

This study was conducted according to the principles expressed in the Declaration of Helsinki. This study was registered at the Dutch Trial Register (NTR 1725). The Medical Ethical Committee of the Maastricht University Medical Centre (MEC 08-4-063) approved this study and waived the necessity to obtain informed consent from participants because of the observational design. Electronic health records were anonymized prior to use.

\section{Measurement of vancomycin}

Vancomycin plasma concentrations were measured as standard clinical care with a fluorescence polarization immune assay using of Cobas Integra 800 system (Roche Diagnostics®). The calibration curve ranged from 2.0 to $80 \mathrm{mg} / \mathrm{L}$. The accuracy and coefficients of variation (CV) of the controls $(6.9,17.7$ and $31.0 \mathrm{mg} / \mathrm{L})$ were within $90 \%-110 \%$ and $<3.3 \%$, respectively. Patients with at least two plasma samples available, drawn in such a manner to ensure calculations of vancomycin clearance (CLva) were included. Blood samples were collected at least one hour after the end of infusion and trough levels were obtained just before the next dose.

\section{PK-analysis}

Pharmacokinetic parameters (CLva, Vd) of vancomycin in individual patients were calculated with maximum a posterior (MAP) Bayesian estimation computer program (MW/Pharm 3.60, Mediware, the Netherlands). Bayesian priors from a two compartment open pharmacokinetic model based on previous studies, were applied: V1 $0.21 \pm 0.04 \mathrm{~L} / \mathrm{kg}, \mathrm{k}_{\mathrm{elm}} 0.0143 \pm 0.0029 \mathrm{~h}^{-1}, \mathrm{k}_{\mathrm{elr}}=\mathrm{k}_{\text {slope }} \times \mathrm{CLcr}$ $(\mathrm{mL} / \mathrm{min}), 0.00327 \pm 0.00109 \mathrm{~h}^{-1} / \mathrm{mL} / \mathrm{min}, \mathrm{k}_{12} 1.12 \pm 0.28 \mathrm{~h}^{-1}$, and $\mathrm{k}_{21} 0.48 \pm 0.12 \mathrm{~h}^{-1}$ $[12,13]$, where $\mathrm{V} 1$ is volume of distribution central compartment $(\mathrm{L} / \mathrm{kg}) ; \mathrm{k}_{\mathrm{elm}}$, metabolic elimination rate constant $\left(\mathrm{h}^{-1}\right) ; \mathrm{k}_{\text {slope }}$, renal elimination rate constant $\left(\mathrm{h}^{-}\right.$ 
$1 / \mathrm{mL} / \mathrm{min}) ; \mathrm{k}_{\mathrm{elr}}$, renal elimination rate constant $\left(\mathrm{h}^{-1}\right) ; \mathrm{k}_{12}\left(\mathrm{~h}^{-1}\right)$, rate constant from the $1^{\text {st }}$ to the $2^{\text {nd }}$ compartment; and $\mathrm{k}_{21}\left(\mathrm{~h}^{-1}\right)$, vice versa. The elimination rate constant $\mathrm{k}_{\mathrm{el}}$ $=\mathrm{k}_{\mathrm{elm}}+\mathrm{k}_{\mathrm{elr}}=\mathrm{k}_{\mathrm{elm}}+\left(\mathrm{k}_{\text {slope }} \times\right.$ CLcr $)$ [14]. With MAP Bayesian estimation all patient characteristics and measured vancomycin concentrations are fitted on an existing population model. With at least two concentrations per patient individual pharmacokinetic parameters can be adequately derived with MAP Bayesian estimation $[15,16]$. With these individual pharmacokinetic parameters, dosing simulations were made to adjust the dose individually; this MAP Bayesian estimation is a standard procedure in institutes which provide TDM service.

The $\mathrm{AUC}_{24}$ in steady-state was calculated with the formula: 24-hour dose/CLva.

\section{Analysis of patients with and without neutropenia}

Pharmacokinetic, clinical and demographic parameters were compared in patients with and without neutropenia in all patients and in patients with hematological malignancies. Furthermore, pharmacokinetic parameters of two vancomycin administration periods within the same patients were compared. Both patients with two vancomycin administrations during two different neutropenia periods and patients with two vancomycin administrations during one neutropenia period and one period without neutropenia were compared.

\section{Statistical analysis}

Normal distribution was evaluated for metric variables by means of the Shapiro-Wilk test and presented as mean $( \pm \mathrm{SD})$. If not, median and ranges were given. Categorical variables are presented as frequencies and percentages. Metric and categorical variables were evaluated between patients with and without neutropenia using the Student t-test or non-parametric test (Kruskal Wallis), respectively.

First, the influence of co-variables on CLva was determined in univariable (Pearson) analysis. Subsequently, only the significant co-variables in the univariable analyses were included in the multivariable analysis, after checking the assumptions. The Enter method was used in the multivariable linear regression. CLcr is estimated with the C\&G formula which includes serum creatinine, age, weight and gender [11]. To avoid multicollinearity, serum creatinine, age, weight and gender were left out of the multivariable model. Data analysis was done with IBM SPSS-pc version 20.0. A p-value of $<0.05$ was considered to be statistically significant. 


\section{Results}

\section{Study group}

The mean age was $59( \pm 14)$ years and $61 \%$ were male. Patients were admitted on different general wards; hematology ward $(40 \%, 68 / 171)$, surgery ward $(19 \%, 32 / 171)$, internal ward $(11 \%, 19 / 171)$, neurosurgery ward $(11 \%, 18 / 171)$, orthopedic ward $(10 \%, 17 / 171)$, cardiac $(9 \%, 15 / 171)$ and eye ward $(1 \%, 2 / 171)$. The majority of patients had sepsis $(46 \%, 79 / 171)$, implant infection $(16 \%, 27 / 171)$ or abdominal infection $(15 \%, 25 / 171)$. A total of 171 patients with a mean $( \pm S D)$ of $6( \pm 3)$ vancomycin plasma concentrations were included.

\section{Pharmacokinetics analysis}

The mean dose $( \pm \mathrm{SD})$ of vancomycin per 24 hours was $1683( \pm 759) \mathrm{mg}$, with a mean $\mathrm{Vd}$ of $58( \pm 30) \mathrm{L}$ and $\mathrm{AUC}_{24}$ of $502( \pm 97) \mathrm{mg} \times \mathrm{h} / \mathrm{L}$. The mean $( \pm \mathrm{SD})$ trough concentration in steady state $(\mathrm{SS})$ was $13( \pm 4) \mathrm{mg} / \mathrm{L}, \mathrm{CmeanSS}$ was $21( \pm 4)$ $\mathrm{mg} / \mathrm{L}$, peak concentration in SS was $49( \pm 14) \mathrm{mg} / \mathrm{L}$, CLva was $56( \pm 25) \mathrm{mL} / \mathrm{min}$ and serum creatinine was $89( \pm 68) \mu \mathrm{mol} / \mathrm{L}$.

\section{Analysis of patients with and without neutropenia}

Sixty eight patients had a hematological malignancy and 56 patients were neutropenic, Figure 1. Neutropenic patients $(n=56)$ had higher CLva, $67( \pm 26)$ $\mathrm{mL} / \mathrm{min}$, compared to non-neutropenic patients $(\mathrm{n}=115)$, CLva $50( \pm 22) \mathrm{mL} / \mathrm{min}$ $(P<0.001)$. No significant difference in serum creatinine and $\mathrm{Vd}$ was found, Table 1 and Figure 1. Forty eight percent (27/56) of the neutropenic patients had CLva>70 $\mathrm{mL} / \mathrm{min}$, compared to $21 \%(24 / 115)$ without neutropenia. Of the 68 patients with a hematological malignancy, 55 patients were neutropenic and 13 were not neutropenic. Within the hematologic malignancy patients, neutropenic patients had higher CLva, than non-neutropenic patients, Table 1 and Figure 2. Physicians used TDM and adjusted vancomycin dosing as shown by the mean dose of vancomycin in patients with neutropenia of $2017( \pm 720) \mathrm{mg}$ compared to $1521( \pm 727) \mathrm{mg}$ in patients without neutropenia, $P<0.001$. On average, among patients with neutropenia the daily vancomycin dose was $33 \%$ (500 mg/day) higher to achieve the same $\mathrm{AUC}_{24}$ (Table 1). Patients with sepsis $(\mathrm{n}=79)$ had higher CLva and were younger than patients without sepsis $(n=92) . V d$ and CLcr were not different, Table 2. Neutropenic patients with sepsis $(n=47)$ seemed to have slightly higher CLva of 69 $( \pm 27) \mathrm{mL} / \mathrm{min}$ than neutropenic patients without sepsis $(\mathrm{n}=9)$ CLva $60( \pm 22)$ $\mathrm{mL} / \mathrm{min}, P=0.269$. Both neutropenic patients with sepsis and without sepsis had higher CLva than non-neutropenic patients.

Of the 171 patients, 15 neutropenic patients received a second period of vancomycin, of which 5 patients received vancomycin during both an neutropenic and non neutropenic period. Ten patients received two vancomycin episodes during neutropenic periods. However, 3 patients developed kidney failure and were taken out. Leaving 7 patients with two vancomycin periods during neutropenia, Figure 1. Therefore, the data of 7 patients with two neutropenic periods and 5 patients with both a neutropenic and non-neutropenic period could be compared. The median (range) of time between the two vancomycin administrations was 30 (20-108) days for these 7 patients and 21 (14-136) days for the 5 patients with both a neutropenic 


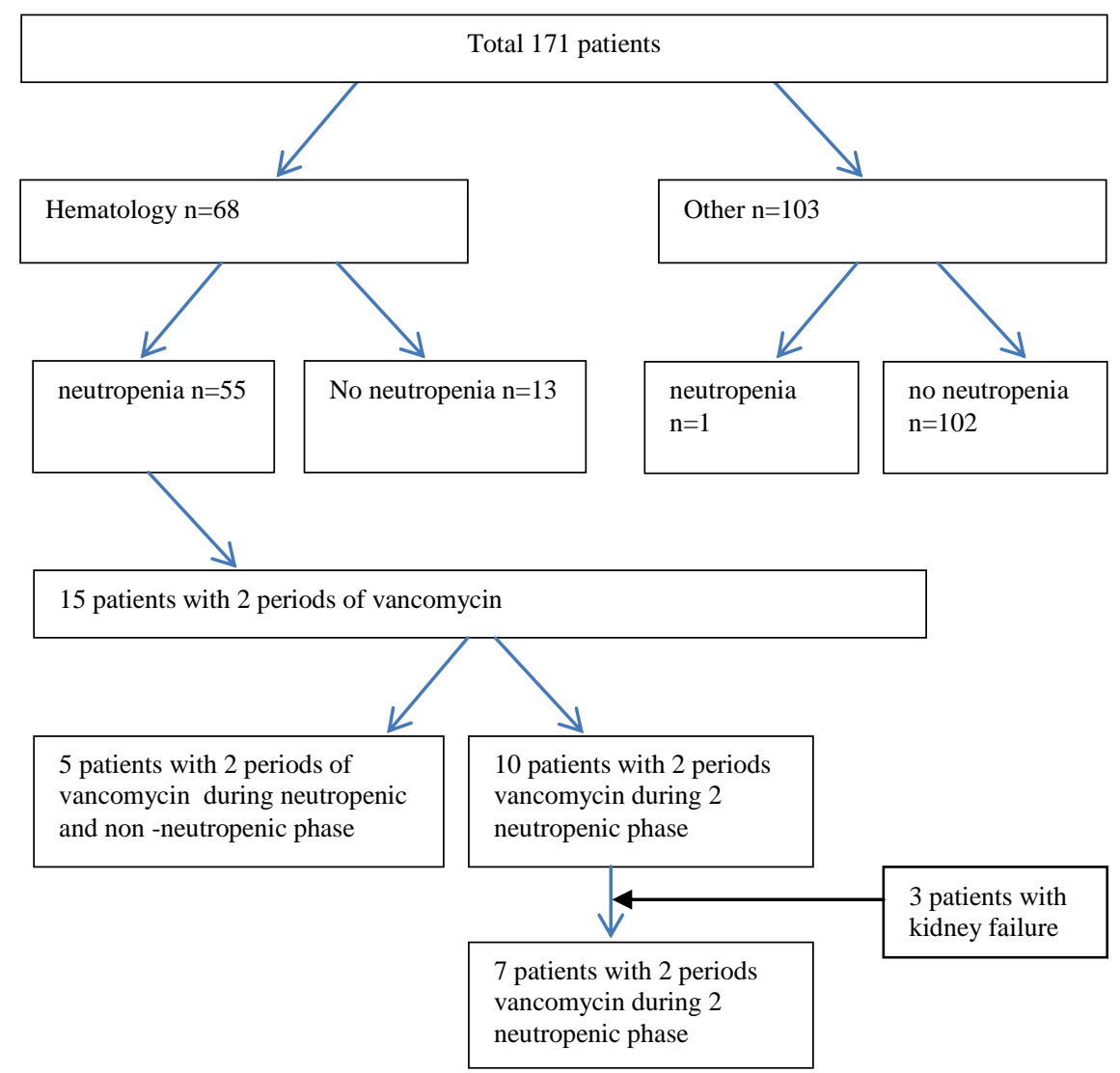

Figure 1. Flow of the 171 included patients with regard to hematology, neutropenia and two vancomycin administration periods.

Table 1. Mean $( \pm \mathrm{SD})$ for Age, CLcr, CLva, Vd, Dose $24 \mathrm{~h}$ and $\mathrm{AUC}_{24}$ of patients with and without neutropenia in all patients (A) and in patients with haematological malignancy (B)

\begin{tabular}{|c|c|c|c|c|c|c|c|c|}
\hline \multicolumn{9}{|c|}{ A] All patients $(n=171)$} \\
\hline $\begin{array}{l}\text { Neutro- } \\
\text { penia }\end{array}$ & $\mathrm{N}$ & $\begin{array}{l}\text { Age } \\
\text { year }\end{array}$ & $\begin{array}{l}\mathrm{CLcr} \\
\mathrm{mL} / \mathrm{min}\end{array}$ & $\begin{array}{l}\text { CLva } \\
\mathrm{mL} / \mathrm{min}\end{array}$ & $\begin{array}{l}\text { Creatinine } \\
\mu \mathrm{mol} / \mathrm{L}\end{array}$ & $\begin{array}{l}\text { Vd } \\
\mathrm{L}\end{array}$ & $\begin{array}{l}\text { Dose 24h } \\
\text { mg }\end{array}$ & $\begin{array}{l}\mathrm{AUC}_{24} \\
\mathrm{mg} \times \mathrm{h} / \mathrm{L}\end{array}$ \\
\hline No & $\begin{array}{l}11 \\
5\end{array}$ & $61( \pm 14)$ & $107( \pm 78)$ & $50( \pm 22)$ & $95( \pm 67)$ & $56( \pm 29)$ & $1521( \pm 727)$ & $499( \pm 102)$ \\
\hline $\begin{array}{l}\text { Yes } \\
P\end{array}$ & 56 & $\begin{array}{l}55( \pm 13) \\
0.01\end{array}$ & $\begin{array}{l}113( \pm 57) \\
0.142\end{array}$ & $\begin{array}{l}67( \pm 26) \\
<0.001\end{array}$ & $\begin{array}{l}80( \pm 31) \\
0.873\end{array}$ & $\begin{array}{l}62( \pm 32) \\
0.304\end{array}$ & $\begin{array}{l}2017( \pm 719) \\
<0.001\end{array}$ & $\begin{array}{l}507( \pm 87) \\
0.259\end{array}$ \\
\hline \multicolumn{9}{|c|}{ B] Patients with haematological malignancy $(n=68)$} \\
\hline $\begin{array}{l}\text { Neutro- } \\
\text { penia }\end{array}$ & $\mathrm{N}$ & $\begin{array}{l}\text { Age } \\
\text { Year }\end{array}$ & $\begin{array}{l}\text { CLcr } \\
\mathrm{mL} / \mathrm{min}\end{array}$ & $\begin{array}{l}\text { CLva } \\
\mathrm{mL} / \mathrm{min}\end{array}$ & $\begin{array}{l}\text { Creatinine } \\
\mu \mathrm{mol} / \mathrm{L}\end{array}$ & $\begin{array}{l}\mathrm{Vd} \\
\mathrm{L}\end{array}$ & $\begin{array}{l}\text { Dose } 24 \mathrm{~h} \\
\mathrm{mg}\end{array}$ & $\begin{array}{l}\mathrm{AUC}_{24} \\
\mathrm{mg} \times \mathrm{h} / \mathrm{L}\end{array}$ \\
\hline No & 13 & $57( \pm 11)$ & $111( \pm 58)$ & $53( \pm 16)$ & $96( \pm 59)$ & $59( \pm 18)$ & $1604( \pm 646)$ & $502( \pm 102)$ \\
\hline Yes & 55 & $55( \pm 14)$ & $114( \pm 57)$ & $68( \pm 26)$ & $79( \pm 29)$ & $62( \pm 32)$ & $2040( \pm 705)$ & $509( \pm 87)$ \\
\hline$P$ & & 0.839 & 0.714 & 0.024 & 0.779 & 0.691 & 0.028 & 0.697 \\
\hline
\end{tabular}

CLva: vancomycin clearance

CLcr: creatinine clearance calculated from serum creatinine with Cockcroft and Gault [11]

Vd: volume of distribution

AUC: 24 hour area under the curve 
Table 2. Mean $( \pm$ SD) for Age, CLcr, CLva, Vd, Creatinine for patients with sepsis and without sepsis.

\begin{tabular}{lllllll}
\hline & N & $\begin{array}{l}\text { Age } \\
\text { years }\end{array}$ & $\begin{array}{l}\text { CLva } \\
\mathbf{m L} / \mathbf{m i n}\end{array}$ & $\begin{array}{l}\text { Vd } \\
\text { L }\end{array}$ & $\begin{array}{l}\text { CLcr } \\
\mathbf{m L} / \mathbf{m i n}\end{array}$ & $\begin{array}{l}\text { Creatinine } \\
\boldsymbol{\mu m o l} / \mathbf{L}\end{array}$ \\
\hline Sepsis & 79 & $56( \pm 13)$ & $60( \pm 27)$ & $57( \pm 26)$ & $108( \pm 56)$ & $84( \pm 38)$ \\
No sepsis & 92 & $61( \pm 14)$ & $52( \pm 23)$ & $58( \pm 33)$ & $110( \pm 83)$ & $96( \pm 71)$ \\
$P$ & & 0.017 & 0.048 & 0.639 & 0.535 & 0.894 \\
\hline
\end{tabular}

CLva: vancomycin clearance

CLcr: creatinine clearance calculated from serum creatinine with Cockcroft and Gault [11]

Vd: volume of distribution

and non neutropenic period. For the 7 patients with vancomycin administrations in two neutropenic periods, the CLva remained similar: $77( \pm 30)$ to $70( \pm 23) \mathrm{mL} / \mathrm{min}$ $(P=0.748)$, as did the serum creatinine $68( \pm 13)$ to $66( \pm 11) \mu \mathrm{mol} / \mathrm{L}(P=0.701)$ and CLcr $120( \pm 41)$ to $117( \pm 35) \mathrm{mL} / \mathrm{min}(P=0.848)$. The 5 patients with vancomycin administrations in both a neutropenic and non-neutropenic period had a statistically significantly higher CLva, $91( \pm 26) \mathrm{mL} / \mathrm{min}$, during the neutropenic phase compared to CLva, $45( \pm 10) \mathrm{mL} / \mathrm{min}$ during the non-neutropenic phase $(P=0.009)$. Serum creatinine, $65( \pm 10)$ and $69( \pm 11) \mu \mathrm{mol} / \mathrm{L}(P=0.462)$ and CLcr, $141( \pm 70)$ and 113 $( \pm 48) \mathrm{mL} / \mathrm{min}$ during the neutropenic and non-neutropenic periods, respectively, were not significantly different $(P=0.402)$, Figure 3 and neither was the $\mathrm{Vd}$ was 74 $( \pm 24)$ L during neutropenic and $51( \pm 10)$ L during non-neutropenic phase $(P=0.175)$.
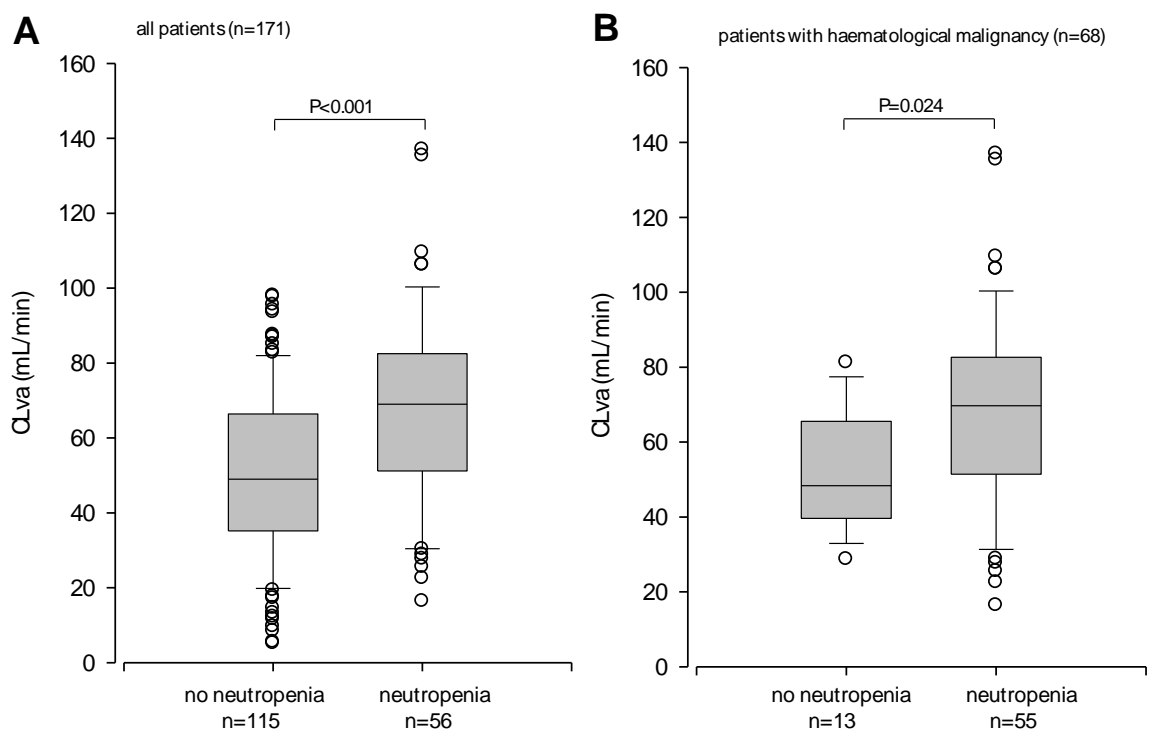

Figure 2. Boxplot for vancomycin clearance (CLva) in patients with and without neutropenia in all patients (A) and in patients with haematological malignancy (B). Lower and higher boundary of the box indicates $25^{\text {th }}$ and $75^{\text {th }}$ percentile, respectively, the line within the box marks the median, the whiskers above and below the box indicate the $90^{\text {th }}$ and $10^{\text {th }}$ percentiles and the open circles indicate outside the $90^{\text {th }}$ and $10^{\text {th }}$ percentiles. 

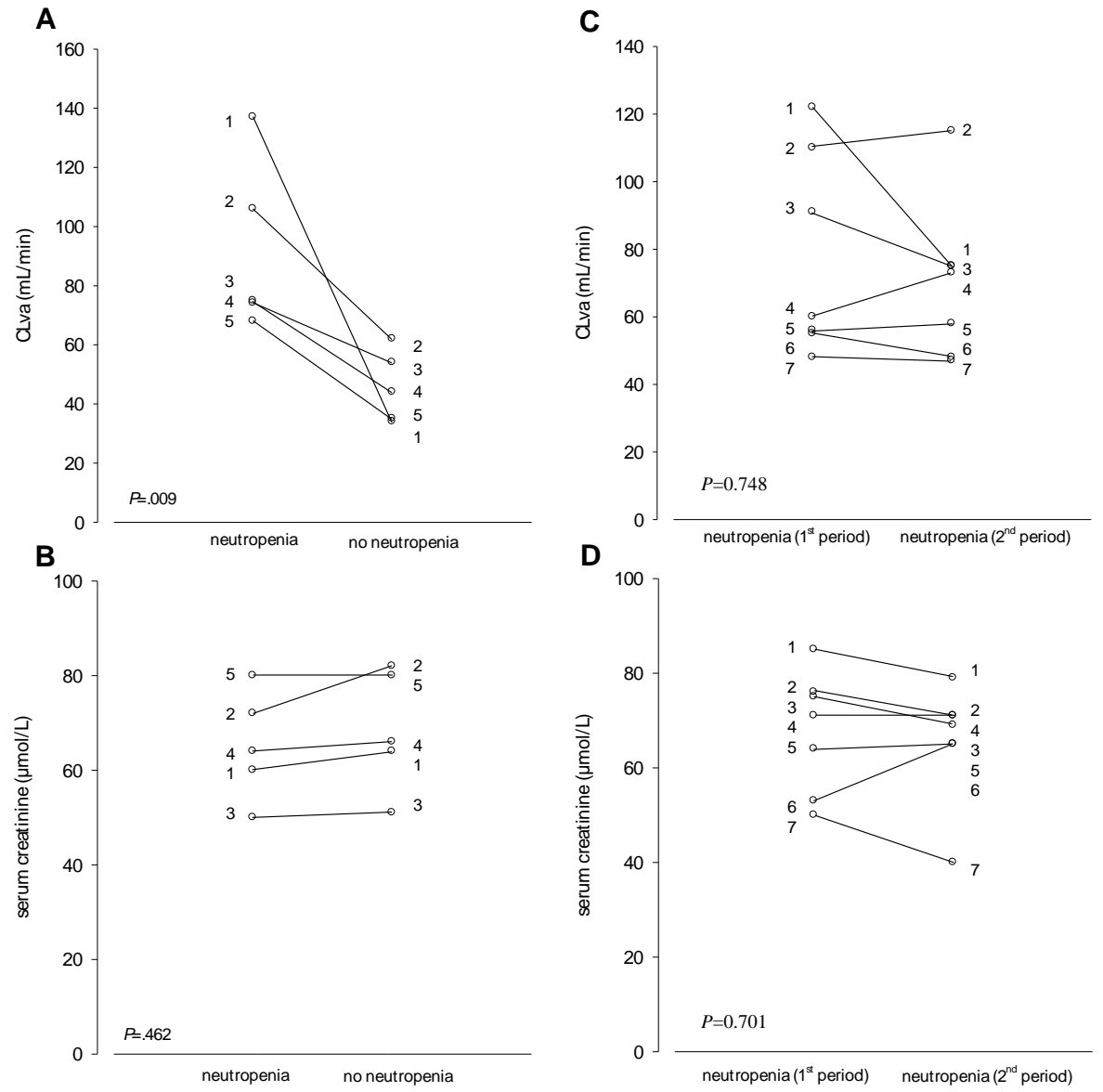

Figure 3. A. Vancomycin clearance (CLva) and B. serum creatinine of 5 patients (number 1-5) during both a neutropenic and a non-neutropenic phase and C. CLva and D. serum creatinine of 7 patients (number 1-7) during two neutropenic phases.

CLcr, neutropenia, hematologic malignancy and sepsis were correlated with CLva in the univariable analysis, Table 3. In the multivariable analysis, CLva was positively associated with CLcr (B: 0.205, 95\%CI: 0.164-0.245, $P<0.001)$ and neutropenia (B: 12.122, 95\%CI: 1.095 to $23.149, P=0.031$ ), Table 3 . 
Table 3. Univariable and multivariable correlation coefficients between CLva and predictors used in this study.

\begin{tabular}{|c|c|c|c|c|c|c|}
\hline & \multicolumn{2}{|c|}{ Univariable $^{\mathrm{a}}$} & \multicolumn{4}{|c|}{ Multivariable $^{\mathrm{b}}$} \\
\hline & $\mathrm{R}$ & $P$-value & $\mathrm{B}$ & $95 \%$ confidence & interval for B & $P$-value \\
\hline & & & & Lower bound & Upper bound & \\
\hline CLcr & 0.599 & $<0.001$ & 0.205 & 0.164 & 0.245 & $<0.001$ \\
\hline Neutropenia & 0.322 & $<0.001$ & $\begin{array}{l}12.12 \\
2\end{array}$ & 1.095 & 23.149 & 0.031 \\
\hline $\begin{array}{l}\text { Hematologic } \\
\text { malignancy }\end{array}$ & 0.300 & $<0.001$ & 3.582 & -8.404 & 15.569 & 0.556 \\
\hline Sepsis & 0.170 & 0.027 & 0.427 & -7.236 & 8.090 & 0.913 \\
\hline $\mathrm{Vd}$ & 0.008 & 0.915 & - & - & - & - \\
\hline
\end{tabular}

CLva: vancomycin clearance

CLcr: creatinine clearance

$\mathrm{Vd}$ : volume of distribution

${ }^{a}$ Pearson correlation was performed as the univariable analysis

${ }^{b}$ Only co-variates that were significantly correlated with CLva in the univariable analysis $(P<0.05)$ were included in the multivariable analysis 


\section{Discussion}

Our study shows that higher doses of vancomycin are needed during neutropenic periods to achieve vancomycin target $\mathrm{AUC}_{24}$ and target trough concentrations. The augmented clearance of vancomycin in neutropenic patients seems reversible. Augmented clearance of vancomycin cannot be predicted with the estimated CLcr, as serum creatinine and estimated CLcr in our study are not significantly different in neutropenic and non-neutropenic patients. Moreover, the estimated CLcr is not reliable above $125 \mu \mathrm{mol} / \mathrm{L}$ and shows a poor agreement with measured CLcr in urine in critically ill patients displaying augmented clearance of creatinine $[17,18]$. Our Bayesian calculated CLva is in line with the population estimated CLva in patients with hematological malignancies in the simulations by Buelga et al. [7]. However, our routine patient care observations demonstrate that augmented clearance is associated with neutropenia rather than hematological malignancy and sepsis. In the multivariable analysis neutropenia (yes/no) was positively associated with CLva, independently of the other co-variables. Although, our group of patients that received a second administration of vancomycin is small, the augmented clearance of vancomycin seems to be temporarily and reversible, as the CLva returned to normal during the non-neutropenic phase. The mechanism of augmented clearance is not completely clarified; most likely more than one factor is involved in developing augmented clearance. Young age, increased blood flow to the kidneys, genetic factors and other medication has been proposed to influence the CLva [5, 6]. Neutropenia might be added to this list. Most likely augmented clearance also influences other renally cleared antibiotics [9, 10]. Therefore, TDM of these antibiotics or/and at least one 24-hour creatinine measurement in urine to determine the most accurate CLcr at the ICU is recommended $[5,19,20]$. Our data suggest that this recommendation may be extended to neutropenic patients.

Our study has a couple of limitations. Firstly, our study is a real-life observational study and we assumed the TDM protocol was strictly followed by clinicians, especially the timing of peak concentrations. Secondly, our group of patients with a second vancomycin administration was rather small to prove the demonstrated tendency of reversibility of elevated CLva, at the moment when patients are recovering from neutropenia. Further research is needed to fully understand the complex pharmacokinetics of vancomycin and other antibiotics in patients with neutropenia. A prospective study may elucidate which other factors are involved in augmented CLva, but such a study would need a multicentre design and inclusion of many patients. Until, we fully understand augmented clearance, we suggest to increase the initial daily dose of vancomycin with $33 \%(13 \mathrm{mg} / \mathrm{kg}$ three times daily) in patients with neutropenia and to perform TDM after the first vancomycin dose in patients to prevent low plasma concentrations of vancomycin and consequently reduced efficacy. When patients are recovering from neutropenia, TDM is again necessary to adjust the vancomycin dose to prevent toxicity due to high vancomycin exposure.

\section{Acknowledgements}

The authors acknowledge the support provided by department of Pharmacy laboratory and the excellent statistical advice of Casper den Heijer. 


\section{References}

1. Scott BL, Park JY, Deeg HJ, Marr KA, Boeckh M, Chauncey TR, Appelbaum FR, Storb R, Storer BE: Pretransplant neutropenia is associated with poor-risk cytogenetic features and increased infection-related mortality in patients with myelodysplastic syndromes. Biology of blood and marrow transplantation : journal of the American Society for Blood and Marrow Transplantation 2008, 14(7):799-806.

2. Sepkowitz KA: Antibiotic prophylaxis in patients receiving hematopoietic stem cell transplant. Bone marrow transplantation 2002, 29(5):367-371.

3. Schelenz S, Nwaka D, Hunter PR: Longitudinal surveillance of bacteraemia in haematology and oncology patients at a UK cancer centre and the impact of ciprofloxacin use on antimicrobial resistance. The Journal of antimicrobial chemotherapy 2013, 68(6):1431-1438.

4. Revilla N, Martin-Suarez A, Perez MP, Gonzalez FM, Fernandez de Gatta Mdel M: Vancomycin dosing assessment in intensive care unit patients based on a population pharmacokinetic/pharmacodynamic simulation. British journal of clinical pharmacology 2010, 70(2):201-212.

5. Udy AA, Roberts JA, Boots RJ, Paterson DL, Lipman J: Augmented renal clearance: implications for antibacterial dosing in the critically ill. Clinical pharmacokinetics 2010, 49(1):1-16.

6. Claus BO, Hoste EA, Colpaert K, Robays H, Decruyenaere J, De Waele JJ: Augmented renal clearance is a common finding with worse clinical outcome in critically ill patients receiving antimicrobial therapy. Journal of critical care 2013, 28(5):695-700.

7. Buelga DS, del Mar Fernandez de Gatta M, Herrera EV, Dominguez-Gil A, Garcia MJ: Population pharmacokinetic analysis of vancomycin in patients with hematological malignancies. Antimicrobial agents and chemotherapy 2005, 49(12):4934-4941.

8. Pea F, Viale P, Candoni A, Pavan F, Pagani L, Damiani D, Casini M, Furlanut M: Teicoplanin in patients with acute leukaemia and febrile neutropenia: a special population benefiting from higher dosages. Clinical pharmacokinetics 2004, 43(6):405-415.

9. Pea F, Viale P, Damiani D, Pavan F, Cristini F, Fanin R, Furlanut M: Ceftazidime in acute myeloid leukemia patients with febrile neutropenia: helpfulness of continuous intravenous infusion in maximizing pharmacodynamic exposure. Antimicrobial agents and chemotherapy 2005, 49(8):3550-3553.

10. Sime FB, Roberts MS, Warner MS, Hahn U, Robertson TA, Yeend S, Phay A, Lehman S, Lipman J, Peake SL et al: Altered pharmacokinetics of piperacillin in febrile neutropenic patients with haematological malignancy. Antimicrobial agents and chemotherapy 2014.

11. Cockcroft DW, Gault MH: Prediction of creatinine clearance from serum creatinine. Nephron 1976, 16(1):31-41.

12. Pryka RD, Rodvold KA, Garrison M, Rotschafer JC: Individualizing vancomycin dosage regimens: one- versus two-compartment Bayesian models. Therapeutic drug monitoring 1989, 11(4):450-454.

13. Rodvold KA, Pryka RD, Garrison M, Rotschafer JC: Evaluation of a two-compartment Bayesian forecasting program for predicting vancomycin concentrations. Therapeutic drug monitoring 1989, 11(3):269-275.

14. Manual MP: http://www.mwpharm.nl/downloads/documentation/UK-315-VOL3.PD.

15. van der Meer AF, Marcus MA, Touw DJ, Proost JH, Neef C: Optimal sampling strategy development methodology using maximum a posteriori Bayesian estimation. Therapeutic drug monitoring 2011, 33(2):133-146.

16. Proost JH, Meijer DK: MW/Pharm, an integrated software package for drug dosage regimen calculation and therapeutic drug monitoring. Computers in biology and medicine 1992, 22(3):155-163.

17. Grootaert V, Willems L, Debaveye Y, Meyfroidt G, Spriet I: Augmented renal clearance in the critically ill: how to assess kidney function. The Annals of pharmacotherapy 2012, 46(78):952-959.

18. Hoste EA, Damen J, Vanholder RC, Lameire NH, Delanghe JR, Van den Hauwe K, Colardyn FA: Assessment of renal function in recently admitted critically ill patients with normal serum creatinine. Nephrology, dialysis, transplantation : official publication of the European Dialysis and Transplant Association - European Renal Association 2005, 20(4):747-753. 
19. Udy AA, Putt MT, Shanmugathasan S, Roberts JA, Lipman J: Augmented renal clearance in the Intensive Care Unit: an illustrative case series. International journal of antimicrobial agents 2010, 35(6):606-608.

20. Troger U, Drust A, Martens-Lobenhoffer J, Tanev I, Braun-Dullaeus RC, Bode-Boger SM: Decreased meropenem levels in Intensive Care Unit patients with augmented renal clearance: benefit of therapeutic drug monitoring. International journal of antimicrobial agents 2012, 40(4):370-372. 


\section{Chapter 7}

Evaluation of vancomycin prediction methods based on estimated creatinine clearance and trough levels

M.B. Haeseker, S. Croes, C. Neef, C.A. Bruggeman, L.M.L Stolk and A. Verbon

Submitted Therapeutic Drug Monitoring 


\begin{abstract}
Background. The aim of this study is to investigate if vancomycin clearance (CLva) can be adequately predicted with CLva prediction methods. Additionally, other covariates influencing the CLva were investigated and predictivity of monitoring of only trough levels to 24-hour area under the curve $\left(\mathrm{AUC}_{24}\right)$ was evaluated.

Methods. Routine vancomycin plasma levels were measured with a fluorescence polarization immunoassay. Pharmacokinetic parameters of individual patients, i.e. CLva and volume of distribution, were determined with maximum a posteriori (MAP) Bayesian estimation. CLva was calculated with the three prediction methods, which are solely based on creatinine clearance (CLcr) estimated with Cockcroft and Gault formula, and it was compared with the calculated CLva with MAP Bayesian Estimation. Prediction errors were calculated. Correlations between CLva and CLcr, creatinine, age, weight, gender and neutropenia were made. Furthermore, correlations between trough levels and $\mathrm{AUC}_{24}$ were evaluated.

Results. A total of 171 patients were included. Prediction errors and absolute prediction errors of the 3 methods ranged from $28-80 \%$ and $39-83 \%$, respectively. In the multivariable analysis CLva was significantly associated with CLcr, creatinine, age, weight, gender and neutropenia. Linear correlation between $\mathrm{AUC}_{24}$ and trough levels was $\mathrm{R}^{2} 0.38$.

Conclusions. Large prediction errors make the CLva algorithms based on estimated plasma CLcr unsuitable for use in patient care. Additionally, other factors, which are not accounted for in the current algorithms, influence the CLva individually. Due to low association of $\mathrm{AUC}_{24}$ and trough levels, the $\mathrm{AUC}_{24}$ cannot be predicted with through levels. For a reliable $\mathrm{AUC}_{24}$ guided vancomycin dosing, therapeutic drug monitoring is necessary.
\end{abstract}




\section{Introduction}

Therapeutic Drug Monitoring (TDM) of vancomycin, a reserve glycopeptide antibiotic, in combination with maximum a posterior (MAP) Bayesian estimation has been routinely used in Dutch hospitals to calculate the vancomycin clearance (CLva) and to dose vancomycin optimally using the calculated 24 hour area under the curve $\left(\mathrm{AUC}_{24}\right)$. TDM is needed since vancomycin is renally cleared and dose adjustments are necessary when kidney function is reduced to prevent toxicity. Furthermore, PK/PD targets $\left(\mathrm{AUC}_{24} / \mathrm{MIC}\right.$ ratio) are necessary for an optimal antimicrobial result [1]. TDM is more labour intensive and costly, than an CLva prediction method based on CLcr. Therefore, an accurate prediction method could reduce TDM and costs. Another reason for the need of a good prediction model is that in some patients it may be difficult to obtain multiple plasma vancomycin levels. This even led to the suggestion in the Infectious Disease Society of America (IDSA) guidelines to monitor only trough levels of vancomycin [2]. Several prediction methods based on the clearance of creatinine (CLcr) have been proposed to estimate CLva. Murphy et al. showed that seven different prediction methods were insufficiently reliable to replace TDM [3], but most of the tested prediction methods consisted of small patient groups $(n=12-56)$. New approaches based on the CLcr have been proposed to predict CLva during the last years $[1,4,5]$. DeRyke et al. combined equations of two older studies into a new formula $[6,7]$. Pea et al. studied 70 critically ill patients retrospectively and prospectively tested his formula in 63 critically ill patients [4]. The key aspects of these prediction methods studies are summarized in Table 1 . The new prediction methods were suggested to be more reliable than the prediction methods reviewed by Murphy et al [1,3-5]. However, these new prediction methods are all based on CLcr calculated from serum creatinine to predict CLva. Therefore, they all depend on the method used for CLcr estimation from serum creatinine levels. Many different methods exist to estimate the CLcr, e.g. the Cockcroft-Gault (C\&G) formula [8], several Modification of Diet in Renal Disease (MDRD) formula's [1, 9, 10] and Chronic Kidney Disease Epidemiology Collaboration formula (CKD-epi) [11, 12]. It is not clear which of these methods should be used in the prediction methods.

Table 1. Key aspects of the three vancomycin clearance prediction methods.

\begin{tabular}{|c|c|c|c|}
\hline & Pea et al. & DeRyke et $a l$. & Moise-Broder et al. \\
\hline Patient population & critically ill patients & $\begin{array}{l}\text { serious systemic } \\
\text { infections }\end{array}$ & S. aureus RTI \\
\hline Vancomycin dose & $\begin{array}{l}\text { continous infusion } 30 \\
\mathrm{mg} / \mathrm{kg}\end{array}$ & $\begin{array}{l}\text { intermittent, } 15 \mathrm{mg} / \mathrm{kg} \\
\text { bd }\end{array}$ & intermittent \\
\hline CLcr estimation & $\mathrm{C} \& \mathrm{G}$ & $\mathrm{C} \& \mathrm{G}$ & $\mathrm{C} \& \mathrm{G}$ \\
\hline Formula: CLva= & $(0.29 \times$ CLcr $)+0.94$ & CLcr $\times 0.75$ & $(0.79 \times$ CLcr $)+15.4$ \\
\hline
\end{tabular}

RTI: respiratory tract infection

CLcr: creatinine clearance

C\&G: Cockcroft and Gault

CLva: vancomycin clearance 
The aim of this study is to compare the three CLva prediction methods with the MAP Bayesian estimated CLva. We also determined the strength of the association between trough levels and $\mathrm{AUC}_{24}$ in real life. Additionally, we investigated which method to estimate the CLcr is strongest associated with the CLva and which other co-variates influence the CLva. The ultimate goal is to determine whether TDM can be reduced with prediction methods and if dosing guided by trough levels only is reliable. 


\section{Materials and Methods}

\section{Study group}

This was an observational study, which collected data from routine patient care. Patients older than 18 years treated with vancomycin intravenously (iv) and hospitalised at the Maastricht University Medical Centre (MUMC), a 715 bed university hospital, were included. Vancomycin was started at the discretion of the attending physician, either empirically or as therapy for bacteria susceptible to vancomycin. Dose individualization was applied since an initial loading dose of 15 $\mathrm{mg} / \mathrm{kg}$ was followed by dose adjustment based on TDM and renal function. Vancomycin plasma levels were measured as standard clinical care with a fluorescence polarization immunoassay using of Cobas Integra 800 system (Roche Diagnostics $($ ). The calibration curve ranged from 2.0 to $80 \mathrm{mg} / \mathrm{L}$. The accuracy and coefficients of variation $(\mathrm{CV})$ of the controls $(6.9,17.7$ and $31.0 \mathrm{mg} / \mathrm{L})$ were within $90 \%-110 \%$ and $<3.3 \%$, respectively. Patients with at least two plasma samples available, drawn in such a manner to ensure calculations of CLva, were included. Blood samples were collected at least one hour after the end of infusion and trough levels were obtained just before the next dose. Demographic and clinical data, such as age, gender, weight, temperature, co-medication, length of hospital stay, time of administration of vancomycin and laboratory parameters, such as, plasma creatinine (Jaffé method), and leucocytes were retrieved from the electronic patient file (SAP®, the Netherlands). Neutropenia was defined as $<0.5 \times 10^{9}$ cells/L. Patients were excluded when admitted at the Intensive Care Unit (ICU). This study was registered at the Dutch Trial Register (NTR 1725) and was approved by the Medical Ethical Committee of the MUMC (MEC 08-4-063).

\section{Pharmacokinetic analysis}

Pharmacokinetic parameters (CLva, volume of distribution (Vd), half-life $\left(T^{1} / 2\right)$ ) of vancomycin in individual patients were calculated with MAP Bayesian estimation computer program (MW/Pharm 3.60, Mediware, the Netherlands). A two compartment open pharmacokinetic model was used. Bayesian priors from the population, established and routinely used in our institute, were applied: V1 0.21 $\pm 0.04 \mathrm{~L} / \mathrm{kg}, \mathrm{k}_{\text {elm }} 0.0143 \pm 0.0029 \mathrm{~h}^{-1}, \mathrm{k}_{\text {slope }}\left(\mathrm{k}_{\text {elr }}=\mathrm{k}_{\text {slope }} \times\right.$ CLcr $\left.(\mathrm{mL} / \mathrm{min})\right), 0.00327$ $\pm 0.00109 \mathrm{~h}^{-1} / \mathrm{mL} / \mathrm{min}, \mathrm{k}_{12} 1.12 \pm 0.28 \mathrm{~h}^{-1}$, and $\mathrm{k}_{21} 0.48 \pm 0.12 \mathrm{~h}^{-1}[13,14]$, where $\mathrm{V} 1$ is volume of distribution central compartment; $\mathrm{k}_{\mathrm{elm}}$, metabolic elimination rate constant; $\mathrm{k}_{\text {slope }}$, renal elimination rate constant; $\mathrm{k}_{\mathrm{elr}}$, renal elimination rate constant; $\mathrm{k}_{12}$, rate constant from the $1^{\text {st }}$ to the $2^{\text {nd }}$ compartment; and $\mathrm{k}_{21}$, vice versa. With MAP Bayesian estimation all patient characteristics and measured vancomycin levels are fitted on an existing population model. With two levels per patient individual steady state pharmacokinetic parameters can be adequately calculated with MAP Bayesian estimation.[15, 16] With these individual fitted pharmacokinetic parameters, dosing simulations were made to adjust the dose individually; this is standard procedure in laboratories which provide therapeutic drug monitoring service. 
CminSS (trough level steady state), CmeanSS and CmaxSS (peak level steady state) were calculated with MW/Pharm. The $\mathrm{AUC}_{24}$ in steady state (SS) was calculated with the formula: 24-hour dose/CLva.

\section{Comparison of CLcr estimation formulas}

CLcr was calculated with the C\&G formula [(140 - age in years $) \times$ weight in $\mathrm{kg}$ ] $/$ [creatinine in $\mu \mathrm{mol} \times$ factor] using total bodyweight.[8] The CLcr estimation formulas of Modification of Diet in Renal Disease-4 (MDRD-4)[11], MDRD-5 [17], MDRD-6 [10] and CKD-epi [11, 12] are described elsewhere. The $\mathrm{C} \& \mathrm{G}$ formula is based on age, weight and creatinine, the MDRD-4 is based on creatinine, age and sex, in the MDRD-5 formula plasma urea is added and in the MDRD-6 urea and albumin are added. The CKD-epi is based on plasma creatinine, sex, age and race $[11,12]$.

\section{Performance of CLva prediction methods}

CLcr with the highest linear correlation with the CLva determined with TDM was used in all CLva prediction methods: i.e. Pea et al. $0.48 \times$ CLcr +15.6 [4], DeRyke et al. $0.75 \times$ CLcr [5] and Moise-Broder et al. 0.79×CLcr +15.4 [1]. The prediction bias and precision were calculated as percentage of prediction error [= (actual value - predicted value)/actual value $\times 100 \%$ ] and as percentage of absolute prediction error $[=+($ actual value - predicted value $) /$ actual value $\times 100 \%]$.

\section{Dosing on trough levels}

Correlations between $\mathrm{AUC}_{24}$ and trough levels were determined. Attainment rates of the efficacy targets of $\mathrm{AUC}_{24} / \mathrm{MIC} \geq 400$ [1], were calculated for measured trough levels $<10,10-15,15-20$ and $>20 \mathrm{mg} / \mathrm{L}$ for simulated MIC ranges $1-2 \mathrm{mg} / \mathrm{L}$.

\section{Factors influencing the pharmacokinetics of vancomycin}

The influence of co-variates was determined using a predetermined set of predictors; correlation was calculated between CLva, CLcr, creatinine, age, weight, gender and neutropenia in univariable and multivariable analysis.

\section{Statistical analysis}

Metric variables were tested for normality of distribution by the ShapiroWilk test and presented as mean $( \pm \mathrm{SD})$. If not, median and ranges were given. Categorical variables are presented as frequencies and percentages. Univariable analysis on CLva with categorical and metric variables is either done by Student ttest or by non-parametric test (Kruskal Wallis). Pearson correlation coefficients (R) for this outcome with the dichotomous predictor (gender) and metric variables are also presented. Linear correlation $\left(\mathrm{R}^{2}\right)$ between CLcr en CLva. Bland Altmann plots were made for the 3 prediction methods. Pearson correlation coefficients $(\mathrm{R})$ and linear correlation $\left(\mathrm{R}^{2}\right)$ between trough levels and $\mathrm{AUC}_{24}$ are presented.

The influence of co-variables on CLva was determined in univariable (Pearson) analysis. Subsequently, only the significant co-variables in the univariable 
analyses were included in the multivariable analysis, after checking the assumptions. The Enter method was used in the multivariable linear regression. To avoid multicollinearity CLcr was left out of the multivariable model. Data analysis was done with IBM SPSS-pc version 20.0. A $P$-value of $<0.05$ was considered to be statistically significant. 


\section{Results}

\section{Study group}

A total of 171 patients with a mean $( \pm S D)$ of $6( \pm 3)$ vancomycin plasma levels were included from May 2011 until July 2013. The mean age was $59( \pm 14)$ years and $61 \%$ of all patients were male (Table 2). Most patients had a sepsis (46\%, 79/171), implant infection, i.e. orthopedic device, ventricular or lumbar drain and intravascular device (16\%), abdominal infection (15\%), or endocarditis $(6 \%)$, Table 2.

Table 2. Characteristics of 171 hospitalised patients.

\begin{tabular}{|c|c|}
\hline & Median (range) \\
\hline Age (years) & $60(18-88)$ \\
\hline Weight (kg) & $74(45-149)$ \\
\hline Number of blood levels & $5(2-18)$ \\
\hline Vancomycin iv (days) & $10(1-105)$ \\
\hline Admission (days) & $35(2-180)$ \\
\hline Gender & Frequency (percentage) \\
\hline - $\quad$ Male & $104(61 \%)$ \\
\hline - $\quad$ Female & $67(39 \%)$ \\
\hline Infection & Frequency (percentage) \\
\hline - $\quad$ Central venous catheter & $79(46 \%)$ \\
\hline - Abdominal infection & $25(15 \%)$ \\
\hline - Implant infection & $27(16 \%)$ \\
\hline - Endocarditis & $10(6 \%)$ \\
\hline - Osteomyelitis & $6(4 \%)$ \\
\hline - Brain abscess or meningitis & $5(3 \%)$ \\
\hline - Other & $15(9 \%)$ \\
\hline - No infection & $4(2 \%)$ \\
\hline Vancomycine in combination with & Frequency (percentage) \\
\hline - $\quad$ No other antibiotic & $47(28 \%)$ \\
\hline - $\quad$ Broadspectrum penicillin* & $65(38 \%)$ \\
\hline - Cefalosporine & $16(10 \%)$ \\
\hline - $\quad$ Meropenem & $24(14 \%)$ \\
\hline - $\quad$ Ciprofloxacin & $8(5 \%)$ \\
\hline - $\quad$ Rifampicin & $6(4 \%)$ \\
\hline - $\quad$ Other** & $5(4 \%)$ \\
\hline
\end{tabular}

*amoxicillin/clavulanic acid or piperacillin/tazobactam

** Gentamicine, linezolid and cotrimoxazol

\section{Pharmacokinetics analysis}

The mean dose $( \pm \mathrm{SD})$ per 24 hours was $1683( \pm 759) \mathrm{mg}$. The mean $\mathrm{Vd}$ was $58( \pm 30) \mathrm{L}, \mathrm{AUC}_{24}$ was $502( \pm 97) \mathrm{mg} / \mathrm{L} \times \mathrm{h}, \mathrm{CminSS}$ (trough level steady state) was $13( \pm 4) \mathrm{mg} / \mathrm{L}, \mathrm{CmeanSS}$ was $21( \pm 4) \mathrm{mg} / \mathrm{L}$ and CmaxSS (peak level steady state) was $49( \pm 14) \mathrm{mg} / \mathrm{L}$. The mean CLva calculated with MAP Bayesian estimation of all patients was $56( \pm 25) \mathrm{mL} / \mathrm{min}$. 


\section{Comparison of CLcr estimation formulas}

The mean plasma creatinine was $90( \pm 58) \mu \mathrm{mol} / \mathrm{L}$. Five different methods of estimation CLcr were compared. Using C\&G 53 (31\%) patients had a CLcr>125 $\mathrm{mL} / \mathrm{min}, 76(44 \%)$ patients $60-125 \mathrm{~mL} / \mathrm{min}$ and $42(25 \%)$ patients $\leq 60 \mathrm{~mL} / \mathrm{min}$. Using MDRD-4 39 (23\%) patients and MDRD-5 38 (22\%) patients had a CLcr $\leq 60$ $\mathrm{mL} / \mathrm{min}$. Albumin was available in only 67 patients, for the MDRD-6 and $27(40 \%)$ had a CLcr of $\leq 60 \mathrm{~mL} / \mathrm{min}$. Using CKD-epi 15 (9\%) patients had a CLcr $>125,117$ (68\%) patients $60-125$ and $39(23 \%)$ patients $\leq 60 \mathrm{~mL} / \mathrm{min}$. The best linear correlations between CLcr and CLva was $\mathrm{R}^{2} 0.50$ with C\&G followed by MDRD-5 $\mathrm{R}^{2}$ 0.47, CKD-epi $\mathrm{R}^{2} 0.43$ and MDRD-4 $\mathrm{R}^{2} 0.43$. The MDRD-6 did not improve the correlation with CLva (data not shown).

C\&G was used for calculating the CLcr, which was applied in the 3 prediction methods to predict CLva. Only patients with $C \& G \leq 125 \mathrm{~mL} / \mathrm{min}$ were used $(n=118)$, to prevent over estimation of CLcr. However, the results did not change significantly when $\mathrm{C} \& \mathrm{G}>125$ was set at $125 \mathrm{~mL} / \mathrm{min}$ (data not shown).

\section{Performance of prediction methods}

The mean estimated CLva of Moise-Broder et al. was $74( \pm 25) \mathrm{mL} / \mathrm{min}$, de Ryke et al. was $56( \pm 23) \mathrm{mL} / \mathrm{min}$ and Pea et al. was $51( \pm 15) \mathrm{mL} / \mathrm{min}$ and the mean CLva calculated with MAP Bayesian Estimation of patients with $C \& G \leq 125 \mathrm{~mL} / \mathrm{min}$ $(\mathrm{n}=118)$ was $48( \pm 22) \mathrm{mL} / \mathrm{min}$. The prediction errors were very large for Moise Broder $-80 \%$ and large for De Ryke $-28 \%$ and Pea $-29 \%$. The absolute prediction errors were also very large for Moise Broder $83 \%$ and large for De Ryke 39\% and Pea $42 \%$ (Figure 1).

\section{Dosing on trough levels}

Pearson correlation $(\mathrm{R})$ and linear correlations $\left(\mathrm{R}^{2}\right)$ between $\mathrm{AUC}_{24}$ and trough levels were 0.631 and 0.381 , respectively, Figure 2 . In Table 3 the vancomycin attainment rates $\left(\mathrm{AUC}_{24} / \mathrm{MIC}\right.$ ratios $\left.\geq 400\right)$ and trough levels are shown. Trough levels of $10-15 \mathrm{mg} / \mathrm{L}$ have $92 \%$ vancomycin attainment rate at $\mathrm{MIC}=1$ $\mathrm{mg} / \mathrm{L}$. With an increasing MIC to $>1 \mathrm{mg} / \mathrm{L}$ the vancomycin attainment rate dropped significantly (Table 3 ).

\section{Factors influencing the pharmacokinetics of vancomycin}

CLva was correlated to CLcr, creatinine, age, weight, gender and neutropenia in the univariable analysis (Table 4). In the multivariable analysis, CLva was positively associated with creatinine (B: $-0.229,95 \% \mathrm{CI}:-0.276 /-0.183$, $P<0.001$ ), age (B: $-0.43895 \%$ CI $-0.644 /-0.232, P<0.001$ ), neutropenia (B: 12.743 , 95\%CI: 2.293/23.293, $P=0.017$ ) and weight (B: 0.313 , 95\%CI 0.134/0.492, $P=0.001)$, Table 4. Patients with neutropenia $(n=56)$ had higher CLva, $67( \pm 26)$ $\mathrm{mL} / \mathrm{min}$, compared to patients without neutropenia $(\mathrm{n}=115)$, CLva $50( \pm 22) \mathrm{mL} / \mathrm{min}$ $(P<0.001)$, while no difference in plasma creatinine was noticed, $80( \pm 31)$ and 95 $( \pm 67) \mu \mathrm{mol} / \mathrm{L}$, respectively $(P=0.873)$. Patients above 70 years had lower CLva than patients younger than 70 years (Table 5). 

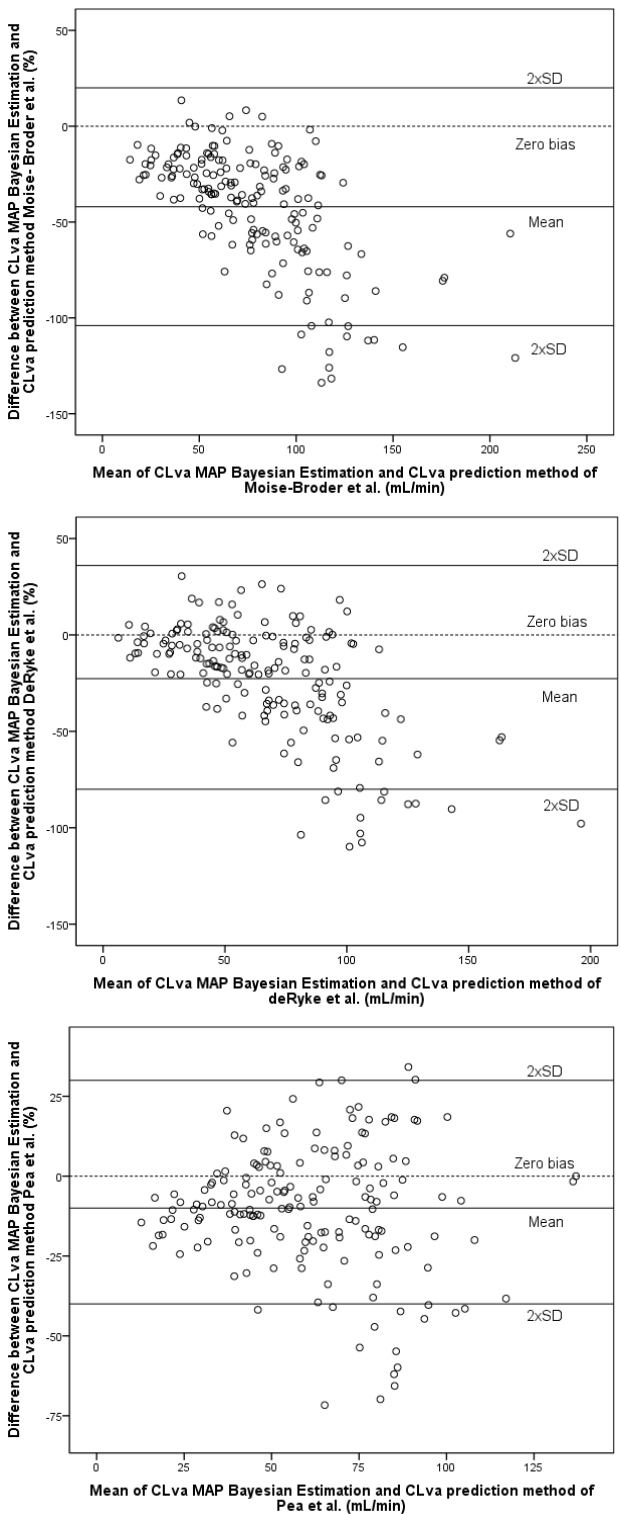

Figure 1. Bland Altmann plots for the three prediction methods, Moise-Broder et al., DeRyke et al. and Pea et al.

CLva: vancomycin clearance, SD: standard deviation. 


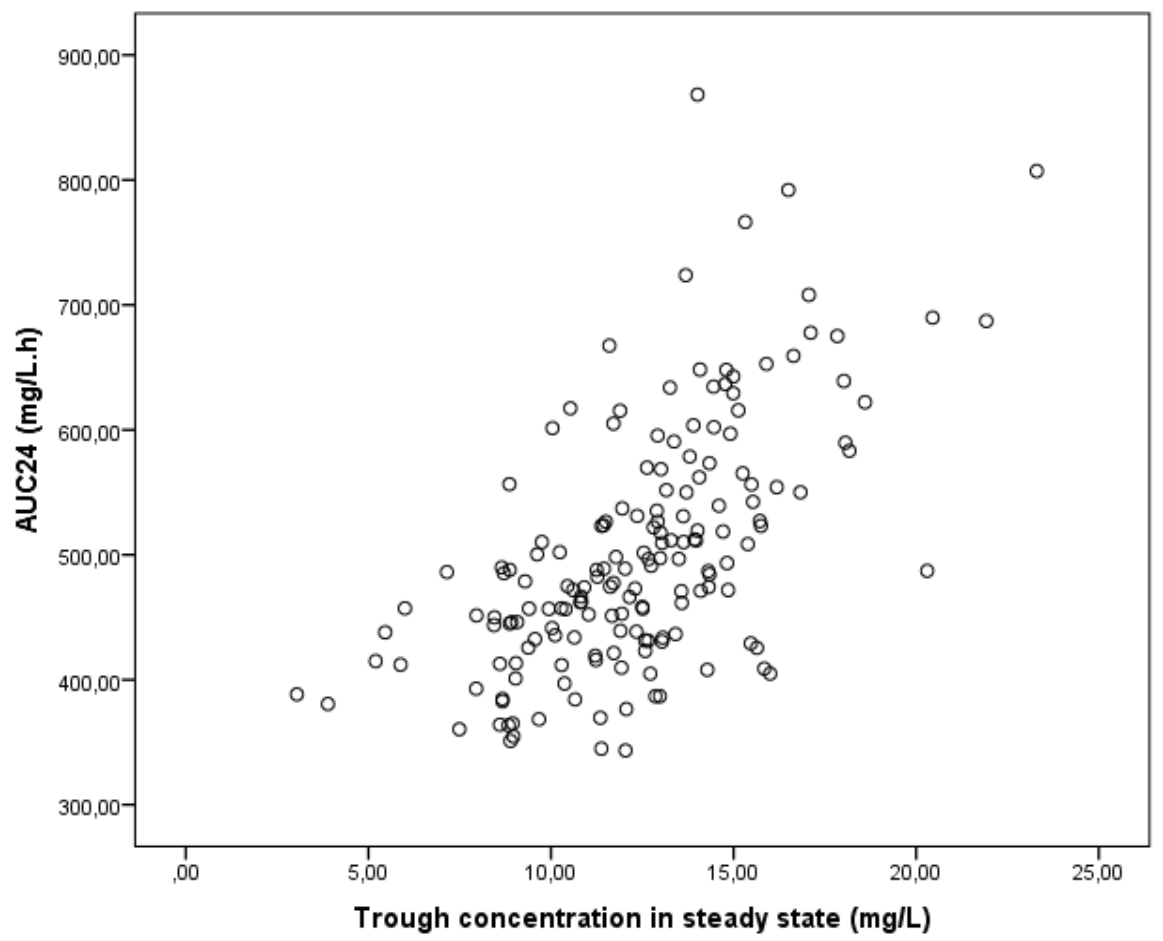

Figure 2. Scatter plot between 24 hour Area Under Curve $\left(\mathrm{AUC}_{24}\right)$ and trough levels in steady state.

Table 3. Vancomycin target attainment rates, $\mathrm{AUC}_{24} / \mathrm{MIC} \geq 400$ in patients in our study with a simulated $\mathrm{MIC}=1-2 \mathrm{mg} / \mathrm{L}$.

\begin{tabular}{|c|c|c|c|c|c|}
\hline \multirow{2}{*}{$\begin{array}{c}\text { Trough levels } \\
\quad(\mathrm{mg} / \mathrm{L})\end{array}$} & \multirow{2}{*}{$\begin{array}{c}\mathrm{N} \\
171\end{array}$} & \multirow{2}{*}{$\begin{array}{c}\mathrm{AUC}_{24} \\
\text { Median (range) } \\
(\mathrm{mg} \times 24 \mathrm{~h} / \mathrm{L})\end{array}$} & \multicolumn{3}{|c|}{$\mathrm{AUC}_{24} / \mathrm{MIC} \geq 400$} \\
\hline & & & $\begin{array}{c}\mathrm{MIC}=1 \\
(\mathrm{mg} / \mathrm{L})\end{array}$ & $\begin{array}{c}\mathrm{MIC}=1.5 \\
(\mathrm{mg} / \mathrm{L})\end{array}$ & $\begin{array}{l}\mathrm{MIC}=2 \\
(\mathrm{mg} / \mathrm{L})\end{array}$ \\
\hline$<10$ & 37 & $428(351-557)$ & $73 \%$ & $0 \%$ & $0 \%$ \\
\hline $10-15$ & 106 & $502(343-868)$ & $92 \%$ & $15 \%$ & $1 \%$ \\
\hline $15-20$ & 24 & $587(405-792)$ & $100 \%$ & $54 \%$ & $2 \%$ \\
\hline$>20$ & 4 & $668(487-807)$ & $100 \%$ & $75 \%$ & $25 \%$ \\
\hline
\end{tabular}

$\mathrm{AUC}_{24}: 24$ hour area under the curve

MIC: minimal inhibition level 
Table 4. Univariable Pearson and multivariable correlation coefficients between CLva and predictors used in this study.

\begin{tabular}{lllllll}
\hline & \multicolumn{7}{l}{ Univariable } & \multicolumn{2}{l}{ Multivariable } \\
\hline & R & $\boldsymbol{P}$-value & B & 95\% confidence & interval for B & $\boldsymbol{P}$-value \\
\hline CLcr & & & & Lower bound & Upper bound & \\
Creatinine & 0.599 & $<0.001$ & & & & -0.183 \\
Age & -0.597 & $<0.001$ & -0.229 & -0.276 & -0.232 & $<0.001$ \\
Neutropenia & -0.386 & $<0.001$ & -0.438 & -0.644 & 23.293 & 0.017 \\
Hematologic & 0.322 & $<0.001$ & 12.743 & 2.293 & 11.615 & 0.944 \\
malignancy & 0.300 & $<0.001$ & 0.400 & -10.815 & & \\
Sepsis & & & & & 4.582 & 0.488 \\
Vd & 0.170 & 0.027 & -2.496 & -9.582 & - & - \\
Gender & 0.008 & 0.915 & - & & 10.641 & 0.155 \\
Weight & 0.189 & 0.014 & 4.290 & -1.641 & 0.492 & 0.001 \\
\hline
\end{tabular}

CLva: vancomycin clearance

CLcr: creatinine clearance

Vd: volume of distribution

Table 5. CLcr, CLva, Vd, Dose $24 \mathrm{~h}$ and $\mathrm{AUC}_{24}$ broken down for age groups and neutropenia.

\begin{tabular}{|c|c|c|c|c|c|c|c|}
\hline $\begin{array}{l}\text { Age } \\
\text { group } \\
\text { (years) }\end{array}$ & $\mathbf{N}$ & $\begin{array}{l}\text { CLcr } \\
\mathrm{mL} / \mathrm{min}\end{array}$ & $\begin{array}{l}\text { CLva } \\
\mathrm{mL} / \mathrm{min}\end{array}$ & $\begin{array}{l}\text { Creatinine } \\
\mu \mathrm{mol} / \mathrm{L}\end{array}$ & $\begin{array}{l}\text { Vd } \\
\text { L }\end{array}$ & $\begin{array}{l}\text { Dose 24h } \\
\text { mg }\end{array}$ & $\begin{array}{l}\mathrm{AUC}_{24} \\
\mathrm{mg} \times 24 \mathrm{~h} / \mathrm{L}\end{array}$ \\
\hline$<70$ & 132 & $123( \pm 75)$ & $61( \pm 25)$ & $84( \pm 46)$ & $55( \pm 27)$ & $1838( \pm 746)$ & $505( \pm 98)$ \\
\hline$>70$ & 39 & $65( \pm 30)$ & $39( \pm 18)$ & $114( \pm 85)$ & $69( \pm 36)$ & $1158( \pm 545)$ & $490( \pm 94)$ \\
\hline $\begin{array}{l}P \text { - } \\
\text { value }\end{array}$ & & $<0.001$ & $<0.001$ & 0.005 & $<0.001$ & $<0.001$ & 0.306 \\
\hline $\begin{array}{l}\text { Neutro } \\
\text {-penia }\end{array}$ & $\mathbf{N}$ & $\begin{array}{l}\text { CLcr } \\
\mathrm{mL} / \mathrm{min}\end{array}$ & $\begin{array}{l}\text { CLva } \\
\mathrm{mL} / \mathrm{min}\end{array}$ & $\begin{array}{l}\text { Creatinine } \\
\mu \mathrm{mol} / \mathrm{L}\end{array}$ & $\begin{array}{l}\text { Vd } \\
\text { L }\end{array}$ & $\begin{array}{l}\text { Dose 24h } \\
\text { mg }\end{array}$ & $\begin{array}{l}\mathrm{AUC}_{24} \\
\mathrm{mg} \times 24 \mathrm{~h} / \mathrm{L}\end{array}$ \\
\hline No & 115 & $107( \pm 78)$ & $50( \pm 22)$ & $95( \pm 67)$ & $56( \pm 29)$ & $1521( \pm 727)$ & $499( \pm 102)$ \\
\hline Yes & 56 & $113( \pm 57)$ & $67( \pm 26)$ & $80( \pm 31)$ & $62( \pm 32)$ & $2017( \pm 719)$ & $507( \pm 87)$ \\
\hline $\begin{array}{l}P \text { - } \\
\text { value }\end{array}$ & & 0.142 & $<0.001$ & 0.873 & 0.304 & $<0.001$ & 0.259 \\
\hline
\end{tabular}

CLva: vancomycin clearance

CLcr: creatinine clearance

Vd: volume of distribution

$\mathrm{AUC}_{24}$ : 24 hour area under the curve 


\section{Discussion}

Here, we showed that the CLva prediction methods have a low correlation with CLva determined with MAP Bayesian estimation. Moise-Broder et al. had the highest mean and absolute prediction error, where DeRyke et al. and Pea et al. had lower prediction errors. However, prediction errors were still more than $25 \%$. The prediction methods are based on CLcr only and our study showed a linear correlation of $\mathrm{R}^{2} 0.50$ between the CLcr and CLva. This indicates that CLva prediction methods reported in literature are unsuitable for clinical use $[1,4,5]$.

In our hands, the CLcr estimated with the C\&G formula proved to have the best correlation with CLva. The estimated CLcr has a good correlation (0.8-0.9) with the 24-hour measured creatinine in urine, but is of less value in elderly, critically ill patients and when CLcr is higher than $125 \mathrm{~mL} / \mathrm{min}$ [9]. A 24-hour urine creatinine measurement to calculate CLcr might increase the correlation of CLcr with CLva, is cumbersome and other co-variates besides CLcr also influence the CLva. In our study age and neutropenia also influence the CLva. Higher exposure to vancomycin can be expected in elderly patients, as the CLva is lower. On the other hand, lower exposure due to augmented CLva can be expected in critically ill patients and in neutropenic patients with haematological malignancies $[18,19]$.

Another option to reduce TDM is proposed in the IDSA guidelines that recommend monitoring only trough plasma levels as the most practical method to monitor plasma vancomycin levels [2]. Furthermore, the IDSA guidelines suggest increasing the desired trough levels to $15-20 \mathrm{mg} / \mathrm{L}$ to obtain an increased target attainment of the $\mathrm{AUC}_{24} / \mathrm{MIC}$ ratios $\geq 400$ with bacterial $\mathrm{MIC} \leq 1 \mathrm{mg} / \mathrm{L}$. [2] Although, a $100 \%$ of the patients in our study with bacterial $\mathrm{MIC} \leq 1 \mathrm{mg} / \mathrm{L}$ reached an $\mathrm{AUC}_{24} \geq 400 \mathrm{mg} / \mathrm{L} \times \mathrm{h}$ at trough levels of $15-20 \mathrm{mg} / \mathrm{L}$, the majority $(92 \%)$ of our patients with bacterial MIC $\leq 1 \mathrm{mg} / \mathrm{L}$ reached an $\mathrm{AUC}_{24} \geq 400 \mathrm{mg} / \mathrm{L} \times \mathrm{h}$ with trough levels between $10-15 \mathrm{mg} / \mathrm{L}$. The target of $\mathrm{AUC}_{24} \geq 400 \mathrm{mg} / \mathrm{L} \times \mathrm{h}$ cannot be reached when bacterial MIC $>1 \mathrm{mg} / \mathrm{L}$. Vancomycin induced nephrotoxicity is estimated to be twice as high with trough levels $>15 \mathrm{mg} / \mathrm{L}$, increasing from $12 \%$ with trough levels $\leq 15 \mathrm{mg} / \mathrm{L}$ to $25 \%$ with trough levels $>15 \mathrm{mg} / \mathrm{L}$ in the meta-analysis from van Hal et al. [20]. Therefore, the majority of patients in our study group have an unnecessary increased risk of nephrotoxicity when dosed at high trough levels $(15-20 \mathrm{mg} / \mathrm{L})$. Furthermore, the trough levels have a poor correlation with $\mathrm{AUC}_{24}$ in our study. This is line with Neeley et al., who showed that monitoring of only trough levels is a poor surrogate for $\mathrm{AUC}_{24}$ [21]. Although monitoring of vancomycin through levels is associated with decreased vancomycin induced nephrotoxicity [2], it does not allow accurate calculation of PK parameters (i.e. CLva and $\mathrm{AUC}_{24}$ ).

Our study has several limitations. Our study is a real life observational study. We assumed the TDM protocol was followed by clinicians, especially the timing of peak and trough levels. Another limitation of our study is that our study population differs from the study populations from the prediction methods. Finally, we only investigated estimated CLcr, which could weaken our conclusions about the prediction methods based on estimated CLcr. 


\section{Conclusions}

The mean and absolute prediction error were large for all tested prediction methods. Therefore, the prediction methods are unsuitable for clinical use. Furthermore, dosing based only on trough levels of $15-20 \mathrm{mg} / \mathrm{L}$ will bring patients needlessly at risk for toxicity and is not sufficient for reaching the efficacy target when MIC $>1 \mathrm{mg} / \mathrm{L}$. The high variability and unpredictability of CLva and $\mathrm{AUC}_{24}$ make TDM with MAP Bayesian estimation inevitable for optimal dosing of vancomycin.

\section{Acknowledgements}

This work was supported by Care and Public Health Research Institute (CAPHRI), Maastricht, the Netherlands and the Medical University Centre Maastricht, the Netherlands. 


\section{References}

1. Moise-Broder PA, Forrest A, Birmingham MC, Schentag JJ: Pharmacodynamics of vancomycin and other antimicrobials in patients with Staphylococcus aureus lower respiratory tract infections. Clinical pharmacokinetics 2004, 43(13):925-942.

2. Rybak M, Lomaestro B, Rotschafer JC, Moellering R, Jr., Craig W, Billeter M, Dalovisio JR, Levine DP: Therapeutic monitoring of vancomycin in adult patients: a consensus review of the American Society of Health-System Pharmacists, the Infectious Diseases Society of America, and the Society of Infectious Diseases Pharmacists. American journal of healthsystem pharmacy : AJHP : official journal of the American Society of Health-System Pharmacists 2009, 66(1):82-98.

3. Murphy JE, Gillespie DE, Bateman CV: Predictability of vancomycin trough concentrations using seven approaches for estimating pharmacokinetic parameters. American journal of health-system pharmacy : AJHP : official journal of the American Society of Health-System Pharmacists 2006, 63(23):2365-2370.

4. Pea F, Furlanut M, Negri C, Pavan F, Crapis M, Cristini F, Viale P: Prospectively validated dosing nomograms for maximizing the pharmacodynamics of vancomycin administered by continuous infusion in critically ill patients. Antimicrobial agents and chemotherapy 2009, 53(5):1863-1867.

5. deRyke C, Alexander D: Optimizing vancomycin dosing through pharmacodynamic assessment targeting area under the concentration-time curve/minimum inhibitory concentration. Hosptial Pharmacy 2009, 44(9):751-765.

6. Matzke GR, McGory RW, Halstenson CE, Keane WF: Pharmacokinetics of vancomycin in patients with various degrees of renal function. Antimicrobial agents and chemotherapy 1984, 25(4):433-437.

7. Rodvold KA, Blum RA, Fischer JH, Zokufa HZ, Rotschafer JC, Crossley KB, Riff LJ: Vancomycin pharmacokinetics in patients with various degrees of renal function. Antimicrobial agents and chemotherapy 1988, 32(6):848-852.

8. Cockcroft DW, Gault MH: Prediction of creatinine clearance from serum creatinine. Nephron 1976, 16(1):31-41.

9. Lamb EJ, Tomson CR, Roderick PJ, Clinical Sciences Reviews Committee of the Association for Clinical B: Estimating kidney function in adults using formulae. Annals of clinical biochemistry 2005, 42(Pt 5):321-345.

10. Traynor J, Mactier R, Geddes CC, Fox JG: How to measure renal function in clinical practice. Bmj 2006, 333(7571):733-737.

11. Levey AS, Coresh J, Greene T, Marsh J, Stevens LA, Kusek JW, Van Lente F, Chronic Kidney Disease Epidemiology C: Expressing the Modification of Diet in Renal Disease Study equation for estimating glomerular filtration rate with standardized serum creatinine values. Clinical chemistry 2007, 53(4):766-772.

12. Stevens LA, Schmid CH, Greene T, Zhang YL, Beck GJ, Froissart M, Hamm LL, Lewis JB, Mauer M, Navis GJ et al: Comparative performance of the CKD Epidemiology Collaboration (CKD-EPI) and the Modification of Diet in Renal Disease (MDRD) Study equations for estimating GFR levels above $60 \mathrm{~mL} / \mathrm{min} / 1.73 \mathrm{~m} 2$. American journal of kidney diseases : the official journal of the National Kidney Foundation 2010, 56(3):486-495.

13. Pryka RD, Rodvold KA, Garrison M, Rotschafer JC: Individualizing vancomycin dosage regimens: one- versus two-compartment Bayesian models. Therapeutic drug monitoring 1989, 11(4):450-454.

14. Rodvold KA, Pryka RD, Garrison M, Rotschafer JC: Evaluation of a two-compartment Bayesian forecasting program for predicting vancomycin concentrations. Therapeutic drug monitoring 1989, 11(3):269-275.

15. van der Meer AF, Marcus MA, Touw DJ, Proost JH, Neef C: Optimal sampling strategy development methodology using maximum a posteriori Bayesian estimation. Therapeutic drug monitoring 2011, 33(2):133-146. 
16. Proost JH, Meijer DK: MW/Pharm, an integrated software package for drug dosage regimen calculation and therapeutic drug monitoring. Computers in biology and medicine 1992, 22(3):155-163.

17. Kuan Y, Hossain M, Surman J, El Nahas AM, Haylor J: GFR prediction using the MDRD and Cockcroft and Gault equations in patients with end-stage renal disease. Nephrology, dialysis, transplantation : official publication of the European Dialysis and Transplant Association - European Renal Association 2005, 20(11):2394-2401.

18. Baptista JP, Sousa E, Martins PJ, Pimentel JM: Augmented renal clearance in septic patients and implications for vancomycin optimisation. International journal of antimicrobial agents 2012, 39(5):420-423.

19. Buelga DS, del Mar Fernandez de Gatta M, Herrera EV, Dominguez-Gil A, Garcia MJ: Population pharmacokinetic analysis of vancomycin in patients with hematological malignancies. Antimicrobial agents and chemotherapy 2005, 49(12):4934-4941.

20. van Hal SJ, Paterson DL, Lodise TP: Systematic review and meta-analysis of vancomycininduced nephrotoxicity associated with dosing schedules that maintain troughs between 15 and 20 milligrams per liter. Antimicrobial agents and chemotherapy 2013, 57(2):734744.

21. Neely MN, Youn G, Jones B, Jelliffe RW, Drusano GL, Rodvold KA, Lodise TP: Are vancomycin trough concentrations adequate for optimal dosing? Antimicrobial agents and chemotherapy 2014, 58(1):309-316. 


\section{Chapter 8}

Summarising discussion $\&$ future perspectives 
Elderly people are a large growing population of healthcare consumers with high numbers of infection and high antimicrobial drug use. To improve antimicrobial treatment of infections in elderly patients, it is important to understand infections and antimicrobial therapy in elderly patients. Infections occur more often in elderly patients. Impaired immunity, which is illustrated by a diminished antibody response after vaccination in elderly patients [1-3], make elderly patients more vulnerable to infections. The environment of elderly patients, such as living in long term care facilities and increased admissions in hospitals, contribute to the risk of infection.

The majority of antimicrobial drugs are prescribed by general practitioners. In chapter 2 antimicrobial prescriptions were studied in Dutch general practices. The trend from 2000-2009 showed an increase in antimicrobial prescriptions in all adult age groups. This was most striking in the very elderly patients; the percentage of patients $>80$ years with at least one antimicrobial prescription per year increased from $9 \%$ in 2000 to $22 \%$ in 2009 . Moreover, the patients $>80$ years were also most often prescribed multiple antimicrobial prescriptions per year compared to younger age groups. The rise was evident in all antibiotic classes, except for the macrolides. Traditionally, the human antimicrobial consumption is low in the Netherlands, but it is slowly increasing and might increase further with the ageing population [4-6]. The exact cause of this increase is not clear. There are no changes in Dutch general practice guidelines for infections. However, the increase in fluoroquinolone prescriptions suggests that the guidelines are not always followed. The increase also might be explained by an increase in consultations. Unfortunately, we had no access to consultation frequency for acute infections in our study. The increase in antimicrobial prescriptions is worrisome, as there is a clear relation with antimicrobial resistance. Recently, the Dutch Ministry of Health obligated Dutch hospitals to assign antimicrobial stewardship teams and programs. However, more efficient reduction in antimicrobial use might be feasible in Primary Care. Based on our findings, the elderly should be a specific target group.

When prescribing antimicrobial therapy in elderly patients, there is an increased risk of adverse drug events (ADE) or drug-drug interactions. In chapter 2 co-medication was the most important risk factor for ADE. Elderly patients had more co-medication and co-morbidity. In the multivariate analysis co-medication was the only independent risk factor of $\mathrm{ADE}$, and not age or co-morbidity. Additional risk factors of ADE in elderly patients are increased antimicrobial drug blood levels due to altered pharmacokinetics as a result of physiologic changes of ageing. Higher age is characterised by a decrease in functional capacity of most organs, leading to pharmacokinetic changes in absorption, distribution, protein binding and elimination [7]. The most important pharmacokinetic changes that influence antimicrobial blood concentrations are a decrease in kidney function and changes in volume of distribution ( $\mathrm{Vd}$ ) (chapter 1). Reviews of antimicrobial pharmacokinetic studies in elderly patients are scarce and dated $[8,9]$. In chapter 1 the pharmacokinetic studies are reviewed: the decrease in renal clearance is the most consistent age related pharmacokinetic change, but no or inconsistent changes in $\mathrm{Vd}$ are seen.

In chapter 3 a High Performance Liquid Chromatography (HPLC) with fluorescence detection was developed for measurement of ciprofloxacin and validated according to US Food and Drug Administration (FDA) requirements for 
accuracy, precision, selectivity, sensitivity, reproducibility and stability [10]. In chapter 4 this method was used to study ciprofloxacin pharmacokinetics in hospitalised patients. An assay based on HPLC with UV detection was used in chapter 5 to measure amoxicillin and a fluorescence polarization immunoassay with monoclonal antibodies was used in chapters 6 and 7 to measure vancomycin in hospitalised patients. Both methods were validated according to FDA requirements. Amoxicillin and vancomycin are hydrophilic and renally cleared antimicrobial drugs, whereas ciprofloxacin is lipophilic and renally cleared. Expected age associated pharmacokinetic changes are a decrease in renal clearance, a decrease in $\mathrm{Vd}$ of hydrophilic antimicrobial drugs and an increase in Vd of lipophilic antimicrobial drugs. Increased blood concentrations of amoxicillin, ciprofloxacin and vancomycin were observed in elderly patients, due to a decrease in antimicrobial clearance in chapter 4, 5 and 7 (Table 1). No changes or only minor changes were seen in $\mathrm{Vd}$ for amoxicillin and ciprofloxacin (Table 1).

Table 1. Mean $( \pm \mathrm{SD}) \mathrm{CL}, \mathrm{CLcr}, \mathrm{Vd}$ and $\mathrm{AUC}_{24}$ for amoxicillin, ciprofloxacin and vancomycin in patients using amoxicillin/clavulanic acid broken down per age group.

\begin{tabular}{|c|c|c|c|c|c|}
\hline \multicolumn{6}{|l|}{ Amoxicillin } \\
\hline $\begin{array}{l}\text { Age group } \\
\text { [years] }\end{array}$ & $\mathbf{N}$ & $\begin{array}{l}\text { CLcr }[\mathrm{mL} / \mathrm{min}] \\
\text { mean }(\mathrm{SD})\end{array}$ & $\begin{array}{l}\text { CLam [L/h] } \\
\text { mean (SD) }\end{array}$ & $\begin{array}{l}\text { Vd }[L] \\
\text { mean }(S D)\end{array}$ & $\begin{array}{l}\mathrm{AUC}{ }_{24}[\mathrm{mg} \times \mathrm{h} / \mathrm{L}] \\
\text { mean }(\mathrm{SD})\end{array}$ \\
\hline$<70$ & 31 & $82( \pm 25)$ & $15(5)$ & $24( \pm 5)$ & $312(128)$ \\
\hline$>70$ & 26 & $55( \pm 19)$ & $10(5)$ & $23( \pm 6)$ & 467 (255) \\
\hline$P$-value & & 0.007 & 0.003 & 0.46 & 0.006 \\
\hline \multicolumn{6}{|l|}{ Ciprofloxacin } \\
\hline $\begin{array}{l}\text { Age group } \\
\text { [years] }\end{array}$ & $\mathbf{N}$ & $\begin{array}{l}\text { CLcr }[\mathbf{m L} / \mathbf{m i n}] \\
\text { mean }(\mathrm{SD})\end{array}$ & $\begin{array}{l}\text { CLci }[\mathbf{L} / \mathbf{h}] \\
\text { mean (SD) }\end{array}$ & $\begin{array}{l}\mathbf{V d}[\mathbf{L}] \\
\text { mean }(\mathrm{SD})\end{array}$ & $\begin{array}{l}\mathrm{AUC}_{24}[\mathrm{mg} \times \mathrm{h} / \mathrm{L}] \\
\text { mean }(\mathrm{SD})\end{array}$ \\
\hline$<70$ & 41 & $85(49)$ & $19(8)$ & $181(55)$ & $43(20)$ \\
\hline$>70$ & 39 & $55(37)$ & $14(7)$ & $177(82)$ & $55(24)$ \\
\hline$P$-value & & $<0.001$ & 0.001 & 0.48 & 0.013 \\
\hline \multicolumn{6}{|l|}{ Vancomycin } \\
\hline $\begin{array}{l}\text { Age group } \\
\text { [years] }\end{array}$ & $\mathbf{N}$ & $\begin{array}{l}\text { CLcr }[\mathrm{mL} / \mathrm{min}] \\
\text { mean }(\mathrm{SD})\end{array}$ & $\begin{array}{l}\text { CLva }[\mathrm{L} / \mathrm{h}] \\
\text { mean }(\mathrm{SD})\end{array}$ & $\begin{array}{l}\text { Vd [L] } \\
\text { mean (SD) }\end{array}$ & $\begin{array}{l}\operatorname{AUC}_{24}[\mathrm{mg} \times \mathrm{h} / \mathrm{L}] \\
\text { mean }(\mathrm{SD})\end{array}$ \\
\hline$<70$ & 132 & $123( \pm 75)$ & $61( \pm 25)$ & $55( \pm 27)$ & $505( \pm 98)$ \\
\hline$>70$ & 39 & $65( \pm 30)$ & $39( \pm 18)$ & $69( \pm 36)$ & $490( \pm 94)$ \\
\hline$P$-value & & $<0.001$ & $<0.001$ & $<0.001$ & 0.306 \\
\hline
\end{tabular}

CLcr, creatinine clearance

CLci, ciprofloxacin clearance

CLam, amoxicillin clearance

CLva, vancomycin clearance

$\mathrm{Vd}$, volume of distribution

$\mathrm{AUC}_{24}$, area under the curve in 24-hours

An exception was the $\mathrm{Vd}$ of the hydrophilic vancomycin, where an increase of $\mathrm{Vd}$ is observed, despite a suspected decrease in water volume in elderly patients. This increase in $\mathrm{Vd}$ is also found by others [11-13]. The $\mathrm{Vd}$ is influenced by other patient factors, such as serum albumin, fluid infusions and sepsis.

Dividing the elderly patients further into $70-80$ and $>80$ years, the clearance of amoxicillin, ciprofloxacin and vancomycin further decreases with increasing age, whereas the $\mathrm{Vd}$ for amoxicillin and ciprofloxacin only slightly decreases in the very elderly patients (Table 2). 
Table 2. Mean $( \pm$ SD) CL, CLcr, Vd and for amoxicillin, ciprofloxacin and vancomycin in patients broken down per age group.

\begin{tabular}{|c|c|c|c|c|c|}
\hline \multicolumn{6}{|l|}{ Amoxicillin } \\
\hline $\begin{array}{l}\text { Age group } \\
\text { [years] }\end{array}$ & $\mathbf{N}$ & $\begin{array}{l}\mathrm{CL}_{\mathrm{cr}}[\mathrm{mL} / \mathrm{min}] \\
\text { mean }(\mathrm{SD})\end{array}$ & $\begin{array}{l}\text { CLam }[\mathrm{L} / \mathrm{h} /] \\
\text { mean }(\mathrm{SD})\end{array}$ & $\begin{array}{l}\text { Vd }[L] \\
\text { mean }(S D)\end{array}$ & $\begin{array}{l}\mathrm{AUC}_{24}[\mathrm{mg} \times \mathrm{h} / \mathrm{L}] \\
\operatorname{mean}(\mathrm{SD})\end{array}$ \\
\hline$<70$ & 31 & $82(25)$ & $15(5)$ & $24(5)$ & $312(128)$ \\
\hline $70-80$ & 16 & 65 (15) & $12(5)$ & $24(6)$ & $383(170)$ \\
\hline$>80$ & 10 & $39(11)$ & $8(4)$ & $22(7)$ & $602(317)$ \\
\hline \multicolumn{6}{|l|}{ Ciprofloxacin } \\
\hline $\begin{array}{l}\text { Age group } \\
\text { [years] }\end{array}$ & $\mathbf{N}$ & $\begin{array}{l}\mathrm{CL}_{\mathrm{cr}}[\mathrm{mL} / \mathrm{min}] \\
\text { mean }(\mathrm{SD})\end{array}$ & $\begin{array}{l}\text { CLci }[\mathbf{L} / \mathbf{h}] \\
\text { mean }(\mathrm{SD})\end{array}$ & $\begin{array}{l}\text { Vd [L] } \\
\text { mean (SD) }\end{array}$ & $\begin{array}{l}\mathrm{AUC} \\
\text { mean }(\mathrm{SD})\end{array}$ \\
\hline$<70$ & 41 & 85 (49) & $19(8)$ & $181(55)$ & $43(20)$ \\
\hline $70-80$ & 24 & $58(40)$ & $15(7)$ & $178(83)$ & $52(22)$ \\
\hline$>80$ & 15 & $51(33)$ & $12(6)$ & $176(84)$ & $59(27)$ \\
\hline \multicolumn{6}{|l|}{ Vancomycin } \\
\hline $\begin{array}{l}\text { Age group } \\
\text { [years] }\end{array}$ & $\mathbf{N}$ & $\begin{array}{l}\mathrm{CL}_{\mathrm{cr}}[\mathrm{mL} / \mathrm{min}] \\
\text { mean }(\mathrm{SD})\end{array}$ & $\begin{array}{l}\text { CLva }[\mathrm{L} / \mathrm{h}] \\
\text { mean }(\mathrm{SD})\end{array}$ & $\begin{array}{l}\mathrm{Vd}[\mathrm{L}] \\
\text { mean }(\mathrm{SD})\end{array}$ & $\begin{array}{l}\operatorname{AUC}_{24}[\mathrm{mg} \times \mathrm{h} / \mathrm{L}] \\
\text { mean }(\mathrm{SD})\end{array}$ \\
\hline$<70$ & 132 & $123(75)$ & $61(25)$ & $55(27)$ & $505(98)$ \\
\hline $70-80$ & 31 & $68(33)$ & $40(18)$ & 71 (39) & $480(88)$ \\
\hline$>80$ & 8 & $56(18)$ & $35(16)$ & $60(24)$ & $528(110)$ \\
\hline
\end{tabular}

$\mathrm{CL}_{\mathrm{cr}}$, creatinine clearance

$\mathrm{CL}$, ciprofloxacin clearance

$\mathrm{Vd}$, volume of distribution

$\mathrm{AUC}_{24}$, area under the curve in 24-hours

The Pearson correlation coefficients between serum creatinine and clearance of amoxicillin, ciprofloxacin and vancomycin were $\mathrm{R}=-0.529,-0.507$ and -0.597 , respectively, and between estimated CLcr and clearance of amoxicillin, ciprofloxacin and vancomycin were $\mathrm{R}=0.843,0.692$ and 0.599 , respectively (Table 3 ). This means that the serum creatinine or the estimated CLcr only partly predicts the clearance of amoxicillin, ciprofloxacin and vancomycin (51-60\%) and other factors influence the antimicrobial clearance. In the multivariable analysis age and creatinine were independently associated with the clearance of amoxicillin, ciprofloxacin and vancomycin (Table 3). Therefore, monitoring serum creatinine and estimation of CLcr with an algorithm from serum creatinine is necessary in elderly patients, but because of moderate correlation with antimicrobial clearance the value is limited in antimicrobial dosing. Indeed, in Chapter 7 prediction methods based on CLcr to predict the vancomycin clearance, showed large prediction errors and were unsuitable for patient care. Different methods to estimate the CLcr, i.e. Cockcroft-Gault formula, several Modification of Diet in Renal Disease and Chronic Kidney Disease Epidemiology Collaboration formula were compared, but all methods showed a correlation of $\mathrm{R}^{2}$ of 0.50 with the measured clearance of vancomycin. More precise determination of kidney function, such as measurement of creatinine in urine, inulin, iohexol, or ${ }^{125}$ I-Iothalamate, or still better therapeutic drug monitoring (TDM) of the antimicrobial drugs should be considered in elderly patients. Other factors influence the clearance of antimicrobial drugs; e.g. age independently decreases the amoxicillin, ciprofloxacin and vancomycin clearance (Table 3). Additionally, in chapter 6 we showed that neutropenia independently augments the vancomycin clearance. Similar augmented clearance is observed in Intensive Care Unit patients [14-16]. Most likely augmented clearance 
also influences other renally cleared antibiotics [17, 18]. More in depth studies are needed to understand the aetiology, duration and consequences of augmented clearance of antimicrobial drugs.

Table 3. Univariable Pearson correlation coefficients and multivariable linear regression analysis of amoxicillin, ciprofloxacin and vancomycin.

\begin{tabular}{|c|c|c|c|c|c|c|}
\hline \multirow[t]{2}{*}{ Amoxicillin } & \multicolumn{2}{|c|}{ Univariable CLam } & \multicolumn{3}{|c|}{ Multivariable CLam } & \multirow[b]{2}{*}{$P$-value } \\
\hline & $\mathbf{R}$ & P-value & Beta & $\begin{array}{l}95 \% \text { CI } \\
\text { Lower }\end{array}$ & Upper & \\
\hline Age & -0.503 & $<0.001$ & -0.141 & -0.188 & -0.094 & $<0.001$ \\
\hline Creatinine & -0.529 & $<0.001$ & -0.069 & -0.090 & -0.049 & $<0.001$ \\
\hline Gender & -0.111 & 0.409 & & & & \\
\hline Weight & 0.396 & 0.002 & 0.363 & -0.024 & 0.064 & 0.363 \\
\hline $\mathrm{Vd}$ & 0.623 & $<0.001$ & 0.506 & 0.352 & 0.659 & $<0.001$ \\
\hline \multirow[t]{2}{*}{ Ciprofloxacin } & \multicolumn{2}{|c|}{ Univariable CLci } & \multicolumn{2}{|c|}{ Multivariable CLci } & & \\
\hline & $\mathbf{R}$ & P-value & Beta & $\begin{array}{l}\text { 95\% CI } \\
\text { Lower }\end{array}$ & Upper & $P$-value \\
\hline Age & -0.377 & 0.001 & -0.144 & -0.223 & -0.064 & 0.001 \\
\hline Creatinine & -0.507 & $<0.001$ & -0.030 & -0.040 & -0.019 & $<0.001$ \\
\hline Gender & -0.199 & 0.076 & & & & \\
\hline Weight & 0.154 & 0.173 & & & & \\
\hline $\mathrm{Vd}$ & 0.334 & 0.002 & 0.036 & 0.017 & 0.055 & $<0.001$ \\
\hline \multirow[t]{2}{*}{ Vancomycin } & \multicolumn{2}{|c|}{ Univariable CLva } & \multicolumn{2}{|c|}{ Multivariable CLva } & & \\
\hline & $\mathbf{R}$ & P-value & Beta & $\begin{array}{l}\text { 95\% CI } \\
\text { Lower }\end{array}$ & Upper & $P$-value \\
\hline Age & -0.386 & $<0.001$ & -0.405 & -0.602 & -0.208 & $<0.001$ \\
\hline Creatinine & -0.597 & $<0.001$ & -0.228 & -0.275 & -0.181 & $<0.001$ \\
\hline Gender & 0.189 & 0.014 & 4.121 & -1.78 & 10.08 & 0.169 \\
\hline Weight & 0.200 & 0.009 & 0.334 & 0.160 & 0.509 & $<0.001$ \\
\hline $\mathrm{Vd}$ & 0.008 & 0.915 & & & & \\
\hline Neutropenia & 0.322 & $<0.001$ & 13.169 & 2.75 & 23.59 & 0.014 \\
\hline $\begin{array}{l}\text { Hemato- } \\
\text { oncology }\end{array}$ & 0.300 & $<0.001$ & 0.849 & -10.34 & 12.04 & 0.881 \\
\hline Sepsis & 0.170 & 0.027 & -2.839 & -9.90 & 4.22 & 0.428 \\
\hline
\end{tabular}

CLci, ciprofloxacin clearance

CLam, amoxicillin clearance

CLva, vancomycin clearance

$\mathrm{Vd}$, volume of distribution

In chapter 4 and 5, we showed that pharmacodynamic (PD) targets are not reached with standard dosing regimens in a considerable part of the hospitalised patients, both young and elderly, which is in line with other studies [19-21]. In Chapter 4, 21\% and $75 \%$ of the patients that received the standard dose of ciprofloxacin did not reach the PD-target of $\mathrm{AUC}_{24} / \mathrm{MIC}>125$ with bacterial minimal inhibition concentration (MIC) of 0.25 and $0.5 \mathrm{mg} / \mathrm{L}$, resp. The percentages of elderly patients that did not reach the PD-target were, $18 \%$ and $59 \%$ with bacterial MIC of 0.25 and $0.5 \mathrm{mg} / \mathrm{L}$, resp. In Chapter 5, 7\% and $35 \%$ of the total amount of patients that received the standard dose of amoxicillin/clavulanic acid did not reach the PD target of $40 \% \mathrm{~T}>\mathrm{MIC}$ with bacterial $\mathrm{MIC}$ of 4 and $8 \mathrm{mg} / \mathrm{L}$, resp. The percentages of elderly patients ( $>70$ years) that did not reach the PD-target were $0 \%$ and $13 \%$ with bacterial MIC of 4 and $8 \mathrm{mg} / \mathrm{L}$, respectively. Ciprofloxacin and amoxicillin are underdosed in adult patients and this dose is more appropriate for 
elderly patients. Vancomycin is dosed with TDM and most patients reached an $\mathrm{AUC}_{24} \geq 400 \mathrm{mg} \times \mathrm{h} / \mathrm{L}$, where the PD-target is reached for $\mathrm{MIC}=1 \mathrm{mg} / \mathrm{L}$. However, elderly patients needed lower vancomycin mean 24 -hour dose $( \pm \mathrm{SD})$ than younger patients, i.e. patients $>70$ years received a mean of $1158( \pm 545) \mathrm{mg}$ of vancomycin per 24 hours and patients $<70$ years $1838( \pm 746) \mathrm{mg}$. Dosing on the PD-target of vancomycin $\mathrm{AUC}_{24} / \mathrm{MIC} \geq 400$ is not advisable with $\mathrm{MIC} \geq 2 \mathrm{mg} / \mathrm{L}$ due to toxicity [22] (chapter 7). In general our hospitalised patients did not reach the PD-targets with the standard antimicrobial dose. Increasing the standard dose for ciprofloxacin iv to $400 \mathrm{mg}$ three times daily decreases the percentage of patients that did not reach the PD-target to $1 \%$ and $37 \%$, for MIC 0.25 and $0.50 \mathrm{mg} / \mathrm{L}$, resp. (chapter 4) and increasing the amoxicillin iv dose to $1000 \mathrm{mg} 6$ times daily decreases the percentage to $0 \%$ and $5 \%$ for MIC 4 and $8 \mathrm{mg} / \mathrm{L}$, respectively (chapter 5). A ciprofloxacin dose of $400 \mathrm{mg} 3$ times daily is sufficient for most elderly patients, because the percentage of patients that did not reach the PD-target is $0 \%$ and $15 \%$ for bacterial MIC of $0.25 \mathrm{mg} / \mathrm{L}$ and $0.50 \mathrm{mg} / \mathrm{L}$, respectively. The standard dose of amoxicillin is appropriate for all elderly patients in our study group.

In conclusion, age and serum creatinine are independent factors of the clearance of amoxicillin, ciprofloxacin and vancomycin. This results in increased amoxicillin, ciprofloxacin and vancomycin blood concentrations in elderly patients. However, the decrease in antimicrobial clearance is difficult to predict with serum creatinine and estimated CLcr, as the correlation of serum creatinine and estimated CLcr with antimicrobial clearance is only moderate and a high interindividual difference in decline of glomular filtration rate is seen with ageing [28]. The Vd of both hydrophilic and lipophilic renally cleared antimicrobial drugs does not change consistently. Therefore, it is not possible to adjust antimicrobial dosing according to changes in $\mathrm{Vd}$ with ageing. Especially in elderly patients, TDM is necessary to ensure efficacy and prevent toxic concentrations for antimicrobial drugs with small therapeutic window, such as aminoglycosides, vancomycin and linezolid. Additionally, in elderly patients TDM might prevent ADEs in antimicrobial drugs close to high toxic levels. In specific groups of patients with risk of underdosing due to augmented clearance, such as patients admitted at the ICU and in neutropenic patients, TDM might be worthwhile to reach PD targets and improve outcome. 


\section{Future perspectives}

Improving antimicrobial therapy in the growing population of elderly patients will require more studies, both on the exact dose of antimicrobial drugs and on targeted blood levels. Studies that follow trends in antimicrobial prescriptions over time should be continued, especially in elderly patients. Studies analysing drug prescriptions, factors for increasing antimicrobial drug use in association with diagnosis and treatment are needed both in hospital setting and in primary care.

To fill the gap in pharmacokinetic studies in elderly patients, antimicrobial pharmacokinetic population studies are needed. These studies should be done in well-defined age groups with specific attention to patients at the end of the life spectrum, i.e. very elderly patients ( $>80$ year) and frail elderly patients. Age related pharmacokinetic changes might be more clear at the end of the life spectrum. FDA approved measuring methods of antimicrobial blood levels should be used.

Our suggested dose adjustments of amoxicillin/clavulanic acid 1000/200 mg iv 6 times daily and ciprofloxacin $400 \mathrm{mg}$ iv three times daily to attain PD-targets, should be validated in prospective studies. In depth studies of mechanism, duration and other covariates of augmented antimicrobial drug clearance in neutropenic and ICU-patients should be combined with preferably not burdensome and more precise measurement of kidney function. The augmented antimicrobial drug clearance together with other suggested covariates, such as co-medication, sepsis, age and genetic factors should be followed over time to get more insight in duration and mechanism of augmented antimicrobial drug clearance.

A standard antimicrobial dose might be sufficient for the majority of patients, but does not fit all patients. This thesis shows that elderly patients generally need lower dose than younger patients to reach PD-targets of antimicrobial drugs. Especially, for antimicrobial drugs with small therapeutic range more individual dosing of elderly patients with TDM will be necessary to safely increase the dose to improve clinical outcome and keep toxicity low. It might decrease antimicrobial drug resistance. Individual dosing of antimicrobial drugs which takes into account the MIC of an antimicrobial drug for the infecting micro-organism and TDM or a dosing regimen that is likely to obtain the PD-targets should also be a strategy in antibiotic stewardship programs. 


\section{References}

1. Howells $\mathrm{CH}$, Vesselinova-Jenkins $\mathrm{CK}$, Evans $\mathrm{AD}$, James J: Influenza vaccination and mortality from bronchopneumonia in the elderly. Lancet 1975, 1(7903):381-383.

2. Phair J, Kauffman CA, Bjornson A, Adams L, Linnemann C, Jr.: Failure to respond to influenza vaccine in the aged: correlation with $\mathrm{B}$-cell number and function. The Journal of laboratory and clinical medicine 1978, 92(5):822-828.

3. Vermeiren AP, Hoebe CJ, Dukers-Muijrers NH: High non-responsiveness of males and the elderly to standard hepatitis $B$ vaccination among a large cohort of healthy employees. Journal of clinical virology : the official publication of the Pan American Society for Clinical Virology 2013, 58(1):262-264.

4. Adriaenssens N, Coenen S, Versporten A, Muller A, Minalu G, Faes C, Vankerckhoven V, Aerts M, Hens N, Molenberghs G et al: European Surveillance of Antimicrobial Consumption (ESAC): outpatient antibiotic use in Europe (1997-2009). The Journal of antimicrobial chemotherapy 2011, 66 Suppl 6:vi3-12.

5. Goossens H, Ferech M, Coenen S, Stephens P, European Surveillance of Antimicrobial Consumption Project G: Comparison of outpatient systemic antibacterial use in 2004 in the United States and 27 European countries. Clinical infectious diseases : an official publication of the Infectious Diseases Society of America 2007, 44(8):1091-1095.

6. SFK: Antiobioticagebruik groeit gestaag (Antibiotic use is growing). http://wwwsfknl/publicaties/farmacie in cijfers/2010/2010-07html 2010.

7. Turnheim K: Drug dosage in the elderly. Is it rational? Drugs \& aging 1998, 13(5):357379.

8. Ljungberg B, Nilsson-Ehle I: Pharmacokinetics of antimicrobial agents in the elderly. Reviews of infectious diseases 1987, 9(2):250-264.

9. Meyers BR, Wilkinson P: Clinical pharmacokinetics of antibacterial drugs in the elderly. Implications for selection and dosage. Clinical pharmacokinetics 1989, 17(6):385-395.

10. validation $\quad$ FGfi-Bm: http://www.fda.gov/downloads/drugs/guidancecomplianceregulatoryinformation/guidanc es/ucm368107.pdf. 2013.

11. Cutler NR, Narang PK, Lesko LJ, Ninos M, Power M: Vancomycin disposition: the importance of age. Clinical pharmacology and therapeutics 1984, 36(6):803-810.

12. Ducharme MP, Slaughter RL, Edwards DJ: Vancomycin pharmacokinetics in a patient population: effect of age, gender, and body weight. Therapeutic drug monitoring 1994, 16(5):513-518.

13. Guay DR, Vance-Bryan K, Gilliland S, Rodvold K, Rotschafer J: Comparison of vancomycin pharmacokinetics in hospitalized elderly and young patients using a Bayesian forecaster. Journal of clinical pharmacology 1993, 33(10):918-922.

14. Claus BO, Hoste EA, Colpaert K, Robays H, Decruyenaere J, De Waele JJ: Augmented renal clearance is a common finding with worse clinical outcome in critically ill patients receiving antimicrobial therapy. Journal of critical care 2013, 28(5):695-700.

15. Revilla N, Martin-Suarez A, Perez MP, Gonzalez FM, Fernandez de Gatta Mdel M: Vancomycin dosing assessment in intensive care unit patients based on a population pharmacokinetic/pharmacodynamic simulation. British journal of clinical pharmacology 2010, 70(2):201-212.

16. Udy AA, Roberts JA, Boots RJ, Paterson DL, Lipman J: Augmented renal clearance: implications for antibacterial dosing in the critically ill. Clinical pharmacokinetics 2010, 49(1):1-16.

17. Pea F, Viale P, Damiani D, Pavan F, Cristini F, Fanin R, Furlanut M: Ceftazidime in acute myeloid leukemia patients with febrile neutropenia: helpfulness of continuous intravenous infusion in maximizing pharmacodynamic exposure. Antimicrobial agents and chemotherapy 2005, 49(8):3550-3553.

18. Sime FB, Roberts MS, Warner MS, Hahn U, Robertson TA, Yeend S, Phay A, Lehman S, Lipman J, Peake SL et al: Altered pharmacokinetics of piperacillin in febrile neutropenic patients with hematological malignancy. Antimicrobial agents and chemotherapy 2014, 58(6):3533-3537.

19. Aubert G, Carricajo A, Coudrot M, Guyomarc'h S, Auboyer C, Zeni F: Prospective determination of serum ceftazidime concentrations in intensive care units. Therapeutic drug monitoring 2010, 32(4):517-519. 
20. Rea RS, Capitano B, Bies R, Bigos KL, Smith R, Lee H: Suboptimal aminoglycoside dosing in critically ill patients. Therapeutic drug monitoring 2008, 30(6):674-681.

21. van Zanten AR, Polderman KH, van Geijlswijk IM, van der Meer GY, Schouten MA, Girbes AR: Ciprofloxacin pharmacokinetics in critically ill patients: a prospective cohort study. Journal of critical care 2008, 23(3):422-430.

22. Rybak M, Lomaestro B, Rotschafer JC, Moellering R, Jr., Craig W, Billeter M, Dalovisio JR, Levine DP: Therapeutic monitoring of vancomycin in adult patients: a consensus review of the American Society of Health-System Pharmacists, the Infectious Diseases Society of America, and the Society of Infectious Diseases Pharmacists. American journal of healthsystem pharmacy : AJHP : official journal of the American Society of Health-System Pharmacists 2009, 66(1):82-98. 
Nederlandse samenvatting 
Het aantal ouderen en het percentage ouderen ten opzichte van de hele bevolking neemt gestaag toe in ontwikkelde landen. Dit komt aan de ene kant doordat de levensverwachting er toeneemt en aan de andere kant het geboortecijfer er afneemt. In hoofdstuk 1 worden classificaties besproken van de oudere patiënt. De meest gebruikte grenzen voor ouderen zijn 65 en 70 jaar. Voor hoogbejaarden wordt een grens van 80 jaar het meest gebruikt, maar elke grens is artificieel. Bovendien bestaat er een grote variatie in kalenderleeftijd en biologische leeftijd van persoon tot persoon. In hoofdstuk 1 wordt een overzicht gegeven van farmacokinetische veranderingen tijdens het verouderingsproces. Ook wordt er een overzicht gegeven van de antimicrobiële farmacokinetische studies bij oudere vrijwilligers en oudere patiënten. Bij ouderen treedt een vermindering op van de functionele capaciteit van alle organen. Dit leidt tot veranderingen in absorptie, eiwitbinding en eliminatie van antimicrobiële middelen bij oudere patiënten. Volgens farmacokinetische reviews van antimicrobiële therapie bij oudere patiënten uit 1987 en 1989 lijken de belangrijkste farmacokinetische veranderingen: 1. een verandering in het verdelingsvolume en 2 . een vermindering van de nierfunctie te zijn. Het verdelingsvolume van ouderen verandert door een afname van het lichaamswater en een toename van het lichaamsvet. Dit zou tot gevolgen kunnen leiden voor water- (hydrofiele) en vetoplosbare (lipofiele) antimicrobiële middelen. Echter, het overzicht van antimicrobiële farmacokinetische studies bij oudere vrijwilligers en patiënten in hoofdstuk 1 laat zien dat de veranderingen in het verdelingsvolume niet eenduidig zijn. De vermindering van de nierfunctie lijkt daarentegen de belangrijkste en meest consistente farmacokinetische verandering bij oudere patiënten. Hierdoor kunnen de concentraties van renaal geklaarde antimicrobiële middelen onbedoeld verhoogd zijn bij oudere patiënten. Het gevaar bestaat dat er bijwerkingen ten gevolge van toxiciteit kunnen optreden. Wel moet een kanttekening gemaakt worden dat er betrekkelijk weinig studies zijn verricht naar de farmacokinetiek van antimicrobiële middelen specifiek in oudere patiënten. Meer onderzoek naar de farmacokinetiek van antimicrobiële middelen bij oudere patiënten is daarom belangrijk.

Het merendeel van alle antimicrobiële middelen wordt door de huisarts voorgeschreven (80\%). In hoofdstuk 2 worden dan ook de antimicrobiële voorschriften bestudeerd in huisartspraktijken van het Registratie Netwerk Huisartsen (RNH) in Limburg. Tussen 2000-2009 zijn 658.940 patiëntjaren onderzocht. Over deze 10 jaar krijgt $11,5 \%$ van de patiënten tenminste één keer een antibioticum voorschrift per jaar. Over deze 10 jaar wordt een duidelijke toename waargenomen van het aantal antimicrobiële voorschriften in alle volwassen leeftijdsgroepen. De grootste stijging wordt bij de aller oudsten gezien, van de leeftijdsgroep ouder dan 80 jaar stijgt het aantal patiënten dat tenminste één antimicrobieel voorschrift per jaar krijgt van $9 \%$ in 2000 naar $22 \%$ in 2009. Ook krijgen mensen ouder dan 80 jaar vaker meer dan één antimicrobieel middel per jaar voorgeschreven. Deze stijging geldt voor alle antimicrobiële middelen, behalve voor de macroliden. Hoewel er geen duidelijke oorzaak van deze stijging wordt gevonden, baart deze ontwikkeling wel zorgen, vanwege de duidelijke relatie tussen het antibiotica gebruik en het ontstaan van antimicrobiële resistentie. Daarnaast is in hoofdstuk 2 gevonden dat oudere patiënten vaker bijwerkingen hebben van antimicrobiële middelen. In de univariate analyse zijn co-medicatie, leeftijd en chronische ziekten geassocieerd met het ontwikkelen van bijwerkingen. In de 
multivariate analyse is alleen co-medicatie nog geassocieerd met het ontwikkelen van bijwerkingen. Oudere patiënten hebben uiteraard veel meer co-medicatie dan jongere patiënten.

In hoofdstuk 3 is een high performance liquid chromatography (HPLC) methode met fluorescentie detectie ontwikkeld om de concentratie van ciprofloxacine in het bloed nauwkeurig te bepalen. Deze methode is volgens de Amerikaanse richtlijnen voor voedsel en medicijn registratie (Food and Drug Administration, FDA) voor accuraatheid, precisie, selectiviteit, sensitiviteit, reproduceerbaarheid en stabiliteit gevalideerd. In hoofdstuk 4 is deze methode gebruikt om ciprofloxacine concentraties in het bloed te bepalen van ziekenhuispatiënten. Een bestaande HPLC met ultraviolet licht detectie is in hoofdstuk 5 gebruikt om amoxicilline concentraties in het bloed van patiënten te bepalen. In hoofdstuk 6 en $\mathbf{7}$ is een fluorescentie polarisatie immunoassay (FPIA) met monoclonale antilichamen toegepast om vancomycine concentraties in het bloed te meten. Alle methoden zijn volgens FDA richtlijnen gevalideerd.

Hoofdstuk 4 en 5 laten zien dat de farmacodynamische targets met de standaard doseringen van ciprofloxacine en amoxicilline/clavulaanzuur in een belangrijk gedeelte van de patiënten niet gehaald worden. In hoofdstuk 4 haalt $21 \%$ van de patiënten de ciprofloxacine target niet als de minimum inhibitory concentration (MIC) van de bacterie, die de infectie veroorzaakt $0.25 \mathrm{mg} / \mathrm{L}$ is. Dit percentage loopt op naar $75 \%$ als de MIC van de bacterie $0.50 \mathrm{mg} / \mathrm{L}$ is. Het percentage ouderen (>70 jaar), die de ciprofloxacine target niet haalt ligt lager, namelijk $18 \%$ bij een MIC van $0.25 \mathrm{mg} / \mathrm{L}$ en $59 \%$ bij een MIC van $0.50 \mathrm{mg} / \mathrm{L}$. Als de MIC van de bacterie (Enterobacteriaceae spp.), die de infectie veroorzaakt, tussen $0.5-1 \mathrm{mg} / \mathrm{L}$ ligt wordt deze als intermediair beschouwd. Het is dan onzeker of het antimicrobiële middel een therapeutisch effect zal hebben. In hoofdstuk 5 haalt respectievelijk 7\% van de patiënten de amoxicilline target niet als de MIC van de bacterie, die de infectie veroorzaakt, $4 \mathrm{mg} / \mathrm{L}$ is. Dit percentage loopt op naar 35\% als de MIC van de bacterie $8 \mathrm{mg} / \mathrm{L}$ is. Bij amoxicilline halen alle ouderen (>70 jaar) de amoxicilline target bij een MIC van $4 \mathrm{mg} / \mathrm{L}$ en slechts een klein deel van de ouderen haalt de target niet (13\%) bij een MIC van $8 \mathrm{mg} / \mathrm{L}$. Als de MIC van de bacterie (Enterobacteriaceae spp.), die de infectie veroorzaakt, groter dan $8 \mathrm{mg} / \mathrm{L}$ is wordt deze als resistent beschouwd. Amoxicilline kan dan niet meer als therapie gegeven worden. Uit deze resultaten kan worden afgeleid dat de concentratie van amoxicilline en ciprofloxacine bij ouderen hoger zijn dan bij jongere patiënten. Dit wordt veroorzaakt door een verminderde klaring van zowel amoxicilline als ciprofloxacine, want het verdelingsvolume van amoxicilline en ciprofloxacine is gelijk bij oudere en jongere patiënten. Een hogere amoxicilline dosering van 6 maal daags $1000 \mathrm{mg}$ iv is vooral belangrijk bij jongere patiënten. De meeste oudere patiënten hebben voldoende aan 4 maal daags $1000 \mathrm{mg}$ iv. Een hogere standaard ciprofloxacine dosering van 3 maal daags $400 \mathrm{mg}$ iv bleek volgens onze simulatie voldoende voor vrijwel alle oudere patiënten én voor de meeste jongere patiënten voldoende.

In hoofdstuk 6 en $\mathbf{7}$ is vancomycine bestudeerd. Vancomycine wordt routinematig gedoseerd op geleide van vancomycine spiegels in het bloed; therapeutic drug monitoring (TDM). Bij gebruik van TDM halen vrijwel alle patiënten de farmacodynamische target en zijn dus goed gedoseerd. Het bleek dat oudere patiënten (>70 jaar) hiervoor gemiddeld een veel lagere vancomycine dosis 
nodig hebben, namelijk $1158 \mathrm{mg} / 24$ uur dan jongere patiënten ( $<70$ jaar), 1838 $\mathrm{mg} / 24$ uur. Hoofdstuk 6 laat ook zien dat patiënten met een neutropenie een snellere klaring van vancomycine hebben en een hogere dosering nodig hebben om de farmacodynamische target te halen. Het lijkt erop dat deze snellere klaring reversibel is onze kleine groep van patiënten, die een tweede episode van vancomycine toegediend hebben kregen tijdens een niet-neutropene fase. Het mechanisme van deze versnelde klaring is nog niet opgehelderd. Waarschijnlijk spelen meerdere factoren een hierbij een rol.

In hoofdstuk 7 zijn methoden om vancomycine klaring te voorspellen op basis van creatinine klaring onderzocht. De onderzochte methoden laten echter grote variatie zien en zijn daarom niet geschikt om te gebruiken bij patiënten. Het meten van vancomycine spiegels blijft daarom noodzakelijk om effectief te doseren ten einde de kans op bijwerkingen zo klein mogelijk te houden.

Van de onderzochte co-variabelen hebben enkele invloed op de klaring van amoxicilline, ciprofloxacine en vancomycine. In hoofdstuk 8 laat de multivariabele analyse zien dat leeftijd en serum creatinine belangrijke factoren zijn, die onafhankelijk van elkaar van invloed zijn op de klaring van amoxicilline, ciprofloxacine en vancomycine. Dit resulteert in hogere concentraties van amoxicilline, ciprofloxacine en vancomycine in serum van oudere patiënten in vergelijking met jongere patiënten. Het meten van creatinine in het bloed om de creatinine klaring te schatten geeft een indicatie van de nierfunctie van ouderen, maar is van beperkte waarde in het doseren van antimicrobiële middelen bij ouderen vanwege een matige correlatie met de antimicrobiële klaring. Bovendien zijn er grote individuele verschillen in de daling van de nierfunctie van oudere patiënten. Aanpassingen van de antimicrobiële dosis bij oudere patiënten op basis van een verminderde nierfunctie wordt hierdoor bemoeilijkt. Wellicht dat in de toekomst ontwikkelde betere bepalingen van de nierfunctie in oudere patiënten wel aanpassingen in dosering mogelijk maken. In hoofdstuk 8 worden geen verschillen in het verdelingsvolume van amoxicilline, ciprofloxacine en vancomycine tussen oudere en jongere patiënten gezien. Het lijkt daarom niet nodig om doseringen aan te passen op de te verwachte veranderingen in het verdelingsvolume bij oudere patiënten. Bij renaal geklaarde antimicrobiële middelen met kleine therapeutische breedte, zoals aminoglycoside, vancomycine en linezolid, is het meten van antimicrobiële spiegels met behulp van TDM de beste optie om optimaal te doseren bij oudere patiënten. Aanpassing van de dosering van renaal geklaarde antimicrobiële middelen met grote therapeutische breedte, zoals amoxicilline, is bij oudere patiënten minder noodzakelijk. Concluderend behoeven oudere patiënten, net zoals jongere patiënten, andere doseringen, waarbij de alleroudsten net zoals de allerjongsten het meest afwijken van het gemiddelde. 
Valorisation of the manuscript 


\section{Relevance for society and economy}

The population in the developed countries is ageing. In 2012 the European life expectancy at birth was 83 years for women and 78 years for men. It is expected that the life expectancy will increase further. However, not only in the developed countries, but also in the developing countries life expectancy is increasing. The United Nations predicts that the global life expectancy will reach 76 years in 2045-2050 and 82 years in 2095-2100 [1]. Another trend in the developed countries is a decreasing birth rate, e.g. in the Netherlands the birthrate in 1950 was $23 \%$ (=23 per 1000 inhabitants) and in 2013 it decreased to $10 \%$ [2], resulting in a relatively larger elderly proportion of the population. As a result of the ageing population many governments are extending the retirement age to 67 years. Further extending of the retirement age can be expected with increasing life expectancy. A substantial proportion of the working population will consist of elderly people. Elderly people have more comorbidities and experience more infections. Elderly people use more antimicrobial agents than younger people. Improving antimicrobial therapy for elderly patients will decrease morbidity and mortality of infections in elderly patients. This is important for the elderly patient and his or her family, but it will also keep the sickness absence in the working elderly population as short as possible. Furthermore, correct dosing might lead to a decrease of antimicrobial resistance. Increasing antimicrobial resistance is a worldwide problem. Antimicrobial stewardship programs are an internationally recognized method to control antimicrobial resistance. Antimicrobial stewardship programs focus on correct antimicrobial therapy, recognizing and controlling antimicrobial resistance. The Dutch Ministry of Health supports these programs. They obligated all Dutch hospitals to have working antimicrobial stewardship programs and antibiotic teams in every Dutch hospital by the end of 2015 .

The goal of this thesis was to study the use and the pharmacokinetics of antimicrobial drugs in elderly and very elderly patients. The ultimate goal by improving the antimicrobial therapy in elderly patients is to improve the health of elderly patients.

\section{Target groups}

Many doctors, such as general practitioners, medical microbiologists and infectious disease specialists, ICU doctors, internal medicine doctors and surgeons, will regularly prescribe antimicrobial therapy to elderly patients. Studies about the use of antimicrobial therapy and antimicrobial pharmacokinetics will improve the knowledge of these doctors, who are treating infections in elderly patients. These studies are also important for the elderly patients themselves and for their families. These studies might also be useful for policy makers of the Ministry of Health and Economics, directories of Hospitals and Nursing homes and insurance companies. 


\section{Activities, innovations, planning and realization}

Traditionally the antimicrobial use in the Netherlands has been low. There are many activities to keep this antimicrobial use low and to improve antimicrobial therapy. However, focus on elderly patients has been lacking, while the necessity and the importance of this increasing age group is acknowledged. This thesis adds more insight in antimicrobial treatment in elderly patients and shows that the elderly patients are a large growing group that consume high quantities of antimicrobial drugs. This thesis indicates that focus on elderly patients is warranted.

The antimicrobial stewardship programs and teams have just recently started and have to evolve to reduce antimicrobial consumption, to ensure correct antimicrobial therapy and to control antimicrobial resistance in the future. The antimicrobial stewardship teams consist of medical microbiologists, infectious disease specialists and clinical pharmacists that focuses on the hospitals. Strategies have to be developed that focus on patient groups that consume the highest quantity of antimicrobial drugs, i.e. the elderly patients. Additionally, general practioners and internist geriatricians might have to be included in these teams and programs.

The Dutch Working Party on Antibiotic Policy (SWAB) monitors antimicrobial resistance in hospitals and in the community, but might have to extend this surveillance to nursing homes. Recently, the yearly SWAB report on human antimicrobial use and surveillance of antimicrobial resistance (Nethmap) included in 2014 a more complete chapter of antimicrobial use in Primary Care and Dutch hospitals [3]. Unfortunately, there was no focus on elderly patients or on other high antimicrobial drugs consuming patient groups.

Finally, more advertisement in more easily accessible programs can also be used to address the importance of antimicrobial therapy in elderly patients. For instance, the European Antibiotic Awareness Day, which is an initiative of the European Centre for Disease Prevention and Control (ECDC), is held yearly to improve awareness of antibiotics. This day could focus on high consuming patient groups, such as the elderly patients. 


\section{References}

1. http://esa.un.org/wpp/Documentation/pdf/WPP2012_Press_Release.pdf

2. http://www.cbs.nl/nl-NL/menu/themas/bevolking/cijfers/default.htm

3. http://www.swab.nl/swab/cms3.nsf/uploads/05ABE3EF93A82F4BC1257D07001DE8BC/ \$FILE/Boek\%20Nethmap-MARAN\%202014\%20TG.pdf 
Epiloog 


\section{Epiloog}

Mijn promotietraject is begonnen met een open sollicitatie in 2008 bij de afdeling Medische Microbiologie van het Academisch Ziekenhuis in Maastricht (AZM). Dit betrof een open sollicitatie omdat mijn vriendin aangenomen was voor de opleiding tot anesthesioloog, ook in het AZM.

Graag wil ik mijn promotoren Annelies Verbon, Cathrien Bruggeman, Christian Hoebe en mijn co-promotor Leo Stolk bedanken voor deze mogelijkheid en het vertrouwen dat zij in mij gesteld hebben. Annelies Verbon en Cathrien Bruggeman hebben mij in korte tijd op meerdere onderzoekssporen gezet waarbij de nadruk op ouderen lag. Het begon met onderzoek bij patiënten met COPD in de $1^{\mathrm{e}}$ lijn. Later volgde onderzoek naar associaties tussen herpesvirussen en hart- en vaatziekten, diabetes mellitus, frailty en mortaliteit in een psychogeriatrisch ouderen cohort van Evelien Pijpers in samenwerking met Valère Goossens en onderzoek naar respiratoire virussen binnen het MUMC in samenwerking met Ruud Deurenberg, Inge van Loo en Petra Wolffs. Antibiotica voorschriften in de eerste lijn in samenwerking met Christian Hoebe, Nicole Dukers en Jochen Cals en antibioticaspiegels bij ouderen in het ziekenhuis in samenwerking met Leo Stolk en Cees Neef. Uiteindelijk heeft dit proefschrift vorm gekregen door de laatst genoemde onderwerpen.

Het eerste deel van dit onderzoek is tot stand gekomen door een samenwerking tussen het RNH, de GGD in Heerlen en de Medische Microbiologie. In samenwerking met Alphons Schroten, Marjan van den Akker, Jochen Cals en professor Metsemakers vanuit het RNH, Christian Hoebe en Nicole Dukers vanuit de GGD en Annelies Verbon en Cathrien Bruggeman vanuit de Medische Microbiologie hebben we antibiotica voorschriften in de RNH database kunnen bestuderen over een periode van 10 jaar.

Het leeuwendeel van dit boek is verricht in samenwerking met de apotheek. Alvorens we verschillende antibiotica spiegels hebben kunnen meten moest er bloed van patiënten verzameld worden. In samenwerking met Otto Bekers en de analisten van de Klinische Chemie werden overgebleven bloedmonsters gebruikt van patiënten, die ook antibiotica kregen toegediend. De secretaresses van A4, B4 en B5 markeerden de aanvragen voor de Klinische Chemie, zodat de medewerkers van de prikdienst en de verpleegkundigen wisten bij welke bloedafnames de afnametijden genoteerd moesten worden. Het restmateriaal en de afnametijden van deze bloedmonsters kon ik na gebruik terugzoeken. Hiervoor was ook de medewerking nodig van de hoofdzusters van deze afdelingen; Jacqueline Scheijen (A4), Marjo Kleijnen (B4) en Gertie Brepoels (B5) en afdelingshoofden van de Interne Geneeskunde en Heelkunde.

Ik wil alle analisten van het labarotorium van de apotheek, en Jeroen Welzen en Jacques van der Heyden in het bijzonder, bedanken voor de prettige en leerzame samenwerking op dit uitstekende lab. Altijd heb ik de nodige hulp gekregen bij de HLPC bepalingen, waardoor ik rustig heb kunnen doorwerken aan alle bepalingen. Ook hebben twee WESP studenten, Inez Widow en Pauline Vinken, geholpen bij de HPLC bepalingen en analyses. De inbreng van Leo Stolk is heel belangrijk geweest, zowel bij het opzetten van de HPLC's, bij het 
valideren van deze HPLC's en bij de pharmacokinetiek met behulp van MW/Pharm. Thomas Havenith en Sander Croes hebben veel werk verricht bij respectievelijk het amoxicilline en het vancomycine onderzoek. Ook Thomas en Sander hebben mijn pharmacokinetische kennis vergroot. Cees Neef wil ik ook hartelijk bedanken voor zijn hulp en medewerking.

Het analyseren van de data en het schrijven van de artikelen moest al snel telefonisch en vooral per email gebeuren. Annelies Verbon heeft mij in korte tijd op het juiste spoor gezet, voordat zij in 2009 vertrok naar het Erasmus MC in Rotterdam. In 2010, precies 2 jaar na de start van mijn promotieonderzoek ben ik ook begonnen aan de opleiding tot Medisch Microbioloog. Niet veel later ging Cathrien Bruggeman met een welverdiend pensioen en uiteindelijk is ook Leo Stolk met een welverdiend pensioen gegaan. Toch hebben deze veranderingen het analyseren en het schrijven van de artikelen niet belemmerd. Integendeel, Annelies en Leo reageerden altijd buitengewoon scherp en snel op al mijn emails. Voor mij heeft dit uitstekend gewerkt. Ik heb altijd rustig kunnen door werken aan mijn promotieonderzoek. Het was gewoon een goed promotieteam, waarbij ook Cathrien, Christian, Nicole, Jochen, Sander, Thomas en Cees altijd adequaat en snel reageerden bij het analyseren en schrijven van de artikelen.

Het is helaas onmogelijk om iedereen te benoemen en te bedanken, die een bijdrage hebben geleverd aan het tot stand komen van dit boek. Desalniettemin, wil ik iedereen, die een bijdrage heeft geleverd bedanken voor alle hulp, informatie en adviezen. Deze zijn allemaal dankbaar in ontvangst genomen. Niet in de laatste plaats wil ik ook alle patiënten bedanken, die deelgenomen hebben aan de RNH-database en alle patiënten in het MUMC, die geen bezwaar hebben gemaakt tegen anoniem gebruik van reeds verzamelde gegevens en van reeds afgenomen lichaamsmaterialen voor wetenschappelijk onderzoek. Een speciaal en niet te onderschatte dankwoord moet ik richten aan de technische dienst, zij hebben bij een incident een groot deel van mijn onderzoek gered. De verouderde -80 researchdiepvries van de apotheek gevuld met de -met bloed, zweet en tranen verzamelde- monsters gaf midden in de nacht de pijp aan Maarten. De technische dienst merkte dit heel snel op en zij hebben 's nachts alle monsters verplaatst naar een splinternieuwe reserve -80 diepvries.

Tot slot wil ik het secretariaat van de Medische Microbiologie bedanken, in het bijzonder Angèle Eerens, die het laatste stukje van mijn promotie in goede banen heeft geleid.

De laatste regels van deze epiloog zijn natuurlijk voor mijn lief en mijn vier lieve dochters, Charley, Yanna, Faye en Imme. "Never a dull moment", zoals Annelies het verwoordde, en dat klopt wel. Vervelen heb ik me de afgelopen jaren niet gedaan! Dit boek draag ik dan ook aan jullie op, Audrey en CYFI. 


\section{Curriculum vitae auctoris}

Michiel Haeseker werd op 27 mei 1974 geboren te Dedza, Malawi. Van 1986 tot 1992 volgde hij het VWO aan het Lodewijk Makeblijde College te Rijswijk. In 1992 startte hij met de studie geneeskunde aan de Rijksuniversiteit van Leiden. Het artsenexamen werd behaald in 1999.

Als voorbereiding op een uitzending naar de Tropen werkte hij als artsassistent chirurgie in het Groene Hart ziekenhuis te Gouda en als arts-assistent gynaecologie/verloskunde in het IJsselland ziekenhuis te Capelle aan de IJssel. De specialisatie tot tropenarts werd uiteindelijk afgerond met het behalen van het diploma Tropical Medicine \& Hygiene (DTM\&H) aan the Netherlands School of Public Health (NSPH) te Utrecht in 2002.

In totaal was hij 4 jaar als tropenarts actief in Afrika. Eén jaar werkte hij als tropenarts in het St. Francis' Hospital, Katete in Zambia, één jaar was hij District Medical Officer in het Ntchisi District Hospital te Malawi en 2 jaar was hij Senior Medical Officer in het Trinity Hospital te Muona, ook in Malawi. Tussen de uitzendingen naar Zambia en Malawi in werkte hij één jaar als algemeen arts in het verpleeghuis Houtwijk te Den Haag. Bij terugkomst uit Afrika werkte hij als donorarts te Nijmegen en deed hij voorwerk en onderzoek voor de Werkgroep Overdraagbare Bloedinfecties bij Sanquin. In 2008 werd er begonnen als arts-onderzoeker bij de Medische Microbiologie in het MUMC te Maastricht onder leiding van prof. dr. Bruggeman en dr. Verbon. In 2010 startte hij met de opleiding tot arts-microbioloog in hetzelfde MUMC met als opleider dr. van Tiel.

Momenteel werkt hij als arts-assistent in opleiding tot arts-microbioloog in het MUMC alwaar hij medio 2016 zijn opleiding zal voltooien. Hij is woonachtig in Voerendaal met zijn vriendin Audrey Beckers en hun vier dochters Charley, Yanna, Faye en Imme. 


\section{List of publications}

A simple and rapid RP-HPLC method to determine ciprofloxacin levels in human serum

M. Haeseker, A. Verbon, J. Welzen, C. Neef, C. Bruggeman, L. Stolk. Asian J Phar Biol Res 2011;1(3):350-354.

Trends in antibiotic prescribing in adults in Dutch general practice M. Haeseker, N. Dukers-Muijrers, C. Hoebe, C. Bruggeman, J. Cals and A. Verbon. PLoS One. 2012;7(12):e51860.

The ciprofloxacin target $\mathrm{AUC} / \mathrm{MIC}$ ratio is not reached in hospitalized patients with the recommended dosing regimens

M. Haeseker, L. Stolk, F. Nieman, C. Hoebe, C. Neef, C. Bruggeman and A. Verbon.

Br J Clin Pharmacol. 2013 Jan;75(1):180-5.

Association of cytomegalovirus and other pathogens with frailty, cardiovascular disease, diabetes mellitus and mortality in psycho-geriatric patients; a prospective cohort study

M. Haeseker, E. Pijpers, N. Dukers-Muijrers, P. Nelemans, C. Hoebe, C. Bruggeman, A. Verbon and V. Goossens.

Immun Ageing. 2013 Jul 23;10(1):30.

Delayed diagnosis and therapy of infant botulism

M. Haeseker, V. Hira, D. van Waardenburg, K. Heijman, T. Hendriks and F. Zijderveld

Infectieziekten bulletin. 2013 Sep; 24(7): 200-201.

Is the standard dose of amoxicillin-clavulanic acid sufficient?

M. Haeseker, L. Stolk, F. Nieman, C. Neef, C. Bruggeman and A. Verbon.

BMC Pharmacol Toxicol. 2014 Jul 21;15(1):38.

Vancomycin needs higher dosing in patients with neutropenia

M. Haeseker, S. Croes, C. Neef, C. Bruggeman, L. Stolk and A. Verbon.

PLoS One. 2014; Nov 12;9(11):e112008.doi

Evalution of vancomycin prediction methods based on estimated creatinine clearance and trough levels

M. Haeseker, S. Croes, C. Neef, C. Bruggeman, L. Stolk and A. Verbon.

Submitted.

Gentamicin is frequently underdosed in patients with sepsis in the emergency department

M. Cobussen, V. Hira, J. de Kort, D. Posthouwer, P. Stassen and M. Haeseker.

Submitted. 